\title{
Herbal hepatotoxicity in traditional and modern medicine: actual key issues and new encouraging steps
}

\author{
Rolf Teschke* and Axel Eickhoff \\ Division of Gastroenterology and Hepatology, Department of Internal Medicine II, Klinikum Hanau, Academic Teaching \\ Hospital of the Medical Faculty of the Goethe University Frankfurt Main, Frankfurt, Germany
}

\section{OPEN ACCESS}

Edited by:

Jia-bo Wang

302 Military Hospital of China, China

Reviewed by:

Hong Yang,

Liaoning Normal University, China

Jia-bo Wang,

302 Military Hospital of China, China

Ji-dong Jia,

Beijing Friendship Hospital, China

${ }^{*}$ Correspondence:

Rolf Teschke,

Division of Gastroenterology and Hepatology, Department of Internal

Medicine II, Klinikum Hanau, Academic Teaching Hospital of the Goethe University of Frankfurt/Main Leimenstrasse 20, D-63450 Hanau,

Germany

rolf.teschke@gmx.de

Specialty section

This article was submitted to

Ethnopharmacology,

a section of the journal

Frontiers in Pharmacology

Received: 19 January 2015 Paper pending published: 10 February 2015

Accepted: 18 March 2015

Published: 23 April 2015

Citation:

Teschke $R$ and Eickhoff A (2015)

Herbal hepatotoxicity in traditional and modern medicine: actual key issues

and new encouraging steps.

Front. Pharmacol. 6:72

doi: 10.3389/fphar.2015.00072
Plants are natural producers of chemical substances, providing potential treatment of human ailments since ancient times. Some herbal chemicals in medicinal plants of traditional and modern medicine carry the risk of herb induced liver injury (HILI) with a severe or potentially lethal clinical course, and the requirement of a liver transplant. Discontinuation of herbal use is mandatory in time when HILI is first suspected as diagnosis. Although, herbal hepatotoxicity is of utmost clinical and regulatory importance, lack of a stringent causality assessment remains a major issue for patients with suspected HILI, while this problem is best overcome by the use of the hepatotoxicity specific CIOMS (Council for International Organizations of Medical Sciences) scale and the evaluation of unintentional reexposure test results. Sixty five different commonly used herbs, herbal drugs, and herbal supplements and 111 different herbs or herbal mixtures of the traditional Chinese medicine (TCM) are reported causative for liver disease, with levels of causality proof that appear rarely conclusive. Encouraging steps in the field of herbal hepatotoxicity focus on introducing analytical methods that identify cases of intrinsic hepatotoxicity caused by pyrrolizidine alkaloids, and on omics technologies, including genomics, proteomics, metabolomics, and assessing circulating micro-RNA in the serum of some patients with intrinsic hepatotoxicity. It remains to be established whether these new technologies can identify idiosyncratic HILI cases. To enhance its globalization, herbal medicine should universally be marketed as herbal drugs under strict regulatory surveillance in analogy to regulatory approved chemical drugs, proving a positive risk/benefit profile by enforcing evidence based clinical trials and excellent herbal drug quality.

\footnotetext{
Keywords: herb induced liver injury, hepatotoxicity, herbal hepatotoxicity, herbs, evidence based trials, herbal traditional Chinese medicine, herbal modern medicine, herbal traditional medicine
}

\section{Introduction}

Ancient Chinese and Egyptian papyruses describe medicinal use of plants for various ailments as early as $3.000 \mathrm{BC}$ and thereby long before recorded history (Major, 1954; IARC Monographs, 2002). Starting at around that time, herbal traditional medicine originating from Mesopotamia, Egypt, and India influenced Byzantine, Greek, Latin, and Indian herbal medicine, thereby establishing principles of Ayurveda in India and developing traditional occidental herbal medicine, which subsequently became popular in numerous European and other Western countries (Major, 1954; 
IARC Monographs, 2002; Raghavendra et al., 2009; NIH, 2013). Indigenous cultures such as African, North American, Middle and South American, Australian, and South Pacific islandic also used herbs in their healing rituals (IARC Monographs, 2002). In other parts of the world, herbal traditional Chinese medicine (TCM) emerged (IARC Monographs, 2002; Raghavendra et al., 2009) and influenced the traditional Oriental herbal medicine in Japan (IARC Monographs, 2002), called Kampo medicine (Nishimura et al., 2009), and other Asian countries such as Korea with its herbal traditional Korean medicine (Park et al., 2012). With TCM originating in China and Ayurveda in India, two most ancient yet living traditions of herbal medicine presently remain and experience some extension over the globe (Patwardhan et al., 2005). Although, most other ancient herbal medicine cultures vanished or are restricted to local use without potential globalization, many countries use herbal medicines (WHO, 2002, 2013).

The worldwide use of medicinal herbs has increased over the past years (WHO, 2002, 2013; Ekor, 2014), but their regulatory surveillance differ among countries due to lack of harmonization (WHO, 2005; Ekor, 2014). The world market for herbal medicines based on traditional knowledge is estimated at US $\$ 60,000$ million annually (WHO, 2002), according to a UN report dating back to 2000 (UN, 2000). Alone in the United States, the total estimated herb retail sales in all channels rose from $\$ 4230$ million in 2000 to $\$ 6032$ million in 2013 , corresponding to $42.6 \%$ overall and to $3.3 \%$ on an annual basis according to the data of the American Botanical Council (Lindstrom et al., 2014). These figures compare to the increased use of complementary and alternative Medicine (CAM), since an estimated \$27 billion was spent by consumers of CAM in the United States in 1997 (Eisenberg et al., 1998) and \$33.9 billion in 2007 (Nahin et al., 2009), equaling a rise of $25.5 \%$. These figures considered all CAM related expenditures spent out of pocket on visits to CAM practitioners and purchases of CAM products, classes, and materials in the United States in 2007, with $\$ 14.5$ billion spent on the purchase of nonvitamin, nonmineral, and natural products (Nahin et al., 2009); the widespread use of herbal medicine exerts a high economic power in our society with special financial benefits for herb producers, providers, and healers. Considering this enormous economic impact and the resulting expenditures, the question is whether these high costs as burden for the consumers and the society are warranted. In addition, herbal medicine is increasingly exposed to major pressure due to concerns of efficacy, safety (NIH, 2014a), and adverse reactions (Podsadzki et al., 2013; Ekor, 2014) such as liver injury (NIH, 2014a).

In this review article, we critically analyze actual key issues of herbal hepatotoxicity by herbal products of traditional and modern medicine and discuss future developments. The expressions of herbal hepatotoxicity and herb induced liver injury (HILI) are used synonymously. Some similarities of HILI exist with DILI (drug induced liver injury) (Teschke et al., 2013f).

\section{Methods}

\section{Data Sources and Searches}

We used the PubMed to identify publications on herbal hepatotoxicity and HILI which each provided hits of around 279.000 and 1.840.000. Our search was then further qualified and extended using additional keywords denoting herbal modern medicine and herbal TCM, providing additional hits. The first 100 hits of publications in each category were considered.

\section{Study Selection}

The focus of our search was on publications in English language, but relevant reports of other languages also were considered. The retrieved publications included case reports, case series and review articles and were analyzed whether they were appropriate and relevant for the topic of this article. Publications also were manually searched for additional publications not yet identified.

\section{Data Extraction and Quality Assessment}

Prior to our analysis, the publications were assessed regarding their scientific and clinical quality. Publications of relevance and good quality were preferred and considered for evaluation.

\section{Key Issues}

Herbal products in traditional and modern medicine are commonly perceived by the general population as well tolerated and devoid of major adverse reactions. One of the most important goals in clinical practice is to offer patients an efficient therapy for their ailment(s), without harming their health. However, efficacy and safety by the use of herbs in traditional and modern medicine are features that may apply to some herbs and patients but certainly not to others. Similar shortcomings are known from conventional chemical drugs, which also are not effective in all patients. The risk of rare adverse reactions occurring in various organs including the liver relates to both, herbs (NIH, 2014a) and synthetic drugs (NIH, 2014b).

\section{Hepatotoxicity Case Reports General Aspects}

Basic knowledge of hepatotoxicity by drugs and numerous other chemicals was summarized by Hyman Zimmerman in his pioneering book 25 years ago, briefly mentioning already some herbs as culprits and referencing a few case reports of herbal hepatotoxicity (Zimmerman, 1999). Since then, many more HILI cases emerged, which previously were reported (Pittler and Ernst, 2003b) and recently analyzed in publications on herbal TCM preparations (Teschke, 2014; Teschke et al., 2014c, 2015b), other commonly used herbal products (Teschke et al., 2013f), and herbal and dietary supplements (HDS) (Halegoua-De Marzio et al., 2013; Teschke et al., 2013d; Navarro et al., 2014; RoblesDiaz et al., 2015).

\section{Epidemiology}

Epidemiology data of hepatotoxicity cases in connection with herbal use are crucial to assess, both in traditional and modern medicine. Actually, the true prevalence of herbal hepatotoxicity is the total number of HILI cases in the population at a given time (Teschke et al., 2013f). It represents an estimate of how common herbal hepatotoxicity is within a population and at a fixed time. Conversely, the incidence of herbal hepatotoxicity is expressed as the total number of new HILI cases during a certain period 
of time, divided by the number of individuals in the population initially at risk. Therefore, incidence differs from prevalence measuring new HILI cases; for chronic liver injury, these values may change.

Incidence commonly provides information about the risk of acquiring HILI, whereas prevalence signifies how widespread HILI is. The true prevalence and incidence of HILI (Navarro, 2009) and HDS (Navarro et al., 2014; Robles-Diaz et al., 2015) is unknown. Global epidemiology considerations of prevalence and incidence refer to all herbs contained in herbal drugs and herbal supplements, whereas specific epidemiology is restricted to one single herb. Global epidemiology data therefore may be used for health economy assessment whereas specific epidemiology data pertain to herbal product safety. For this purpose, true global prevalence and incidence of HILI still has to be determined through cohort studies or case control-studies, a difficult approach. For an appropriate assessment of the risks from a specific herbal product, there is lack of quantitative data for consumption of herbal products, number of HILI patients, and the population at risk. In addition, herbal product authentication is missing in most cases of suspected HILI and impedes causality assessment for the incriminated herb (Teschke et al., 2013f). Case underreporting and overdiagnosing also prevent determination of the true incidence; future studies will have to address these issues in order to provide firm data of prevalence and incidence in HILI.

For DILI by synthetic drugs, respective data are available: the estimated annual incidence rate of DILI at a coordinating center in Spain was $34.2 \pm 10.7$ cases per $10^{6}$ inhabitants (Andrade et al., 2005), and in a French study it was $13.9 \pm 9$ per $10^{6}$ inhabitants per year (Sgro et al., 2002).

\section{Compilation of Hepatotoxicity Cases}

For herbal TCM with potential liver injury, we identified 44 different TCM herbs and 21 herbal TCM mixtures, published in case reports and case series as provided by appropriate references (Table 1). These referenced reports present clinical case details, summarized in part also earlier (Teschke, 2014). The 12 most common Chinese herbal medicines with hepatotoxicity detailed in a recent review (Ma et al., 2014) are also included in the present compilation (Table 1).

Other herbs and herbal products unrelated to TCM showed reported potential hepatotoxicity for 111 items (Table 2), presented as an update of an earlier compilation (Teschke et al., 2012h). Most of the actual 111 items identified single herbs, rarely mixtures with HDS as examples with various ingredients (Table 2). Numerous other HDS with assumed potential hepatotoxicity are listed in compilations of other reports published just recently (Bunchorntavakul and Reddy, 2013; Navarro et al., 2014; Robles-Diaz et al., 2015) and hence were not included in the present compilation (Table 2).

In the past, some review articles focused exclusively on HILI by TCM herbs and herbal preparations (Ma et al., 2014; Teschke, 2014; Teschke et al., 2014c, 2015b) as a primarily neglected topic, which was otherwise considered as part of overall assessments on herbal hepatotoxicity in few publications (Zimmerman, 1999; Abdualmjid and Sergi, 2013; Bunchorntavakul and Reddy, 2013), including an official and well updated NIH statement $(\mathrm{NIH}$, 2014a).

\section{Symptomatology}

Clinical symptoms of herbal hepatotoxicity in traditional and modern medicine are variable and described in published case reports, case series, and regulatory presented spontaneous reports as referenced (Tables $\mathbf{1}, \mathbf{2}$ ). Symptoms are mostly unspecific and sometimes difficult to direct to the liver, which delays early recognition of the unfolding liver injury (Teschke et al., 2013f, 2014c; Ma et al., 2014). Clinical signs may emerge alone or in combination with other features, while jaundice is the symptom initially best recognized by the patient, facilitating the search for advice by the primary care physician. In detail, patients with herbal TCM hepatotoxicity experience fatigue $(67.3 \%)$, jaundice $(60.3 \%)$, anorexia $(58.0 \%)$, nausea $(35.9 \%)$, and fever $(19.3 \%)$, but signs such as rash, pruritus, and pale stools have also been reported (Ma et al., 2014). In another study of 16 cases of Greater Celandine (GC) with established HILI, symptoms were present in 15 cases (Teschke et al., 2012a). Single or multiple symptoms were anorexia $(n=3)$, fatigue $(n=5)$, nausea $(n=6)$, vomiting $(n=2)$, dyspepsia $(n=1)$, bloating $(n=1)$, abdominal discomfort $(n=1)$, right upper quadrant pains $(n=1)$, epigastric pains $(n=1)$, unspecified abdominal pains $(n=1)$, fever $(n=1)$, dark urine $(n=3)$, pale stool $(n=1)$, pruritus $(n=3)$, and jaundice $(n=15)$ (Teschke et al., 2012a). For reasons of transparency, narrative case details and clinical data of patients with assumed HILI should be provided in tabular form, as done previously (Teschke et al., 2008a, 2011a, 2012a,b,d,e; Teschke, 2010a) and shown for GC hepatotoxicity as example (Table 3). Detailed information also allows characterization of HILI by a single herb such as GC (Table 4).

Although, clinical features are quite similar in HILI cases by traditional and modern medicine (Chau et al., 2011; Teschke et al., 2013f; Ma et al., 2014), there is one exception that relates to the hepatic sinusoidal obstruction syndrome (HSOS), formerly hepatic veno-occlusive disease (HVOD); this special liver injury is caused by pyrrolizidine alkaloids (PAs) contained in various TCM herbs, with its major diagnostic features of abdominal distension and pain, ascites, malaise, hepatomegaly, and body weight gain due to ascites and edema caused by fluid accumulation (Wang and Gao, 2014). Jaundice was most frequent with $84.8 \%$ in $100 / 118$ cases of PA induced HSOS by Tu San Qi (Gynura segetum), ascites with $99.2 \%$ (121/122 cases, and hepatomegaly with $92.0 \%$ (104/113 cases) (Lin et al., 2011; Gao et al., 2012).

In a typical HILI case unrelated to PAs, the chronology of symptoms may follow a particular stepwise pattern, as described for HILI caused by Indian Ayurvedic herbs through an excellent observation by a patient under treatment for her vitiligo (Teschke and Bahre, 2009). Her symptoms started with pruritus, followed by loss of appetite, fatigue, nausea, vomiting, dark urine, light stool, until finally jaundice was recognized by her family physician; this sequence of symptoms stretched over almost 4 months under continued herbal medication.

Patients with HILI may be asymptomatic with increased values observed by chance, monosymptomatic, or polysymptomatic. 
TABLE 1 | Compilation of reported cases with suspected hepatotoxicity by herbal traditional Chinese medicine (TCM).

Name with ingredients

Ai Ye Artemisia argyi

An Shu Ling Lycopodium serratum or, rarely, Corydalis species, Panax ginseng, Pseudo ginseng, or two species of Stephania Bai Fang Angelica sinensis, Cyperus rotundus, Ginseng, Ligusticum wallichii, Paeonia alba, Rehmannia glutinosa

Bai Shi Wan Atractylis, Carthamus tinctorius, Dalbergia odorifera, Dioscorea bulbifera, Glycyrrhiza, Lithospermum erythrorhizon, Paeonia suffruticosa, Polygonum multiflorum, Psoralea corylifolia, Salvia miltiorrhiza; Endoconcha sepiae, Ganoderma lucidum (mushroom)

Bai Xian Pi Dictamnus dasycarpus

Bi Ma Zi Rhicinus communis

Ban Tu Wan Angelica sinensis, Chaenomeles, Codonopsis pilosula, Notopterygium, Polygonum multiflorum, Rehmannia, Schisandra

Bo He Mentha haplocalyx

Bo Ye Qing Niu Dan Tinospora crispa

Bofu Tsu Sho San Angelica, Atractylis, Cnidium, Gardenia, Ephedra, Forsythia, Glycyrrhhiza, Gypsum fibrosum, Ledebouriella, Mentha, Paeonia, Platycodon, Rheum, Schizonepeta, Scutellaria, Zingiber; Kadinum (talcum powder), sodium sulfuricum

Boh Gol Zhee Psoralea corylifolia

Cang Er Zi Xanthium sibiricum

Chang Shan Dichora febrifuga Lour

Chai Hu Bupleurum falcatum

Chaso Camellia sinensis, Cassia tora (syn. Senna), Crataegus, Chrysanthenum morifolium Ramat., Lotus, Lycium barbarum; N-nitroso-fenfluramine

Chi R Yun Breynia officinalis

Chinese herbal mixtures (various) Dictamnus dasycarpus, Gentiana scabra, Hedyotis diffusa, Paeonia suffructicosa, Paris polyphylla, Rehmannia glutinosa, Smilax glabra, Sophora subprostrata;

Angelica sinensis, Bupleurum chinese, Dictamnus dasycarpus, Paeonia suffructiosa, Philodendron chinese, Saposhnikovia divaricata, Shisandra chinesis, Shizonepeta tenuifolia, Tribulus terrestris;

Cocculus trilobus, Dictamnus dasycarpus, Eurysolen gracilis, Glycyrrhiza, Lophatherum, Paeonia, Potentilla, Rehmannia glutinosa;

Alisma plantago aquatica, Artemisia capillaris, Bupleurum, Chrysanthemum morifolium, Circuma, Gardenia jasminoidis,

Gentiana scabra, Glycyrrhiza, Magnolia, Paeonia, Plantago asiatica, Saussurea lappa

Chuan Lian Zi Melia toosendan

Ci Wu Jia Acanthopanax senticosus

Da Chai Hu Tang Bupleurum falcatum, Ginseng, Glycyrrhiza glabra, Pinellia, Scutellaria, Zingiber officinale, Zizyphus jujuba

Da Huang Rheum palmatum

Du Huo Angelica archangelica

Fu Fang Qing Dai Wan Angelica dahurica, Isatis indigotica (Indigo naturalis), Massa medicata fermentata (yeast), Salvia milthiorrhiza, Smilax glabra

Gan Cao Glycyrrhiza uralensis, syn. Liquorice

Ge Gen Pueraria lobata, syn. Arrowroot

He Huan Pi Albizia julibrissin

Ho Shou Wu Polygonum multiflorum, syn. He Shou Wu

\section{Cases (n) References}

Ma et al., 2014

Haller et al., 2002

Estes et al., 2003

Talari et al., 2010

Perharic-Walton and Murray, 1992

$1 \quad$ Kane et al., 1995

$1 \quad$ Vautier and Spiller 1995

2 Yuen et al., 2006

$4 \quad$ Jang et al., 2008

$14 \quad$ Kang et al., 2008

2 Sohn et al., 2008

na Ma et al., 2014

1 Cortez et al., 2012

Sangsuwan et al., 2004

Motoyama et al., 2008

Hwang et al., 2001

Nam et al., 2005

Cheung et al., 2009

Chau, 2008;

Ma et al., 2014

Ma et al., 2014

Lee et al., 2011

Adachi et al., 2003

Lin et al., 2002

19 Lin et al., 2003

Perharic-Walton and

Murray, 1992

Kane et al., 1995

Vautier and Spiller, 1995

$1 \quad$ Yoshida et al., 1996

Yuen et al., 2006

Sohn et al., 2008

Kamiyama et al., 1997

Yuen et al., 2006

Björnsson et al., 2013

Verucchi et al., 2002

Yuen et al., 2006

Kim et al., 2009

Ma et al., 2014

Yuen et al., 2006 
TABLE 1 | Continued

Name with ingredients

Hu Bohe You Mentha pulegium, syn. Pennyroyal oil

Hu Zhang Polygonum cuspidatum

Huang Qin Scutellaria baicalensis

Huang Yao Zi Dioscorea bulbifera

Hwang Geun Cho Corydalis speciosa

Ji Gu Cao Abrus cantoniensis

Ji Ji Chloranthus serratus

Ji Xue Cao Centella asiatica, syn. Gotu Kola

Jiguja Hovenia dulcis

Jin Bu Huan Lycopodium serratum or, rarely, Corydalis species,

Panax ginseng, Pseudo ginseng, or two species of Stephania

Jue Ming Zi Cassia obtusifolia, syn. Senna obtusifolia

Kamishoyosan Angelica sinensis, Atractylodes racea, Bupleurum falcatum, Gardenia, Glycyrrhiza glabra, Mentha haplocalyx Moutan, Paeonia alba, Sclerotium Poriae Cocos, Zingiber officinale

Kudzu Pueraria thunbergiana

Ku Lian Zi Melia azedarach

Lei Gong Teng Tripterygium wilfordii Hook

Long Dan Xie Gan Tang Acebia, Alisma, Angelica sinensis, Bupleurum, Gardenia, Gentiana, Glycyrrhiza, Plantago, Rehmannia, Scutellaria

Lu Cha Camellia sinensis, syn. Chinese green tea

Ma Huang Ephedra sinica

\section{Cases (n) References}

Ma et al., 2014

Bae et al., 2010

Chau, 2008

Chau, 2008

Gono et al., 2010

Linnebur et al., 2010

Yang et al., 2012a;

Dhanasekaran et al., 2013

Chau, 2008;

Ma et al., 2014

Kang et al., 2009

Yuen et al., 2006

Chau, 2008

Jorge and Jorge, 2005

Sohn et al., 2008

Kang et al., 2008

Kim et al., 2012

Woolf et al., 1994

Horowitz et al., 1996

Picciotti et al., 1998

Divinsky, 2002;

Haller et al., 2002

Yuen et al., 2006

Inoue et al., 2011

Kang et al., 2008

Ma et al., 2014

Chau, 2008

Ma et al., 2014

Lee et al., 2011

Garcia-Moran et al., 2004

Peyrin-Biroulet et al. 2004

Gloro et al., 2005

Bonkovsky, 2006

Jimenez-Saenz and

Martinez-Sanchez,

2006

Bonkovsky, 2006

Molinari et al., 2006

Björnsson and Olsson, 2007

García-Cortés et al., 2008

Sarma et al., 2008

Mazzanti et al., 2009

Rohde et al., 2011

Navarro et al., 2013

Nadir et al., 1996 
TABLE 1 | Continued

Cases (n) References

Mao Guo Tian Jie Cai Heliotropium lasiocarpum

Onshido Aloe, Camellia sinensis, Crataegus, Gynostemma pentaphyllum makino, Raphanus; N-nitroso-fenfluramine

Qian Li Guang Senecio scandens

Ren Shen Panax ginseng

Sairei To Alisma, Atractylis, Bupleurum, Cinnamomum, Ginseng, Glycyrrhiza,

Pinellia, Polyporus, Poria, Scutellaria, Zingiber, Zizyphus

Shang Lu Phytolacca acinosa

Shen Min Black cohosh, Burdock, Cayenne pepper, Ginkgo biloba, Horse chestnut, Piper nigrum, Polygonum multiflorum, uva ursi; biotin, collagen (hydrolyzed), niacin, pantothenic acid, silica (from plant sources), soy isoflavones, vitamin $A$, vitamin $B_{6}$ Shi Can Teucrium chamaedrys, syn. Germander

Shi Liu Pi Pericarpium granati

Shou Wu Pian Achyranthes bidentata, Cuscuta chinensis, Eclipta prostrata,

Ligustrum lucidum, Lonicera japonica, Morus alba, Polygonum multiflorum,

Psoralea corylifolia, Rehmannia glutinosa, Rosa laevigata, Sesemum indicum,

Siegesbeckia orientalis

Tian Hua Fen Trichosanthes kirilowii

Tu San Qi Gynura segetum

White flood Qian Ceng Ta (Huperzia serrata), Wu Zhu Yu (Evodia rutaecarpa); beet root, caffein, cocoa bean, vinpocetine (from Vinca plant); acesulfame potassium, calcium silicate, carnitine tartrate, Carno-Syn ${ }^{\circledR}$ beta-alanine, citrulline,

cryptoxanthin, folic acid, gamma-aminobutyric acid (GABA), glucuronolactone, selenium, L-norvaline, L-tyrosine, lutein, malic acid, ornithine, potassium gluconate, sucralose, sugar cane, watermelon flavor, zeaxanthin

Wu Bei Zi Galla chinensis

Xi Shu Camptotheca acuminata

Xian Si Zi Abrus Precatorius

Xiao Chai Hu Tang Bupleurum falcatum, Ginseng, Glycyrrhiza glabra,

Pinellia tuber, Scutellaria baicalensis, Zingiber officinale, Zizyphus jujuba

Yin Chen Hao Artemisia capillaris

Zexie Alisma orientalis

Zhen Chu Cao Phyllanthus urinaria
Borum, 2001

Estes et al., 2003

Skoulidis et al., 2005

Reuben et al., 2010

Culvenor et al., 1986

Adachi et al., 2003

Chau, 2008;

Ma et al., 2014

Kang et al., 2008

Aiba et al., 2007

Tsuda et al., 2010

Ma et al., 2014

1 Cárdenas et al., 2006

na Chau, 2008

na Chau, 2008

1 But et al., 1996

1 Park et al., 2001

$1 \quad$ Battinelli et al., 2004

$1 \quad$ Panis et al., 2005

3 Sohn et al., 2008

1 Laird et al., 2008

1 Furukawa et al., 2010

1 Valente et al., 2010

25 Jung et al., 2011

1

na

Banarova et al., 2012

Chau, 2008

Dai et al., 2006

Chen et al., 2007

Li et al., 2010

Lin et al., 2011;

Gao et al., 2012

1 Cohen et al., 2012

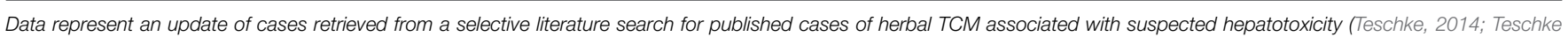

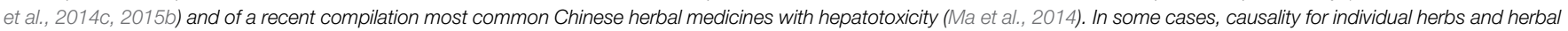

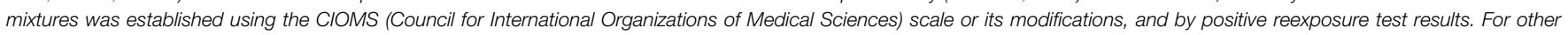
cases, information was fragmentary and did not necessarily allow a firm causal attribution. 
TABLE 2 | Compitalion of commonly used herbs and herbal products with reported hepatotoxicity.

\begin{tabular}{|c|c|}
\hline Search items & Botanical names, ingredients, references \\
\hline Acacia catechu & see Ayurvedic herb \\
\hline Asterceae family & $\begin{array}{l}\text { Adenostyles alliariae } \\
\text { (Sperl et al., 1995) }\end{array}$ \\
\hline Aloe & $\begin{array}{l}\text { Aloe perfoliata var. vera } \\
\text { (Rabe et al., 2005; Kanat et al., 2006; Bottenberg } \\
\text { et al., 2007; Yang et al., 2010) }\end{array}$ \\
\hline $\begin{array}{l}\text { Amorphophallus } \\
\text { Konjac }\end{array}$ & see Hydroxycut ${ }^{\circledR}$ \\
\hline Arrowroot & $\begin{array}{l}\text { Maranta aruninacea or Tacca leontopetaloides } \\
\text { (Kim et al., 2009) }\end{array}$ \\
\hline Atractylis gummifera & see Distaff thistle \\
\hline Ayurvedic herbs & $\begin{array}{l}\text { Psoralea corylifolia, Acacia catechu, Eclipta alba or } \\
\text { Bacopa monnieri, Vetivexia zizaniodis } \\
\text { (Teschke and Bahre, 2009) }\end{array}$ \\
\hline Babchi & $\begin{array}{l}\text { Psoralea corylifolia, see also Ayurvedic herbs } \\
\text { (Nam et al., 2005) }\end{array}$ \\
\hline Bacopa monnieri & see Ayurvedic herbs \\
\hline Bajiaolian & $\begin{array}{l}\text { Dysosma pleianthum } \\
\text { (Kao et al., 1992) }\end{array}$ \\
\hline Boronia Sm. & see Pro-Lean ${ }^{\circledR}$ \\
\hline Buchu Tea & $\begin{array}{l}\text { Agathosma betulina, Agathosma crenulata } \\
\text { (Engels at al., 2013) }\end{array}$ \\
\hline Bush tea & $\begin{array}{l}\text { Crotalaria species } \\
\text { (Smith and Culvenor, 1981) }\end{array}$ \\
\hline Callile pis laureola & see Impila \\
\hline Camellia sinensis & $\begin{array}{l}\text { see green tea, Exolise }{ }^{\circledR} \text {, and Hydroxycut }{ }^{\circledR} \\
\text { see X-elles }{ }^{\circledR}\end{array}$ \\
\hline Cascara sagrada & $\begin{array}{l}\text { Rhamnus purshianus } \\
\text { (Nadir et al., 2000) }\end{array}$ \\
\hline Cassia angustifolia & see Senna \\
\hline Centella asiatica & see Gotu Kola, see Pro-Lean ${ }^{\circledR}$ \\
\hline Chamaerops humilis & see Saw Palmetto \\
\hline Chaparral & Larrea tridentata, Larrea divariatica \\
\hline syn. Creosot & $\begin{array}{l}\text { (Katz and Saibil, 1990; Centers of Disease Control } \\
\text { and Prevention, 1992; Smith and Desmond, 1993; } \\
\text { Alderman et al., 1994; Batchelor et al., 1995; } \\
\text { Gordon et al., 1995; Sheikh et al., 1997; Haller } \\
\text { et al., 2002; Estes et al., 2003) }\end{array}$ \\
\hline Chelidonium majus & 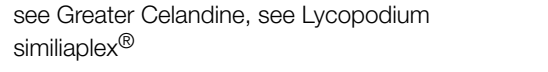 \\
\hline Chinese herbs & Unknown or up to 12 ingredients \\
\hline Chlorophora species & see Kambala tea \\
\hline $\begin{array}{l}\text { Chrysanthemum } \\
\text { leucanthemum }\end{array}$ & see Oxeye Daisy \\
\hline Citrus aurantium & see X-elles ${ }^{\circledR}$ \\
\hline Citrus paradisum & see X-elles ${ }^{\circledR}$ \\
\hline Cyrana scolymus & see X-elles ${ }^{\circledR}$ \\
\hline Cola nitida & see Pro-Lean ${ }^{\circledR}$ \\
\hline Coltsfoot & $\begin{array}{l}\text { Tussilago farfara } \\
\text { (Roulet et al., 1988) }\end{array}$ \\
\hline Comfrey & $\begin{array}{l}\text { Symphytum officinale, Symphytum asperum, } \\
\text { Symphytum uplandicum } \\
\text { (Ridker et al., 1985; Weston et al., 1987; Bach } \\
\text { et al., 1989; Ridker and McDermott, 1989; Miskelly } \\
\text { and Goodyer, 1992) }\end{array}$ \\
\hline
\end{tabular}

TABLE 2 | Continued

\begin{tabular}{|c|c|}
\hline Search items & Botanical names, ingredients, references \\
\hline Compositae species & see Indian herbs \\
\hline Creosot & see Chaparral \\
\hline Crotalaria species & see Bush tea, see Rattlebox \\
\hline Cyperus & see Pro-Lean ${ }^{\circledR}$ \\
\hline Distaff thistle & $\begin{array}{l}\text { Atractylis gummifera } \\
\text { (Georgia, 1988) }\end{array}$ \\
\hline Eclipta alba & see Ayurvedic herbs \\
\hline Emblica officinalis & see Isabgol \\
\hline Ephedra species & $\begin{array}{l}\text { Ephedra californica, Ephedra sinica } \\
\text { (Estes et al., 2003) }\end{array}$ \\
\hline Exolise $^{\circledR}$ & $\begin{array}{l}\text { Garcinia cambogia, Gymnema sylvestre, White } \\
\text { kidney bean, Camellia sinensis, L-Carnitine } \\
\text { fumarate, Calcium, Magnesium chelate, Chromium } \\
\text { chelate, Conjugated linoleic acid, Chitosan } \\
\text { (McDonnell et al., 2009) }\end{array}$ \\
\hline Fallopia multiflora & see Pro-Lean ${ }^{\circledR}$ \\
\hline Foeniculum amare & see Herbalife ${ }^{\circledR}$ \\
\hline Fucus vesiculosus & see Pro-Lean ${ }^{\circledR}$ \\
\hline Garcinia cambogia & see Exilis ${ }^{\circledR}$, see Herbalife ${ }^{\circledR}$, see Hydroxycut ${ }^{\circledR}$ \\
\hline Germander & $\begin{array}{l}\text { Teucrium chamaedrys, Teucrium polium } \\
\text { (Larrey et al., 1992; Mostefa-Kara et al., 1992; Dao } \\
\text { et al., 1993; Mattéi et al., 1995; Laliberté and } \\
\text { Villeneuve, 1996; Starakis et al., 2006) }\end{array}$ \\
\hline Ginkgo biloba & see Pro-Lean ${ }^{\circledR}$ \\
\hline Ginseng & $\begin{array}{l}\text { see Bai Fang, see Dai Saiko To, see Pro-Lean }{ }^{\circledR} \text {, } \\
\text { see Xiao Chai Hu Tan }\end{array}$ \\
\hline Glycyrrhiza glabra & see Dai Saiko To, see Xiao Chai Hu Tang \\
\hline Gotu Kola & $\begin{array}{l}\text { Centella asiatica } \\
\text { (Jorge and Jorge, 2005) }\end{array}$ \\
\hline Greater Celandine & $\begin{array}{l}\text { Chelidonium majus, see also Lycopodium } \\
\text { similiaplex }{ }^{\circledR} \\
\text { (Strahl et al., 1998; Greving et al., 1998; Benninger } \\
\text { et al., 1999; Crijns et al., 2002; Hardeman et al., } \\
\text { 2003; Stickel et al., 2003; BfArM, 2005; Rifai et al., } \\
\text { 2006; Conti et al., 2008; Moro et al., 2009; } \\
\text { Tarantino et al., 2009; EMA, 2010; Teschke et al., } \\
\text { 2011a, 2012a, 2013b) }\end{array}$ \\
\hline Green tea & $\begin{array}{l}\text { Camellia sinensis, see also Lu Cha (Table 1) } \\
\text { (Duenas Sadornil et al., 2004; Garcia-Moran et al., } \\
\text { 2004; Abu el Wafa et al., 2005; Gloro et al., 2005; } \\
\text { Bonkovsky, 2006; Javaid and Bonkovsky, 2006; } \\
\text { Jimenez-Saenz and Martinez-Sanchez, 2006; } \\
\text { Molinari et al., 2006; Martinez-Sierra et al., 2006; } \\
\text { Björnsson and Olsson, 2007; Federico et al., 2007; } \\
\text { Liss and Lewis, 2009; Sarma et al., 2008; Mazzanti } \\
\text { et al., 2009; Verheist et al., 2009; Rohde et al., } \\
\text { 2011; Teschke et al., 2011e, 2014e; Teschke and } \\
\text { Schulze, 2012) }\end{array}$ \\
\hline Groundsel & Senecio longilobus, Senecio species \\
\hline syn. Senecio & Stillman et al., 1977; Fox et al., 1978 \\
\hline Guaraná & $\begin{array}{l}\text { Paullinia cupana } \\
\text { (Dara et al., 2008) }\end{array}$ \\
\hline Gymnema sylvestre & see Exilis ${ }^{\circledR}$, see Hydroxycut ${ }^{\circledR}$ \\
\hline Hawthorn & see Crataegus \\
\hline Hedeoma pulegoides & see Pennyroyal \\
\hline Heliotropium & Heliotropium eichwaldii, Heliotropium species \\
\hline
\end{tabular}


TABLE 2 | Continued

\begin{tabular}{|c|c|}
\hline Search items & Botanical names, ingredients, references \\
\hline & $\begin{array}{l}\text { (Mohabbat et al., 1976; Datta et al., 1978; Tandon } \\
\text { et al., 2008; Kakar et al., 2010) }\end{array}$ \\
\hline Herbalife $^{\circledR}$ & $\begin{array}{l}\text { Solidaginis gigantea, llex paraguariensis, } \\
\text { Petroselinum crispum, Garcinia cambogia, Spiraea, } \\
\text { Matricaria chamomilla, Liquiritia, Foeniculum amare, } \\
\text { Humulus lupulus, Chromium, and various other } \\
\text { ingredients } \\
\text { (Hoffmann et al., 2005; Duque et al., 2007; Elinav } \\
\text { et al., 2007; Schoepfer et al., 2007; Chao et al., } \\
\text { 2008; Manso et al., 2008; Stickel et al., 2009; Chen } \\
\text { et al., 2010; Jóhannsson et al., 2010; Appelhans } \\
\text { et al., 2011; Manso et al., 2011; Appelhans et al., } \\
\text { 2012; Manso, 2012; Halegoua-De Marzio et al., } \\
\text { 2013; Teschke et al., 2013b) }\end{array}$ \\
\hline Horse chestnut & see Venencapsan ${ }^{\circledR}$, see Venoplant ${ }^{\circledR}$ \\
\hline Hydroxycut ${ }^{\circledR}$ & $\begin{array}{l}\text { Camellia sinensis, Gymnema sylvestre, } \\
\text { Amorphophallus Konjac, Paullinia cupana, Garcinia } \\
\text { cambogia, Caffeine, } \alpha \text {-Lipoic acid, L-Carnitine, } \\
\text { Calcium, Potassium, Chromium } \\
\text { (Stevens et al., 2005; Jones and Andrews, 2007; } \\
\text { Dara et al., 2008; Shim and Saab, 2009; Chen } \\
\text { et al., 2010; Fong et al., 2010) }\end{array}$ \\
\hline Humulus lupulus & see Herbalife ${ }^{\circledR}$ \\
\hline Ilex paraguariensis & see Herbalife ${ }^{\circledR}$, see Maté \\
\hline Impila & $\begin{array}{l}\text { Callilepis laureola } \\
\text { (Wainwright et al., 1977; Wainwright and } \\
\text { Schonland, 1977; Popat et al., 2001) }\end{array}$ \\
\hline Indian herbs & $\begin{array}{l}\text { Compositae species } \\
\text { (Kumana et al., 1983) }\end{array}$ \\
\hline Iroko & see Kambala tea \\
\hline Isabgol & $\begin{array}{l}\text { Plantago ovata, Emblica officinalis } \\
\text { (Fraquelli et al., 2000) }\end{array}$ \\
\hline Kambala tea & Chlorophora excelsa, Chlorophora regia \\
\hline syn. Iroko & (Gunawan and Kaplowitz, 2004) \\
\hline Kava & $\begin{array}{l}\text { Piper methysticum } \\
\text { (Strahl et al., 1998; Escher et al., 2001; BfArM, } \\
\text { 2002; Bujanda et al., 2002; Denham et al., 2002; } \\
\text { Weise et al., 2002; Estes et al., 2003; Gow et al., } \\
\text { 2003; Humberston et al., 2003; Russmann et al., } \\
\text { 2003; Schulze et al., 2003; Teschke et al., 2003, } \\
\text { 2008a,b, 2011b, 2012c; Schmidt et al., 2005; } \\
\text { WHO, 2007a; Christl et al., 2009; Teschke and } \\
\text { Wolff, 2009, 2011; Teschke, 2010a,c; Teschke and } \\
\text { Schulze, 2010; Teschke and Lebot, 2011; Schmidt, } \\
\text { 2014) }\end{array}$ \\
\hline Larrea divariatica & see Chaparral \\
\hline Larrea tridentata & see Chaparral \\
\hline Leucanthemum vulgare & see Oxeye Daisy \\
\hline Liquiritia & see Herbalife ${ }^{\circledR}$ \\
\hline $\begin{array}{l}\text { Lycopodium serratum } \\
\text { foot clubmass }\end{array}$ & see Lycopodium similiaplex ${ }^{\circledR}$, see Wolf's \\
\hline $\begin{array}{l}\text { Lycopodium } \\
\text { similiaplex }{ }^{\circledR}\end{array}$ & $\begin{array}{l}\text { Lycopodium serratum, Chelidonium majus } \\
\text { (Conti et al., 2008) }\end{array}$ \\
\hline Maranta aruninacea & see Arrowroot \\
\hline Maté & $\begin{array}{l}\text { Ilex paraguariensis } \\
\text { (McGee et al., 1976) }\end{array}$ \\
\hline Matricaria chamomilla & see Herbalife ${ }^{\circledR}$ \\
\hline Mentha pulegium & see Pennyroyal \\
\hline
\end{tabular}

TABLE 2 | Continued

\begin{tabular}{|c|c|}
\hline Search items & Botanical names, ingredients, references \\
\hline Mistletoe & $\begin{array}{l}\text { Viscum album } \\
\text { (Harvey and Colin-Jones, 1981; Hyde, 1981; } \\
\text { Colin-Jones and Harvey, 1982; Farnsworth and } \\
\text { Loub, 1982; Stirpe, 1983) }\end{array}$ \\
\hline Monascus purpureus & see Red Yeast Rice \\
\hline Morinda citrifolium & see Noni \\
\hline Nerium oleander & see Oleander \\
\hline Noni & $\begin{array}{l}\text { Morinda citrifolium } \\
\text { (Millonig et al., 2005; Stadllbauer et al., 2005, 2008; } \\
\text { Yüce et al., 2006; López-Cepero Andrada et al., } \\
\text { 2007; Yu et al., 2011; Mrzljak et al., 2013) }\end{array}$ \\
\hline Oleander & $\begin{array}{l}\text { Nerium oleander } \\
\text { (Altan et al., 2009) }\end{array}$ \\
\hline Oxeye Daisy & $\begin{array}{l}\text { Leucanthemum vulgare, Chrysanthemum } \\
\text { leucanthemum } \\
\text { (Mokhobo, 1976) }\end{array}$ \\
\hline Paullinia cupana & see Guaraná, see Hydroxycut ${ }^{\circledR}$, see Pro-Lean ${ }^{\circledR}$ \\
\hline Pennyroyal & $\begin{array}{l}\text { Mentha pulegium, Hedeoma pulegoides } \\
\text { (Vallance, 1955; Sullivan et al., 1979; Anderson } \\
\text { et al., 1996; Bakerink et al., 1996) }\end{array}$ \\
\hline Petroselinum crispum & see Herbalife ${ }^{\circledR}$ \\
\hline Petroselinum sativum & see X-elles ${ }^{\circledR}$ \\
\hline Piper methysticum & see Kava \\
\hline Phaseolus vulgaris & see Exilis ${ }^{\circledR}$ \\
\hline Plantago ovata & see Isabgol \\
\hline Pro-Lean ${ }^{\circledR}$ & $\begin{array}{l}\text { Ma Huang, Paullinia cupana, Cola nitida, Centella } \\
\text { asiatica, Salix alba,Ginkgo biloba, Fucus } \\
\text { vesiculosus, Boronia Sm., Ginseng, Fallopia } \\
\text { multiflora, Cyperus, Bee pollen, Caffeine, L-Tyrosine, } \\
\text { Chromium, Vanadium, Magnesiumsalicylat, } \\
\text { Folsäure, Vitamin B12, and various other ingredients } \\
\text { (Joshi et al., 2007) }\end{array}$ \\
\hline Psoralea corylifolia & see Ayurvedic herbs \\
\hline Pyrrolizidine alkaloids & $\begin{array}{l}\text { see Bush tea, see Comfrey, see Groundsel, see } \\
\text { Heliotropium species, } \\
\text { see Indian herbs, see Maté, see Rattlebox }\end{array}$ \\
\hline Rattlebox & Crotalaria species \\
\hline syn. Crotalaria & (Tandon et al., 1976a,b) \\
\hline Red Yeast Rice & $\begin{array}{l}\text { Monascus purpureus } \\
\text { (Roselle et al., 2008) }\end{array}$ \\
\hline Rhamnus purshianus & see Cascara sagrada \\
\hline Rooibos Tea & $\begin{array}{l}\text { Aspalathus linearis } \\
\text { (Engels et al., 2013) }\end{array}$ \\
\hline Salix alba & see Pro-Lean ${ }^{\circledR}$ \\
\hline Sassafras & $\begin{array}{l}\text { Sassafras albidum } \\
\text { (Larrey, 1997; Zimmerman, 1999) }\end{array}$ \\
\hline Saw Palmetto & $\begin{array}{l}\text { Serenoa serpens, Chamaerops humilis } \\
\text { (Lapi et al., 2010) }\end{array}$ \\
\hline Scullcap & $\begin{array}{l}\text { Scutellaria lateriflora, Scutellaria species } \\
\text { (MacGregor et al., 1989; Caldwell et al., 1994; Hullar } \\
\text { et al., 1999; Estes et al., 2003; Yang et al., 2012a) }\end{array}$ \\
\hline Scutellaria species & see Scullcap \\
\hline Senecio & see Groundsel \\
\hline Senna & $\begin{array}{l}\text { Cassia angustifolia } \\
\text { (Beuers et al., 1991; Seybold et al., 2004; } \\
\text { Vanderperren et al., 2005) }\end{array}$ \\
\hline
\end{tabular}




\section{TABLE 2 | Continued}

\begin{tabular}{|c|c|}
\hline Search items & Botanical names, ingredients, references \\
\hline Serenoa serpens & see Saw Palmetto \\
\hline Solidaginis gigantea & see Herbalife ${ }^{\circledR}$ \\
\hline Spiraea & see Herbalife ${ }^{\circledR}$ \\
\hline Symphytum & see Comfrey \\
\hline Tacca leontopetaloides & see Arrowroot \\
\hline Teucrium & see Germander \\
\hline Tussilago farfara & see Coltsfoot \\
\hline Valerian & $\begin{array}{l}\text { Valeriana officinalis } \\
\text { (MacGregor et al., 1989; Mennecier et al., 1999) }\end{array}$ \\
\hline Valeriana officinalis & see Valerian \\
\hline Venencapsan ${ }^{\circledR}$ & $\begin{array}{l}\text { Aesculus hippocastanum, Chelidonium majus, } \\
\text { Melilotus officinalis, Milfoil, Silybum Adans., } \\
\text { Taraxacum officinale } \\
\text { (De Smet et al., 1996) }\end{array}$ \\
\hline Venoplant ${ }^{\circledR}$ & $\begin{array}{l}\text { Aesculus hippocastanum } \\
\text { (Takegoshi et al., 1986) }\end{array}$ \\
\hline Vetivexia zizaniodis & see Ayurvedic herbs \\
\hline Viscum album & see Mistletoe \\
\hline Wolf's foot clubmass & $\begin{array}{l}\text { Lycopodium serratum } \\
\text { (Woolf et al., 1994; Horowitz et al., 1996; Conti } \\
\text { et al., 2008) }\end{array}$ \\
\hline X-elles ${ }^{\circledR}$ & $\begin{array}{l}\text { Petroselinum sativum, Citrus aurantium, Citrus } \\
\text { paradisum, Cyrana scolymus, Camellia sinensis } \\
\text { (Mathieu et al., 2005) }\end{array}$ \\
\hline
\end{tabular}

Data are retrieved from a selective literature search for selective reports of herbs and herbal products with hepatotoxicity and actualized from a previous report (Teschke et al., 2012h). In numerous cases, causality was proposed, but not necessarily established and open for discussion.

Latency period describes the interval between initiation of herb use and time of onset, evidenced by emerging symptoms or increased liver values. Liver injury by herbal TCM develops slowly with clinical symptoms appearing between 1 week and 1 month (Ma et al., 2014), or up to 150 days (Chau et al., 2011); with a longer latency period of 5-260 weeks for green tea extracts (GTE) (Mazzanti et al., 2009; Teschke et al., 2014a); or 1 week-24 months for other herbs such as kava (Teschke et al., 2008a); and 28-134 days for Greater Celandine (GC) (Teschke et al., 2011a). Finally, published HILI symptoms (Chau et al., 2011; Teschke et al., 2013a; Ma et al., 2014) are similar to those of DILI (Andrade et al., 2004; Liss and Lewis, 2009).

\section{Clinical Course}

The clinical course of HILI is variable with details provided in most publications as referenced (Tables 1, 2). For HILI cases, some details of treatment modalities by herbal products of traditional and modern medicine are provided, with focus on daily and cumulative dose, treatment duration, latency period, and reexposure duration (Table 5). With cessation of herbal use, clinical signs usually vanish along with improvements or normalization of initially increased liver values, as illustrated by few examples (Verucchi et al., 2002; Vanderperren et al., 2005; Teschke and Bahre, 2009; Furukawa et al., 2010; Valente et al., 2010; Yang et al., 2010). A well described dechallenge of liver values in suspected HILI is one of the key items to suspect causality for a particular herb. Patients with HILI caused by herbal TCM or modern herbal medicine commonly experience an acute type of liver injury, which is self-limited upon withdrawal of the offending herb with an overall good prognosis. Whether herbs may cause chronic forms of HILI has not yet been evaluated in detail (García-Cortés et al., 2008). However, persistence of increased liver values raises the question whether these are due to a preexisting liver disease present prior to herbal use rather than to HILI (Picciotti et al., 1998). The acute type of HILI rarely may progress to acute liver failure (Stadlbauer et al., 2005; Fong et al., 2010). This is a serious condition that may require a liver transplant and eventually leads to death (Perharic-Walton and Murray, 1992; Yoshida et al., 1996; Haller et al., 2002; Adachi et al., 2003; Estes et al., 2003; Yuen et al., 2006; Sohn et al., 2008; Fong et al., 2010). Between 1992 and 2008; in Seoul (Korea) alone, 24 patients underwent liver transplantation due to toxic hepatitis caused by herbal TCM (Sohn et al., 2008), causing concern in view of poorly documented efficacy of herbal TCM (Manheimer et al., 2009; Teschke, 2014).

Cessation of herbal use is the only therapeutic approach for HILI patients. Other options including evidence based therapy for treating patients with HILI are lacking, but on a case basis treatment was reported with glycyrrhizin (Inoue et al., 2011), ursodesoxycholic acid (Jorge and Jorge, 2005; Inoue et al., 2011), or corticosteroids (Weinstein et al, 2012).

\section{Hepatotoxicity Criteria}

HILI case assessment mandates clear hepatotoxicity criteria for disease characterization including causality assignment (Teschke et al., 2013f, 2014b). Laboratory-based criteria of HILI are best defined by alanine aminotransferase (ALT) and/or alkaline phosphatise (ALP) values, expressed as $\mathrm{N}$ in multiples of the upper limit of their normal range (Figure 1). For ALT, recommendations initially were at $>2 \mathrm{~N}$ (Bénichou et al., 1993; Danan and Bénichou, 1993) and currently are at $>5 \mathrm{~N}$ (Björnsson et al., 2012; Teschke et al., 2014c,d) or at $3 \mathrm{~N}$ if total bilirubin values exceed $2 \mathrm{~N}$ (Aithal et al., 2011); for ALP, values of $>2 \mathrm{~N}$ are considered diagnostic (Bénichou et al., 1993; Danan and Bénichou, 1993; Aithal et al., 2011). Restricting the ALT criteria to $>5 \mathrm{~N}$ will eliminate unspecific ALT increases and substantiate causality at a high level of probability (Björnsson et al., 2012). Considering patients with ALT values of $>2 \mathrm{~N}$ will initially also include numerous cases with nonspecific increases, which then require thorough assessment and stringent exclusion of causes unrelated to the used herb(s). For low threshold values, the rate of alternative diagnoses is high (Teschke et al., 2013g), findings that are plausible and not unexpected (Teschke et al., 2014e). Other values such as aspartate aminotransferase (AST) are not required, unless to be used as substitute for ALT if not available.

Concern emerges whenever hepatotoxicity is assumed even if liver values were only marginally increased, not reported, or not assessed. These problems are not uncommon for cases of assumed HILI, presented for instance by the US Pharmacopeia (USP) (Mahady et al., 2008) relating to both black cohosh (BC) (Teschke, 2010c; Teschke et al., 2011d,e; Teschke 


\section{TABLE 3 | Compilation of narrative case details and clinical data of patients with HILI by Greater Celandine (GC) and established causality.}

\begin{tabular}{|c|c|c|}
\hline Patient & Identification & Specific information for each individual patient \\
\hline 01 & $\begin{array}{l}\text { (Strahl et al., 1998), } \\
42 \text { years Female }\end{array}$ & $\begin{array}{l}\text { GC extract of known brand name and manufacturer ( } 3 \text { capsules/day containing each } 200 \mathrm{mg} \text { of probably dried herb for } 9 \text { months). } \\
\text { Bloating as indication for treatment. Latency period of } 2 \text { months for first symptoms of itching and jaundice, at rechallenge } 1 \text { month. } \\
\text { ALT } 755 \mathrm{U} / \mathrm{L} \text {, AST } 350 \mathrm{U} / \mathrm{L} \text {, ALP } 221 \mathrm{U} / \mathrm{L} \text {. Upon cessation of GC treatment, rapid decrease but not normalization of ALT values } \\
\text { reported. Readministration of GC with positive result. Exclusion of virus hepatitis A-C and infections of other hepatotropic viruses } \\
\text { reported, with lack of any details regarding hepatitis A, B, and C, CMV, EBV, HSV, or VZV. Exclusion of biliary obstruction by } \\
\text { sonography. Exclusion of autoimmune hepatitis reported with lack of specified parameters. Normal values of iron and copper } \\
\text { parameters. Liver histology: Acute hepatitis with confluent liver cell necroses and little inflammation. } \\
\text { Final diagnosis: highly probable GC hepatotoxicity. }\end{array}$ \\
\hline
\end{tabular}

$02 \quad$ (Benninger et al., $\quad$ GC extract as drug of known brand name and manufacturer (unknown dose/day for 3 months). Atopic eczema as indication for GC 1999), their case five treatment. Various herbal and homeopathic drugs as CD. Latency period of 3 months until symptoms of nausea and jaundice. ALT 37 years Female $\quad 813 \mathrm{U} / \mathrm{L}$, AST $898 \mathrm{U} / \mathrm{L}, \mathrm{ALP} 249 \mathrm{U} / \mathrm{L}$. ALT course described. Positive reexposure test for GC. Five months after GC discontinuation, normalization of liver parameters reported. Exclusion of infections by HAV, HBV, HBC, HEV, CMV, and EBV. SMA 1:40, exclusion of $\mathrm{AlH}$. Ultrasound examination with normal bile ducts. Liver histology not done. Final diagnosis: highly probable GC hepatotoxicity.

03 (Benninger et al., 65 years Female
GC extract of unknown brand name and manufacturer (unknown dose/day for 3 months). Dyspepsia as indication for GC treatment. Latency period and symptoms not recorded. No CD. ALT $152 \mathrm{U} / \mathrm{L}$, AST $89 \mathrm{U} / \mathrm{L}$, ALP $451 \mathrm{U} / \mathrm{L}$. After GC discontinuation, ALT course not sufficiently documented. Normalization of liver values 3 months after GC withdrawal. Exclusion of common causes for hepatitis reported, but lack of information regarding specific parameters. Lack of ultrasound data. Liver histology: Moderate drug induced hepatitis with low grade single cell necrosis.

Final diagnosis: probable GC hepatotoxicity.
$04 \quad$ (Crijns et al., 2002), 42 years Female
Herbal mixture of GC and curcuma root (Curcuma longa rhizoma) of known brand name and manufacturer (unknown dose/day for 2 months). Not further described skin complaints as indication for treatment. Before admission, paracetamol (500 mg) tablet on one day. Latency period: 5 weeks until jaundice. Fever $40.5^{\circ} \mathrm{C}$ for 2 weeks, starting 2 weeks after initiation of GC treatment. ALT $1490 \mathrm{U} / \mathrm{L}$, AST $838 \mathrm{U} / \mathrm{L}$, ALP $265 \mathrm{U} / \mathrm{L}$. Following cessation of the herbal mixture, ALT course described with normalization of liver values after 2 months. Exclusion of acute hepatitis A-C and infections by CMV, and EBV, but HSV and VZV not assessed. Normal titres of ANA, but no data of AMA, SMA, and LKM. Sonography with normal biliary tract. Liver histology: Severe acute hepatitis of viral or toxic drug cause.

Final diagnoses: probable GC hepatotoxicity and possible curcuma hepatotoxicity.

\section{5 (Stickel et al., 2003), their case two} 69 years Male

GC extract as drug of known brand name and manufacturer (80 capsules within 5-6 weeks). Postprandial abdominal discomfort as indication for GC treatment. Latency period of 5-6 weeks until symptoms of weakness, abdominal pain in the right upper quadrant, nausea, jaundice, and dark brown urine. Medical history included cholecystectomy 4 years ago. Lack of regular comedication. Alcohol consumption below $20 \mathrm{~g} /$ day. ALT $881 \mathrm{U} / \mathrm{L}$, AST $466 \mathrm{U} / \mathrm{L}$, ALP $312 \mathrm{U} / \mathrm{L}$. ALT course not recorded. Exclusion of acute viral hepatitis including HAV, HBV, HCV, CMV, EBV. Autoimmune parameters not assessed. By abdominal ultrasound and magnetic resonance tomography common and intrahepatic bile ducts inapparent. Liver histology: Cholestatic hepatitis compatible with drug toxicity. Final diagnosis: probable GC hepatotoxicity.
$06 \quad$ (Rifai et al., 2006), 58 years Male
GC extract as drug of known brand name and manufacturer (unknown amounts of tablets/day for 3 weeks). Biliary spasms as indication for GC treatment. Latency period: of 3 weeks until fatigue, dark urine, itching, jaundice, and pale stool. No CD. ALT $903 \mathrm{U} / \mathrm{L}, \mathrm{AST} 380 \mathrm{U} / \mathrm{L}$, ALP $516 \mathrm{U} / \mathrm{L}$. After GC withdrawal well documented ALT course with ALT normalization within 4 weeks. Well documented exclusion of hepatitis A-C, and E, and of infections by CMV, EBV, HSV, and VZV reported. Well documented exclusion of infectious, autoimmune, metabolic, and genetic causes of acute hepatitis. Sonography with slightly thickening of the gall bladder and otherwise normal biliary tract. Liver histology: Lobular hepatitis with severe cholestasis and moderate inflammation that included also the bile ducts.

Final diagnosis: probable GC hepatotoxicity, but also possible causality for biliary disease.
07 (Conti et al., 2008), 46 years Female
GC extract as solution of known brand name and manufacturer, containing also other herbs as are Lycopodium serrata, Carduus marianus, Hamamelis, Ruta, Sepia, Pulsatilla, Collinsonia, and Hydrastis (50 drops/day for 8 weeks). Insomnia and for sedation as indication for treatment. Latency period of 8 weeks until symptoms of nausea, anorexia, asthenia, and abdominal discomfort. Herbal mixture with various herbs and the potentially hepatotoxic Lycopodium serrata as CD. ALT 2,364 U/L, AST 737 U/L, ALP 255 U/L. Rapid decrease of ALT in the further course following treatment cessation with normalization after 2 months. Exclusion of HAV, HBV, $\mathrm{HCV}, \mathrm{CMV}$, EBV, and HSV. Specified serological tests for autoimmune diseases negative. Sonography without reported biliary tract abnormalities. Liver histology: Moderate mixed inflammatory infiltrate with eosinophils.

Final diagnoses: probable GC hepatotoxicity, probable Lycopodium serratum hepatotoxicity.
$08 \quad$ (Moro et al., 2009), 65 years Male
GC extract as herbal tea derived from GC leaves (1 cup/day for 1 month). Pyrosis as indication for GC treatment. Lansoprazole $15 \mathrm{mg} /$ day for 2 years as current CD. Latency period of 1 month. Asthenia, dyspepsia, dark urine, and jaundice as symptoms. ALT $4765 \mathrm{U} / \mathrm{L}$, AST $3235 \mathrm{U} / \mathrm{L}$, ALP not reported. ALT course not reported, but normalization of all liver parameters within 2 months. Three months before symptom onset, treatment with clarithromycin and amoxicillin for 1 week. All antibodies for not further 


\section{TABLE 3 | Continued}

\begin{tabular}{ll}
\hline Patient $\quad$ Identification & Specific information for each individual patient \\
\hline & $\begin{array}{l}\text { specified hepatic viruses resulted negative except for anti-HCV that was found positive despite negative HCV-PCR. Autoimmune } \\
\text { parameters not reported. Hepatomegaly by ultrasound examination. Liver histology: Moderate drug induced hepatitis. } \\
\text { Final diagnosis: probable GC hepatotoxicity. }\end{array}$ \\
\hline BfArM, 2005, & GC extract as drug of known brand name and manufacturer (2 capsules/day for not clearly defined duration). Upper abdominal pains \\
& as indication for treatment. Latency period not report ed, jaundice as symptom. ALT 2196 U/L, AST 714 U/L, ALP 256 U/L. Upon \\
& cessation of GC treatment, decrease but not normalization of ALT and AST values, with lack of reported ALP value. Readministration \\
of GC with pruritus and not further specified increases of liver values and lack of complete resolution upon dechallenge. Overall \\
course of ALT not sufficiently documented, neither at first and second dechallenge, nor in the interval and after the second challenge. \\
Undulating ALT values of unknown clinical significance. Exclusion of virus hepatitis reported, with lack of any details regarding hepatitis \\
A, B, and C, CMV, EBV, HSV, or VZV. Exclusion of biliary obstruction by sonography and ERCP. Exclusion of autoimmune hepatitis \\
with lack of reported parameters. Normal values of ceruloplasmin, $\alpha-1$ Antitrypsin, and electrophoresis. Liver histology: Unspecific \\
hepatitis with liver cell necroses. Poorly documented case including questionable rechallenge and lack of ALT normalization. \\
Final diagnosis: probable GC hepatotoxicity.
\end{tabular}

\begin{tabular}{ll}
\hline BfArM, 2005, & GC extract as drug of known brand name and manufacturer (3 capsules/day for 6 weeks). Upper abdominal pains as indication for \\
96026841 & treatment. Latency period of 6 weeks with jaundice as symptom. Diltiazem 90 for several years and doxycycline for 10 days (start \\
55 years Female & prior to jaundice) for treatment of erythema migrans as CD. ALT 2,016 U/L, AST 620 U/L, ALP 398 U/L. After cessation of GC \\
& treatment, normalization of ALT not reported and with $201 \mathrm{U} / \mathrm{L}$ on day 19 still increased. Overall ALT course poorly documented. \\
& Exclusion of hepatitis A, B, and C reported without details of assessed parameters. Lack of exclusion of virus infections by CMV, EBV \\
& HSV, and VZV. Negative results for AMA, SMA, LKM, and actin. Exclusion of biliary obstruction by sonography and ERCP. Liver \\
& histology: compatible with drug induced liver injury \\
& Final diagnosis: highly probable GC hepatotoxicity.
\end{tabular}
11 BfArM, 2005, GC extract as drug of known brand name and manufacturer (2-3 capsules/day for 42 days). To increase bile flow after $98000501 \quad$ cholecystectomy 20 years ago as indication for treatment. Latency period of 42 days with itching and jaundice as symptoms. ALT 65 years Male $\quad 461 \mathrm{U} / \mathrm{L}$, AST $355 \mathrm{U} / \mathrm{L}$, ALP $260 \mathrm{U} / \mathrm{L}$, normalization not reported. After GC discontinuation, on day $12 \mathrm{ALT} 235 \mathrm{U} / \mathrm{L}$. Exclusion of hepatitis A-C and of infections by CMV, EBV, HSV, and VZV. AMA negative, exclusion of autoimmune hepatitis reported but individual parameters not described. Upon sonography and ERCP normal bile ducts after cholecystectomy.

Final diagnosis: highly probable GC hepatotoxicity.
12 BfArM, 2005, GC extract as drug of known brand name and manufacturer (3 tablets/day for 4 weeks). Upper abdominal pains as indication for $98001447 \quad$ treatment. Latency period of 3.5 weeks with reduced appetite, bloating, epigastric pain, nausea, vomiting, and jaundice as symptoms. 49 years Female ALT $2928 \mathrm{U} / \mathrm{L}$, AST $1116 \mathrm{U} / \mathrm{L}$, ALP $408 \mathrm{U} / \mathrm{L}$. After GC discontinuation, on day 7 ALT was $1356 \mathrm{U} / \mathrm{L}$, and on day 20 it was $426 \mathrm{U} / \mathrm{L}$. Normalization of ALT has not been reported. Exclusion of hepatitis A-C, E and F, and of infections by CMV, EBV, and HSV, but not of VZV. Normal values of ANA, AMA, and SMA. Upon ultrasound and ERC, normal bile ducts and cholecystolithiasis or cholesterol polyps of the gallbladder, by ultrasound questionable cholecystitis. Liver histology: Severe portal hepatitis with beginning fibrosis. Final diagnosis: probable GC hepatotoxicity.

\begin{tabular}{|c|c|c|}
\hline 13 & $\begin{array}{l}\text { BfArM, } 2005 \text {, } \\
98001607 \\
59 \text { years Female }\end{array}$ & $\begin{array}{l}\text { GC extract as drug of known brand name and manufacturer ( } 3 \text { tablets/day for } 7 \text { weeks). Vomiting, upper abdominal pains and } \\
\text { gastro-esophageal reflux as indications for treatment. Latency period } 20 \text { days with tiredness, exhaustion, nausea, vomiting, and } \\
\text { jaundice as symptoms. Asthma, treated with various sprays, and latent hyperthyroidism without treatment as comorbidities. Maximum } \\
\text { values reported for ALT } 960 \mathrm{U} / \mathrm{L} \text {, AST } 421 \mathrm{U} / \mathrm{L} \text {, and ALP } 425 \mathrm{U} / \mathrm{L} \text {, with decrease but not normalization following GC discontinuation, } \\
\text { but actual results have not been reported. Through histology, ERCP, and serology (HAV, HBV, HCV) other hepatobiliary diseases } \\
\text { excluded, but details not reported. Missing exclusion of infections by CMV, EBV, HSV, and VZV. Poorly documented case. } \\
\text { Final diagnosis: probable GC hepatotoxicity. }\end{array}$ \\
\hline 15 & $\begin{array}{l}\text { (BfArM, 2005), } \\
\text { 00000278 } \\
65 \text { years Male }\end{array}$ & $\begin{array}{l}\text { GC extract as drug of known brand name and manufacturer ( } 3 \text { capsules/day for } 4 \text { weeks). Bloating as indication for treatment. } \\
\text { Latency period of } 3.5 \text { weeks with jaundice as symptom. Diclofenac (intermittent), sitosterols, butizide, raubasine, rescinnamine, and } \\
\text { reserpine as CD. ALT } 950 \mathrm{U} / \mathrm{L} \text {, AST } 570 \mathrm{U} / \mathrm{L} \text {, normal ALP. Under treatment with cortisone and at discharge, ALT 193U/L, but } \\
\text { normalization of ALT with and without cortisone not reported. Exclusion of hepatitis A-C and of infections by CMV, EBV, and HSV } \\
\text { reported. Normal titres of ANA, AMA, and SMA. Sonography and ERCP with normal biliary tract. Liver histology: Hepatitis with } \\
\text { cholestasis. } \\
\text { Final diagnosis: probable GC hepatotoxicity. }\end{array}$ \\
\hline
\end{tabular}




\section{TABLE 3 | Continued}

\begin{tabular}{lll}
\hline Patient & Identification & Specific information for each individual patient \\
\hline 16 & (BfArM, 2005), & GC extract as drug of known brand name and manufacturer (O-2 capsules/day for 4.5 months). Dyspepsia as indication for \\
O2001171 & treatment. Latency period of 4.5 months with reduced appetite and jaundice as symptoms. ALT 760 U/L, AST 408 U/L, ALP 337 U/L. \\
& On day 14 after GC cessation, ALT 379 U/L, and on day 24 ALT 207 U/L. Normalization of ALT not reported. Exclusion of hepatitis \\
& & A-C reported, but details not presented. No exclusion of infections by CMV, EBV, HSV, and VZV. Autoimmune parameters not done. \\
& Sonography, MRCP and MRT with normal biliary tract. Insufficiency of the mitral valve. \\
& Final diagnosis: probable GC hepatotoxicity.
\end{tabular}

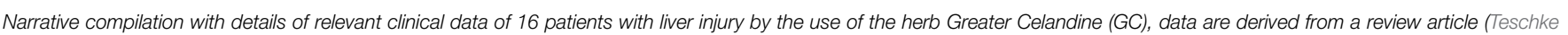

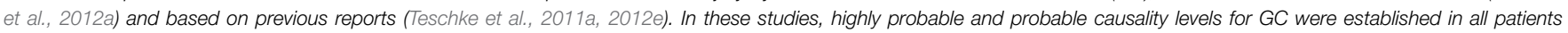

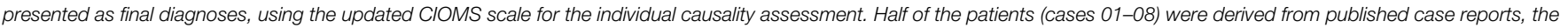

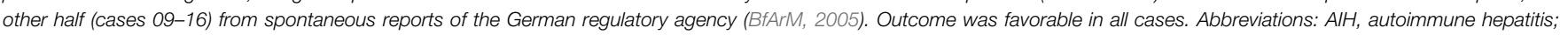

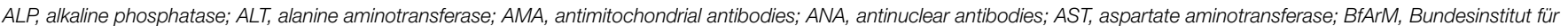

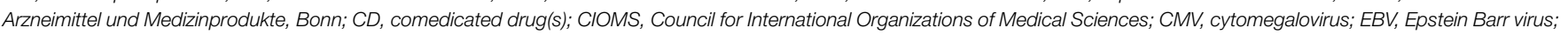

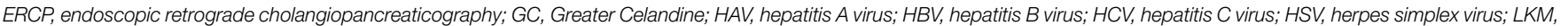

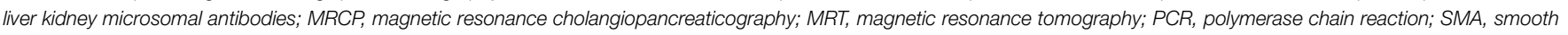
muscle antibodies; VZV, varicella zoster virus.

TABLE 4 | Preferred documentation as example: clinical characteristics of GC hepatotoxicity.

\section{Characteristics of HILI by GC}

Characterization of GC hepatotoxicity as a specific disease entity was feasible and based on high causality levels for GC in 16 patients with liver disease.

Causality for GC was graded highly probable and probable in 4 and 12 patients, respectively.

Among these 16 patients, there was an additional causality for comedicated curcuma graded as possible, for comedicated Lycopodium serratum graded as probable, and for biliary disease graded as possible.

The existence of GC hepatotoxicity has been verified by a positive reexposure test in two patients

Ages of the 16 patients ranged from 32 to 69 years with an average of 54.7 years, and the ratio of females: males was 10: 6 .

Comedication with synthetic or herbal drugs and dietary supplements including herbal ones and herbal mixtures was used in the majority of assessable cases.

On average, the patients used $10 \mathrm{mg}$ chelidonine daily with lack of daily overdose in any of the cases.

Treatment duration was 3 weeks to 9 months with an average of 2.4 months.

Latency period until first symptoms was 3 weeks to 4.5 months with an average of 1.7 months, which was considerably shorter than the treatment length.

Jaundice was the most frequently reported symptom, rarely also weakness, anorexia, nausea, vomiting, abdominal pains, dark urine, pale stools, and itching.

High serum activities are found for ALT but not for ALP, suggestive of a hepatocellular type of toxic liver injury in patients with GC hepatotoxicity.

Histology showed predominantly liver cell necrosis and hepatitis.

Outcome was favorable in all 16 patients, with lack of both acute liver failure and requirement of a liver transplant.

In one patient, good prognosis was sustained even after 7 months of continued GC Use despite presence of emerging GC hepatotoxicity.

GC hepatotoxicity usually represents the hepatocellular and idiosyncratic type of liver injury with its metabolic subgroup, characterized as acute clinical course.

The underlying mechanism(s) leading to GC hepatotoxicity as well as possible culprit(s) are still unknown.

In cases of liver disease, causality for GC was verified and creates concern regarding safety of patients and pharmacovigilance considerations.

Due to lack of epidemiologic data, the incidence of GC hepatotoxicity cannot accurately be calculated but appears to be low.

Preferred documentation: The data are based on the cases of 16 patients with GC hepatotoxicity and highly probable or probable causality levels for GC and derived from a previous report (Teschke et al., 2012a). Abbreviations: ALT, alanine aminotransferase; ALP, alkaline phosphatase; GC, Greater Celandine.

and Schulze, 2012) and green tea extracts (Sarma et al., 2008; Liss and Lewis, 2009); by the WHO, relating to kava (WHO, 2007a; Teschke and Wolff, 2009); the German regulatory agency BfArM (Bundesinstitut für Arzneimittel und Medizinprodukte) (BfArM, 2002, 2005) relating to kava (Schmidt et al., 2005; Teschke et al., 2008a); or the Drug Commission of the German Medical Association (DCGMA, 2011) relating to Pelargonium sidoides (PS) (Teschke et al., 2012b,e). In published case reports receiving the benefit of appropriate peer reviews, the presented HILI cases commonly provide high values of aminotransferases and/or ALP and basic data support of potential hepatotoxicity, as shown also for some cases with a positive reexposure test results (Teschke et al., 2014b). In other HILI case series, however, criteria were not or incompletely documented; neglecting these aspects in effect invalidates the causality assessment.

In spontaneous reports of regulatory agencies, a clear hepatotoxicity definition was provided by EMA (2007) but not by the U.S. Pharmacopeia (USP) (Mahady et al., 2008; Sarma et al., 2008), the German BfArM (2002), or the WHO (2007a). For instance, EMA mentions cases with assumed HILI by BC but clarifies that a causal attribution cannot be made with the required certainty in face of missing liver values (EMA, 2007). Consequently, missing regulatory hepatotoxicity definitions represent 
TABLE 5 | Some chracteristics of daily and cumulative doses, treatment duration, latency period, and reexposure period of cases with hepatotoxicity by herbs of traditional and modern medicine.

\begin{tabular}{|c|c|c|c|c|c|c|c|c|}
\hline Case & $\begin{array}{l}\text { Sex } \\
\text { Age }\end{array}$ & Herb Herbal mixture & Daily dose & $\begin{array}{c}\text { Cumulative } \\
\text { dose }\end{array}$ & $\begin{array}{l}\text { Treatment } \\
\text { duration }\end{array}$ & $\begin{array}{l}\text { Latency } \\
\text { period }\end{array}$ & $\begin{array}{l}\text { Reexposure } \\
\text { duration }\end{array}$ & References \\
\hline 1. & $F / 62 y$ & Aloe & $420 \mathrm{mg}$ & $37800 \mathrm{mg}$ & 3.0 month & 2.75 month & 1.0 month & Yang et al., 2010 \\
\hline 2. & M/71y & Chaparral & 1 tablet & 90 tablets & 3.0 month & 3.5 month & 1.0 month & Batchelor et al., 1995 \\
\hline 3. & $F / 39 y$ & Chinese herbal mixture & n.a. & n.a. & 2.0 month & 2.0 month & 0.1 month & Kane et al., 1995 \\
\hline 4. & $F / 9 y$ & Chinese herbal mixture & n.a. & n.a. & 6.0 month & 5.25 month & 1.0 month & Davies et al., 1990 \\
\hline 5. & F/66y & Chinese Jin Bu Huan & $0-2$ tablets & 60 tablets & 3.0 month & 2.75 month & 0.5 month & Woolf et al., 1994 \\
\hline 6. & M/46y & Chinese Jin Bu Huan & 0-3 tablets & 216 tablets & 6.0 month & 6.0 month & 1.0 month & Woolf et al., 1994 \\
\hline 7. & $F / 52 y$ & Chinese Syo Saiko To & $7.5 \mathrm{~g}$ & $338 \mathrm{~g}$ & 1.5 month & 1.5 month & 1.0 month & Itoh et al., 1995 \\
\hline 8. & $F / 58 y$ & Chinese Syo Saiko To & $7.5 \mathrm{~g}$ & $675 \mathrm{~g}$ & 3.0 month & 3.0 month & 0.25 month & Itoh et al., 1995 \\
\hline 9. & $F / 42 y$ & Chinese Syo Saiko To & $7.5 \mathrm{~g}$ & $158 \mathrm{~g}$ & 0.75 month & 0.75 month & 0.07 month & Itoh et al., 1995 \\
\hline 10. & $F / 54 y$ & Germander & $600 \mathrm{mg}$ & $23,400 \mathrm{mg}$ & 1.3 month & 1.3 month & 1.0 month & Larrey et al., 1992 \\
\hline 11. & $F / 25 y$ & Germander & n.a. & n.a. & 4.0 month & 4.0month & 0.75 month & Larrey et al., 1992 \\
\hline 12. & M/48y & Germander & $900 \mathrm{mg}$ & $81,000 \mathrm{mg}$ & 3.0 month & 3.75 month & 0.33 month & Larrey et al., 1992 \\
\hline 13. & $F / 45 y$ & Germander & $260 \mathrm{mg}$ & $468,00 \mathrm{mg}$ & 6.0 month & 6.0 month & 0.25 month & Laliberté and Villeneuve, 1996 \\
\hline 14. & $F / 42 y$ & Greater Celandine & $600 \mathrm{mg}$ & $162,000 \mathrm{mg}$ & 9.0 month & 2.0 month & 1.5 month & Strahl et al., 1998 \\
\hline 15. & $F / 56 y$ & Green tea & $14 \mathrm{ml}$ & $210 \mathrm{ml}$ & 4.0 month & 3.3 month & 1.0 month & $\begin{array}{l}\text { Jimenez-Saenz and } \\
\text { Martinez-Sanchez, } 2006\end{array}$ \\
\hline 16. & $F / 37 y$ & Green tea & n.a. & n.a. & 4.0 month & 4.0 month & 1.0 month & Bonkovsky, 2006 \\
\hline 17. & F/63y & Herbalife & n.a. & n.a. & 4.0 month & 3.5 month & n.a. & Hoffmann et al., 2005 \\
\hline 18. & $F / 39 y$ & Kava & $60 \mathrm{mg}$ & $10,800 \mathrm{mg}$ & 6.0 month & 6.0.month & 0.5 month & Strahl et al., 1998 \\
\hline 19. & $F / 49 y$ & Mistletoe & $50 \mathrm{mg}$ & $1500 \mathrm{mg}$ & 1.0 month & 1.0 month & 1.0 month(?) & Harvey and Colin-Jones, 1981 \\
\hline 20. & M/61y & Polygonum multiflorum & n.a. & n.a. & 0.033 month & 0.033 month & 0.033 month & Jung et al., 2011 \\
\hline 21. & $F / 26 y$ & Senna & $100 \mathrm{mg}$ & $12,000 \mathrm{mg}$ & 4.0 month & 3.0 month & n.a. & Beuers et al., 1991 \\
\hline
\end{tabular}

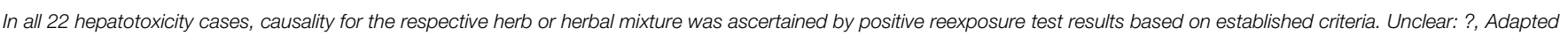
data from a previous report (Teschke et al., 2014b).

confounding variables and result in false high signal cases due to regulatory case overreporting and overdiagnosing (Teschke et al., 2013f).

For reasons of transparency and assessment of case data quality, each HILI case series should provide tabulated information of available or missing case details, as done in various reports (Teschke et al., 2011a, 2012b,e) and shown as example (Table 6) (Teschke, 2010c).

\section{HILI Case Characteristics}

Hepatotoxicity classification is mandatory in cases of assumed HILI to facilitate further evaluation of reexposure results and CIOMS assessments (Teschke et al., 2013f). Based on specific laboratory constellations, differentiation of the hepatocellular, cholestatic or mixed form of hepatotoxicity is feasible by comparing serum activities of ALT and ALP at the time HILI diagnosis is first suspected (Bénichou et al., 1993; Danan and Bénichou, 1993; Teschke et al., 2014d). Enzyme activity is expressed as a multiple of the upper limit of the normal range $(\mathrm{N})$, and the ratio $(\mathrm{R})$ of ALT/ALP is calculated. Liver injury is classified as hepatocellular, if ALT $>2 \mathrm{~N}$ alone or $R=5$; cholestatic, when there is an increase of ALP $>2 \mathrm{~N}$ alone or when $R=2$; of the mixed type if ALT $>$ $2 \mathrm{~N}, \mathrm{ALP}$ is increased, and $2<R<5$ (Figure 1). In a HILI case series of herbal TCM consisting of 27 patients, the pattern of liver injury was hepatocellular in $82 \%$ of the cases, cholestatic in $11 \%$, and mixed in 7\% (Chau et al., 2011).

\section{Liver Histology}

Liver biopsy in HILI and DILI cases requires special attention in any clinical hepatology setting, balancing benefits and risks for the patient (Teschke and Frenzel, 2014). Published and spontaneous HILI reports often contain detailed histological descriptions of liver biopsy findings, mostly associated with pictures obtained by microscopy. This erroneously implies that liver biopsy is an essential part of routine case assessments (BfArM, 2002; Teschke et al., 2008a, 2011a, 2012a,b,f,g; Teschke, 2010c). Histology data were also presented by narrative HILI case reports lacking even any causality for a particular herb (Teschke et al., 2012f,g). This raises the question whether a liver biopsy is justified, considering also that there were no histological findings recognized as specific for all hepatotoxicity cases (Ramachandran and Kakar, 2009). Liver biopsy in chronic hepatotoxicity cases to define prognosis in the absence of an expected specific therapy option remains debatable (Teschke and Frenzel, 2014).

To evaluate liver histology findings, a retrospective case analysis of pathological changes in HILI selectively caused by one single herb with established causality appears the best approach. For instance, HILI cases of kava and GC have such an established causality track. In 12 GC HILI patients with a probable or highly probable causality grading for GC, prevailing histological features included hepatitis, single or confluent liver cell necrosis, inflammation, rarely fibrosis, and cholestasis (Teschke et al., 2011a, 2012a,e). In eight HILI patients with a highly probable, 


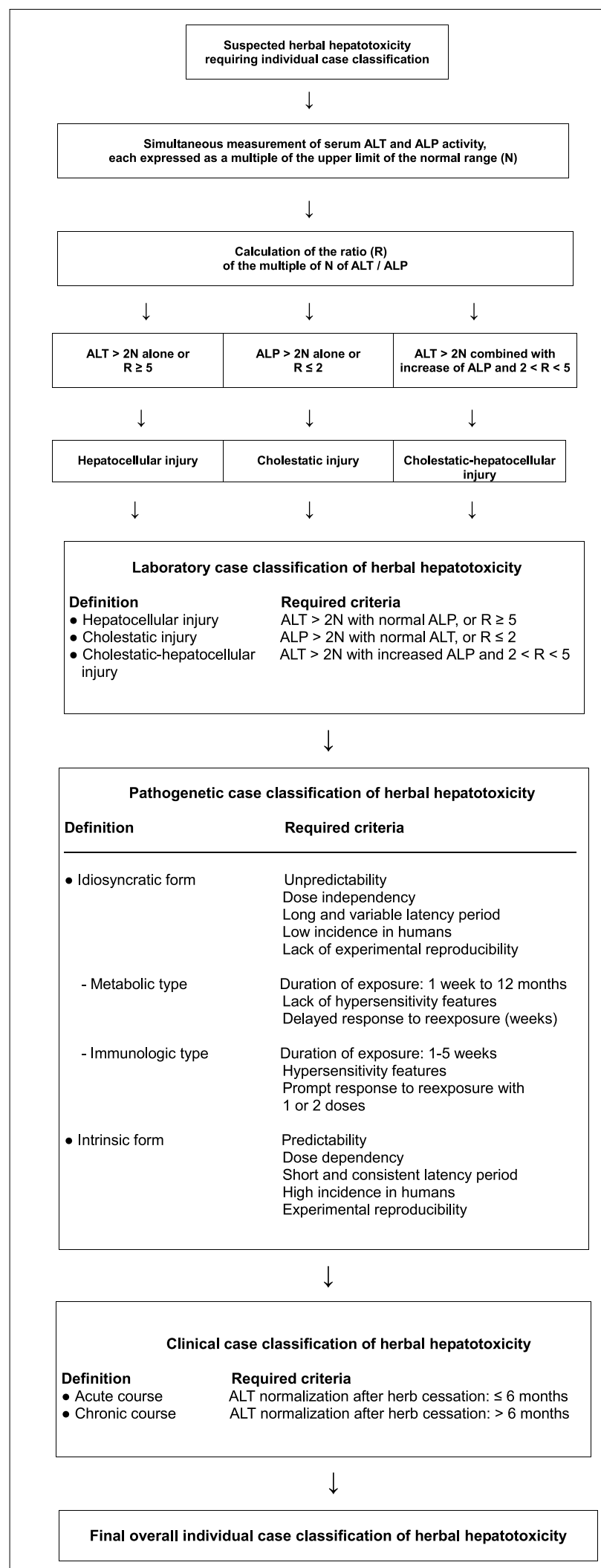

FIGURE 1 | Strategy for assessing HILI cases according to details presented previously (Teschke et al., 2013f). Abbreviations: ALP, alkaline phosphatase; ALT. probable or possible causality for kava, liver histology showed hepatitis, liver cell necrosis, and rarely bile duct proliferation and intrahepatic cholestasis (Teschke et al., 2008a). Therefore, at least for the two herbs GC and kava, the histological features are quite uniform and restricted to two major features, hepatitis and liver cell necroses. These histological characteristics, however, are also found in most other liver diseases unrelated to herbs, obviating liver biopsy in suspected HILI cases due to unspecific results.

Additional insights are provided by the analysis of cases with positive reexposure tests, done unintentionally with the incriminated herb or herbal mixture, and available liver histology results. For instance, in HILI by a herbal mixture of TCM, total liver necrosis prevailed (Perharic-Walton and Murray, 1992); germander (Teucrium chamaedrys) caused hepatocyte necrosis with lobular inflammatory infiltration mainly by mononuclear cells, associated with slightly fibrous portal tracts containing inflammatory cells (Larrey et al., 1992); senna use resulted in liver cell necrosis around the central veins as well as portal and lobular infiltration by lymphocytes, histiocytes, and rare plasma cells (Beuers et al., 1991); chaparral intake was associated with hepatocellular necrosis combined with inflammation, portal tract expansion, mild cholestasis and fibrous septation (Batchelor et al., 1995); and the herbal TCM Chinese skullcap (Scutellaria baicalensis) was considered to cause acidophil bodies, ballooned hepatocytes, lobular inflammatory cell infiltrates including eosinophils, and portal tracts containing mononuclear cells and eosinophils (Yang et al., 2012a). Based on causality established by positive reexposure results, these few examples may provide some insight in morphological liver changes due to herbal use.

Histological features usually are not clinically relevant, but some clinicians still consider a liver biopsy an important part of the diagnostic work-up in suspected hepatotoxicity cases. The question is whether histological results changed the initial diagnosis or benefited the individual patient. In two cases of initially suspected HILI, however, histological findings of giant cell hepatitis were reported and completely ignored (Dunbar and Solga, 2007; Schoepfer et al., 2007), while the clinical course and this particular histological pattern best fitted with an existing severe virus infection with hepatic involvement rather than herbal hepatotoxicity (Teschke and Schwarzenboeck, 2009).

Clearly, the pathologist is not helpful offering diagnoses such as HILI or liver injury compatible with or suggestive for herbal use. Overall, liver histology as a supporting routine method for assessing HILI cases is not recommended, it commonly adds little new specific diagnostic clues as information to the case without benefit for the patient; as an invasive procedure, rare but potentially life threatening complications may occur (Teschke and Frenzel, 2014).

\section{Alternative Causes}

Unrecognized alternative diseases are a real clinical problem when caring for patients with initially assumed but later not confirmed HILI. Several hundred liver diseases have to be considered as diagnoses alternative to HILI, to be ruled out under clinical aspects and with specific diagnostic tools. As a reminder for clinicians, a checklist with details for these alternative diagnoses is available (Table 7) (Teschke et al., 2014d). Numerous missed 
TABLE 6 | Preferred documentation as example: overview of known information regarding all 69 patients with primarily suspected but not established HILI by black cohosh (BC).

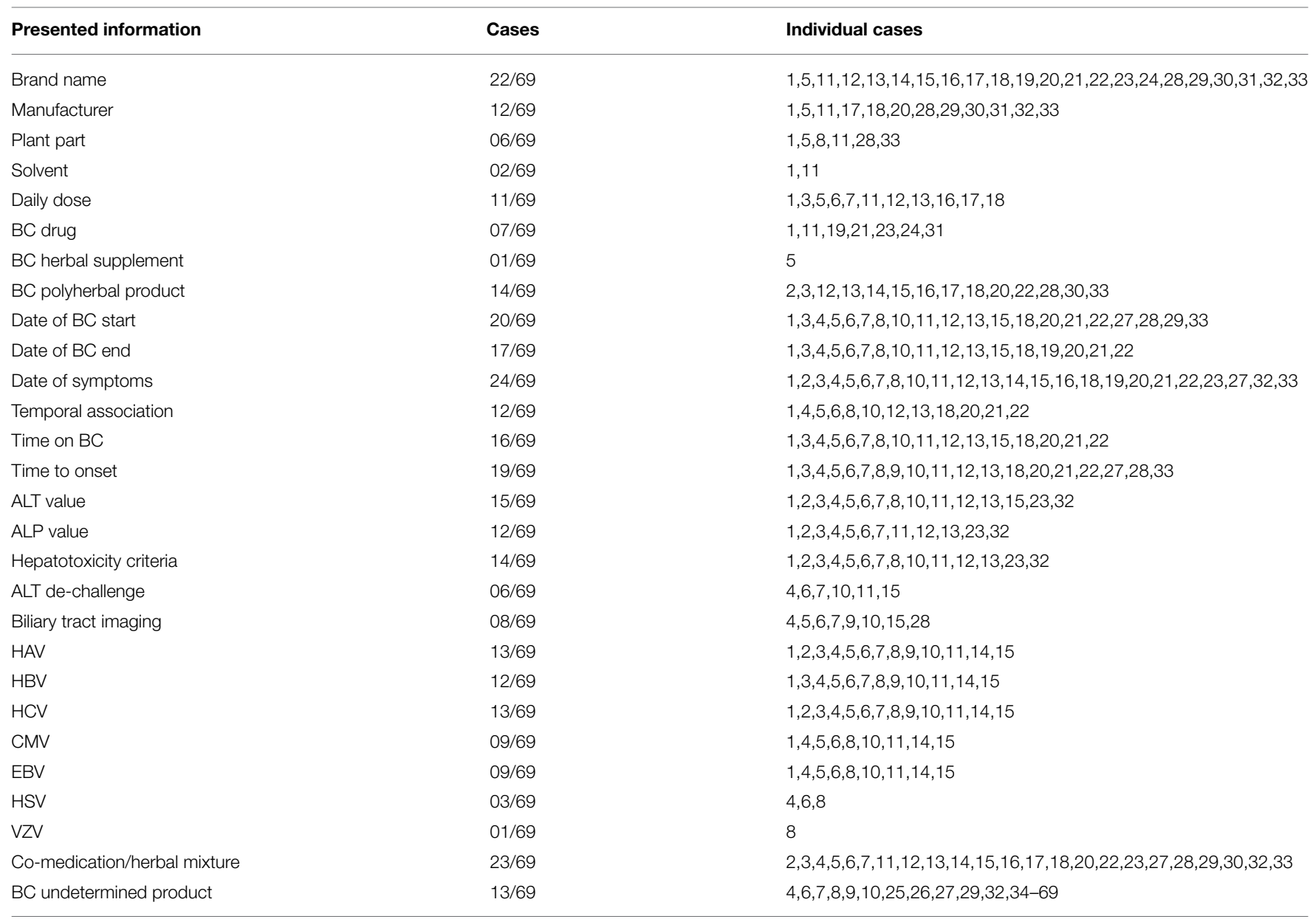

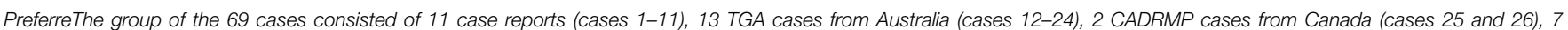

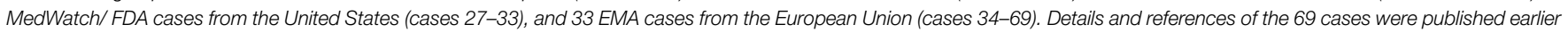

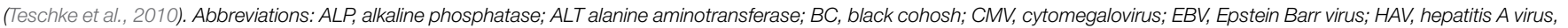
$H B V$, hepatitis B virus, $H C V$, hepatitis $C$ virus; HSV, herpes simplex virus; VZV, varicella zoster virus.

diagnoses were found upon reevaluation of initially assumed HILI cases, with similar problems for DILI (Figure 2) (Teschke et al., 2013g, 2014a). Exclusion of hepatitis E and infections by cytomegalovirus (CMV), Epstein Barr virus (EBV), herpes simplex virus (HSV), and varicella zoster virus (VZV) should be obligatory rather than facultative (Table 7).

\section{Causality Evaluation Reexposure}

Establishing the diagnosis of HILI may be cumbersome in the usual clinical setting, with experts not available in place and in time. Since, convincing biomarkers for all HILI cases are lacking, the gold standard for the diagnosis of hepatotoxicity still is a positive unintentional reexposure test result, if available (Bénichou et al., 1993; Danan and Bénichou, 1993; García-Cortés et al., 2008; Chalasani and Björnsson, 2010). Details of essential criteria are based on the conclusions of an International Consensus Meeting, as referred previously (Bénichou et al., 1993). Accordingly, required data are baseline ALT levels before reexposure, designed ALTb, and reexposure ALT levels, designed ALTr. The reexposure test is positive, if ALTr $=2 \mathrm{ALTb}$ and ALTb is below $5 \mathrm{~N}$, with $\mathrm{N}$ as the upper limit of the normal value (Table 8). Other variations lead to uninterpretable results. Some HILI reports mentioned a positive reaction upon reexposure, and these cases were further analyzed. Not all reexposure tests could be confirmed, partially due to lack of any details; however, for numerous herbs and herbal preparations of TCM and modern medicine, valid reexposure test results confirmed causality in the assessed HILI cases (Table 9) (Teschke et al., 2014b,d); using these cases, some characteristic features of daily and cumulative doses, divergences between treatment duration and latency period, and reexposure duration are evident (Table 5).

\section{CIOMS/RUCAM}

Physicians at armlength from the patient with HILI are well advised to consider a pragmatic thorough clinical evaluation 
TABLE 7 | Differential diagnoses of HILI.

Differential diagnosis

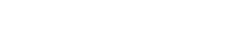

Diagnostic parameters

\begin{tabular}{ll}
$\begin{array}{c}\text { Diagnostic exclusion done } \\
\text { for patient's assessment }\end{array}$ \\
\hline Yes N NO Pa
\end{tabular}

Hepatitis A
Hepatitis B
Hepatitis C
Hepatitis E
Cytomegalovirus (CMV)
Epstein Barr virus (EBV)
Herpes simplex virus (HSV)
Varicella zoster virus (VZV)
Other virus infections
Other infectious diseases
Autoimmune hepatitis (AlH) type I
Autoimmune hepatitis (AlH) type II
Primary biliary cholangitis (PBC)
Primary sclerosing cholangitis (PSC)
Autoimmune cholangitis (AIC)
Overlap syndromes
Non alcoholic steatohepatitis (NASH)
Alcoholic liver disease (ALD)
Drug induced liver injury (DILI)

Cocaine, ecstasy and other amphetamines

Rare intoxications

Hereditary hemochromatosis

Wilson's disease

Porphyria

$\alpha_{1}$-Antitrypsin deficiency

Biliary diseases

Pancreatic diseases

Celiac disease

Anorexia nervosa

Parenteral nutrition

Cardiopulmonary diseases

Addison's disease
Thyroid diseases
Grand mal seizures
Heat stroke
Polytrauma
Systemic diseases

Other diseases

\section{Anti-HAV-lgM}

Anti-HBc-IgM, HBV-DNA

Anti-HCV-lgM, HCV-RNA

Anti-HEV-lgM, Anti-HEV-lgG, HEV-RNA

CMV-PCR, titre change for Anti-CMV-IgM and Anti-CMV-IgG

EBV-PCR, titre change for Anti-EBV-IgM and Anti-EBV-IgG

HSV-PCR, titre change for Anti-HSV-IgM and Anti-HSV- IgG

VZV-PCR, titre change for Anti-VZV-IgM and Anti-VZV- IgG

Specific serology of Adenovirus, Coxsackie-B-Virus, Echovirus, Measles virus, Rubella virus, Flavivirus, Arenavirus, Filovirus, Parvovirus, HIV, and others

Specific assessment of bacteria, fungi, parasites, worms, and others

Gamma globulins, ANA, SMA, AAA, SLA/LP, Anti-LSP, Anti-ASGPR

Gamma globulins, Anti-LKM-1 (CYP 2D6), Anti-LKM-2 (CYP 2C9), Anti-LKM-3

AMA, Anti PDH-E2

p-ANCA, MRC

ANA, SMA

See AlH, PBC, PSC, and AIC

$\mathrm{BMI}$, insulin resistance, hepatomegaly, echogenicity of the liver

Patient's history, clinical and laboratory assessment, sonography

Patient's history, clinical and laboratory assessment, sonography, use of the CIOMS scale

Toxin screening

Toxin screening for household and occupational toxins

Serum ferritin, total iron-binding capacity, genotyping for C2824 and H63D mutation, hepatic iron content

Copper excretion (24 h urine), ceruloplasmin in serum, free copper in serum, Coombs-negative hemolytic anemia, hepatic copper content,

Kayser-Fleischer-Ring, neurologic-psychiatric work-up, genotyping

Porphobilinogen in urine, total porphyrines in urine

$\alpha_{1}-$ Antitrypsin in serum

Clinical and laboratory assessment, hepatobiliary sonography, MRC

Clinical and laboratory assessment, sonography, CT, MRT

TTG antibodies, endomysium antibodies, duodenal biopsy

Clinical context

Clinical context

Cardiopulmonary assessment of congestive heart disease, myocardial infarction, cardiomyopathy, cardiac valvular dysfunction, pulmonary embolism, pericardial diseases, arrhythmia, hemorrhagic shock, and various other conditions

Plasma cortisol

TSH basal, T4, T3

Clinical context of epileptic seizure (duration $>30 \mathrm{~min}$ )

Shock, hyperthermia

Shock, liver injury

Specific assessment of M. Boeck, amyloidosis, lymphoma, other malignant tumors, sepsis, and others

Clinical context

\section{Yes}

$\square$

$\square$

$\square$
$\square$

$\square$

$\square$

$\square$

$\square$

$\square$

$\square$

$\begin{array}{lll}\square & \square & \square \\ \square & \square & \square \\ \square & \square & \square \\ \square & \square & \square \\ \square & \square & \square \\ \square & \square & \square \\ \square & \square \\ \square & \square \\ \square & \square & \square \\ \square & \square & \square \\ & \square & \square\end{array}$

$\square \quad \square$

$\square$

$\square$

$\square$

$\square$

$\square \quad \square$

$\square \quad \square \quad \square$

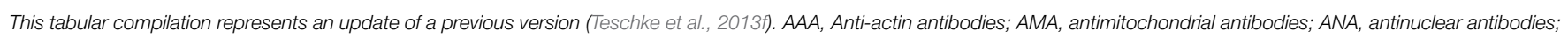

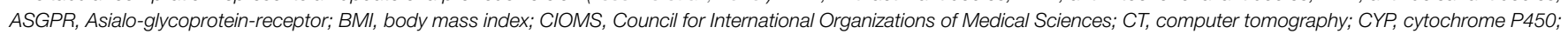

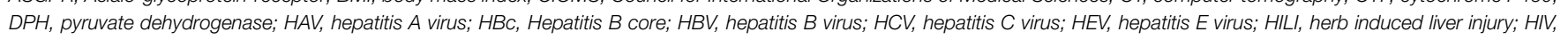

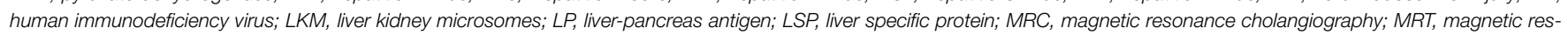

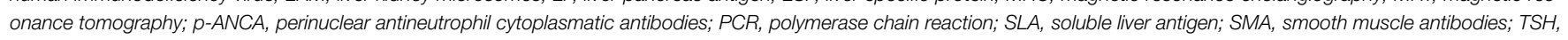
thyroid stimulating hormone; TTG, tissue transglutaminase. 


\section{Primarily suspected herbal and drug hepatotoxicity}

\begin{tabular}{|c|c|}
\hline $\begin{array}{c}\text { Missed diagnoses as alternatives to herbal } \\
\text { hepatotoxicity }\end{array}$ & $\begin{array}{c}\text { Missed diagnoses as alternatives to drug } \\
\text { hepatotoxicity }\end{array}$ \\
\hline $\begin{array}{l}\text { Hepatitis E } \\
\text { Hepatitis by EBV } \\
\text { Hepatitis by HSV } \\
\text { Hepatitis by VZV } \\
\text { Giant cell hepatitis } \\
\text { Infection with hepatic involvement } \\
\text { Autoimmune hepatitis } \\
\text { LKM positive autoimmune hepatitis } \\
\text { SMA positive autoimmune hepatitis } \\
\text { Primary biliary cirrhosis } \\
\text { Overlap syndrome } \\
\text { Alcoholic liver disease/cirrhosis } \\
\text { Non-alcoholic liver cirrhosis } \\
\text { Previous gastric bypass operation } \\
\text { Cardiac hepatopathy } \\
\text { Polytrauma (38) } \\
\text { Preexisting liver diseases/cirrhosis } \\
\text { Questionable liver disease } \\
\text { Liver injury by co-medication } \\
\text { Non-alcoholic steatohepatitis ( } \\
\text { Hyperthyroid hepatopathy } \\
\text { Biliary diseases } \\
\text { Pancreatitis } \\
\text { Rhabdomyolysis by statin }\end{array}$ & $\begin{array}{l}\text { Hepatitis B } \\
\text { Hepatitis C } \\
\text { Hepatitis E } \\
\text { Hepaits by CMV } \\
\text { Hepatitis by EBV } \\
\text { Virus hepatitis } \\
\text { Autoimmune hepatitis } \\
\text { Hemochromatosis } \\
\text { Wilson's disease } \\
\text { Ischemic hepatitis } \\
\text { Cardiac hepatopathy } \\
\text { Liver cirrhosis } \\
\text { Fatty liver } \\
\text { Non alcoholic steatohepatitis } \\
\text { Alcoholic liver disease } \\
\text { Past liver transplantation } \\
\text { Unknown liver disease } \\
\text { Gilbert's syndrome } \\
\text { Benign recurrent intrahepatic cholestasis } \\
\text { Bile duct diseases } \\
\text { Tumors } \\
\text { Lymphoma } \\
\text { Systemic sepsis } \\
\text { Chlamydial infection } \\
\text { Thyroid disease } \\
\text { Postictal state } \\
\text { Polymyositis }\end{array}$ \\
\hline
\end{tabular}

FIGURE 2 | Missed diagnoses in cases of initially suspected hepatotoxicity by herbs and synthetic drugs. Adapted from a previous report (Teschke et al., 2013f), which provides the respective references for each item presented above. Abbreviations: CMV, cytomegalovirus; EBV, Epstein Barr virus; HSV herpes simplex virus; LKM, liver kidney microsomes; SMA, smooth muscle antibodies; VZV, varicella zoster virus. in connection with a prospective structured approach assessing causality, providing the diagnosis in time while the disease is unfolding and without delay due to waiting periods for expert rounds' conclusions months thereafter; this is a crucial issue worldwide. We clearly prefer the CIOMS scale (Council for International Organizations of Medical Sciences), also called RUCAM (Roussel Uclaf Causality Assessment Method), in its original form (Bénichou et al., 1993; Danan and Bénichou, 1993) or better its update (Tables 10, 11) (Teschke et al., 2013a, 2014d). Discussions focused on strengths and weaknesses of CIOMS, a learning system and not immutable (Andrade et al., 2004; Rochon et al., 2008; Aithal et al., 2011; García-Cortés et al., 2011; Teschke and Wolff, 2011; Teschke and Schulze, 2012; Teschke et al., 2008c, 2013e, 2014d; Lewis, 2014; NIH, 2014b). Outlined suggestions for improvement and refinement are incorporated in the updated CIOMS scale (Tables 10, 11) (Teschke et al., 2013e, 2014d). Included is now the search for additional competing causes such as sepsis; or autoimmune hepatitis, chronic hepatitis $\mathrm{B}$ and $\mathrm{C}$, primary biliary cholangitis and sclerosing cholangitis, and genetic liver diseases. HBsAg and HBV-DNA quantification were added to distinguish $\mathrm{HBV}$ infection from immunization, as was HCV-RNA to correctly assess HCV infections. Specific diagnostic criteria now include PCR detection and titer changes of the respective antibodies (IgM, IgG) for CMV, EBV, HEV, HSV, and VZV infections. Hepatobiliary sonography was supplemented by color Doppler sonography including assessments of the liver vessels, endosonography, computed tomography (CT), and magnetic resonance cholangiography (MRC. Alcohol as risk factor is now specified by an intake of $>2$ drinks per day (>14 units/week) in woman and $>3$ drinks per day (21 units/week) in men, whereby one drink corresponds to $10 \mathrm{~g}$ ethanol. For comparison and method validation, causality has been evaluated in 101 hepatotoxicity cases by both the original and updated CIOMS scales, with identical causality results published in 6 studies (Teschke et al., 2014d).Therefore, the updated CIOMS scale was validated, and there is no need for further validation of the updated CIOMS scale vs. the original CIOMS scale.

A selective compilation shows that numerous international registries and regulatory agencies as well as associated groups 
TABLE 8 | Conditions of unintentional reexposure tests in suspected HILI cases.

\begin{tabular}{|c|c|c|c|c|}
\hline \multirow[t]{2}{*}{$\begin{array}{l}\text { Reexposure } \\
\text { test result }\end{array}$} & \multicolumn{2}{|c|}{$\begin{array}{l}\text { Hepatocellular type } \\
\text { of liver injury }\end{array}$} & \multicolumn{2}{|c|}{$\begin{array}{c}\text { Cholestatic ( } \pm \text { hepatocellular) } \\
\text { type of liver injury }\end{array}$} \\
\hline & ALTb & ALTr & ALPb & ALPr \\
\hline Positive & $<5 \mathrm{~N}$ & $\geq 2 \mathrm{ALTb}$ & $<2 \mathrm{~N}$ & $\geq 2 \mathrm{ALPb}$ \\
\hline Negative & $<5 \mathrm{~N}$ & $<2 \mathrm{ALTb}$ & $<2 \mathrm{~N}$ & $<2 \mathrm{ALPb}$ \\
\hline Negative & $\geq 5 \mathrm{~N}$ & $\geq 2 A L T b$ & $\geq 2 \mathrm{~N}$ & $\geq 2 \mathrm{ALPb}$ \\
\hline Negative & $\geq 5 \mathrm{~N}$ & $<2 \mathrm{ALTb}$ & $\geq 2 \mathrm{~N}$ & $<2 \mathrm{ALPb}$ \\
\hline Uninterpretable & $<5 \mathrm{~N}$ & n.a. & $<2 \mathrm{~N}$ & n.a. \\
\hline Uninterpretable & n.a. & $\geq 2 \mathrm{ALTb}$ & n.a. & $\geq 2 \mathrm{ALPb}$ \\
\hline Uninterpretable & n.a. & n.a. & n.a. & n.a. \\
\hline
\end{tabular}

Conditions and criteria for an unintentional reexposure test, adapted from a previous report (Teschke et al., 2014b). Accordingly, required data for the hepatocellular type of liver injury are the ALT level, just before reexposure, designed as baseline ALT or ALTb, and the ALT levels during reexposure, designed as ALTr. Response to reexposure is positive, if both criteria are met: first, ALTb is below $5 \mathrm{~N}$ with $N$ as the upper limit of the normal value, and second $A L T r \geq 2 A L T b$. Other variations lead to negative or uninterpretable results. For the cholestatic ( \pm hepatocellular) type of liver injury, corresponding values of ALP are to be used rather than of ALT. Abbreviations: ALP, Alkaline phosphatase; ALT, Alanine aminotransferase; n.a., not available.

actually apply CIOMS for HILI and DILI cases (Table 12), with its advantages over other causality assessing approaches (Teschke et al., 2013a) including the method of DILIN (DrugInduced Liver Injury Network) (Table 13). As opposed to the DILIN method, CIOMS fascinates by its stringent scoring system (Table 13), with its generation of a quantitative assessment (score) to address probability, which is more precise than a simple yes or no (Gunawan and Kaplowitz, 2004). Support for CIOMS was actually provided by Navarro as DILIN member and senior author of a HDS case series by applying CIOMS for causality assessment (Halegoua-De Marzio et al., 2013), whereas CIOMS was not in favor of Lewis, another DILIN member (Lewis, 2014). Although, connected with an actual commentary on a single HILI case report that did not undergo any formal causality assessment, Navarro also correctly acknowledged that CIOMS/RUCAM is the most frequently referenced scoring system (Fenkel and Navarro, 2011). This assumption supports earlier systematic analyses of 2008 (Tajiri and Shimizu, 2008). Of 61 DILI reports that were reviewed in the PubMed database over the last decade, showing that CIOMS was the most used scale. In a recent confirmative study of 573 HILI cases (Table 14), CIOMS again was the most used method applied in 275 cases (48.0\%) (Teschke et al., 2013g), in line with mainstream opinion (Tables 12, 14) (Wai, 2006; Aithal et al., 2011; NIH, 2014a,b; Björnsson et al., 2012, 2013. The CIOMS scale was widely used for hepatotoxicity assessments in epidemiological studies, clinical trials, case reports, case series, regulatory analyses, and genotyping studies, as referenced in detail recently (Teschke et al., 2013f).

CIOMS is structured, quantitative, and specific and validated for hepatotoxicity, and considers all its core elements (Tables 10, 11) (Teschke et al., 2014d). It was developed by an international expert panel and validated by cases with positive reexposure tests as gold standard, showing good sensitivity (86\%), specificity
(89\%), positive predictive value (93\%), and negative predictive value (78\%) (Bénichou et al., 1993). Of note, the scales for the hepatocellular and the cholestatic ( \pm hepatocellular) type of injury differ slightly (Tables 10, 11).

The CIOMS scale was conceptualized and developed in consensus meetings organized at the request of the Council for International Organizations of Medial Sciences (CIOMS) (Bénichou et al., 1993; Danan and Bénichou, 1993), aiming to overcome experts' previous problems with unstructured and unquantified evaluations lacking defined and scored items,resulting in debated causality assignments. This CIOMS scale represented a breakthrough in DILI and HILI causality assessment methods and extended, specified, and quantified preceding versions (Danan, 1988; Bénichou, 1990). The basis for CIOMS was provided by eight experts in hepatology from 6 countries and included J. P. Benhamou (France), J. Bircher (Germany), G. Danan (France), W. C. Maddrey (USA), J. Neuberger (UK), F. Orlandi (Italy), N. Tygstrup (Denmark), and H. J. Zimmerman (USA) (Bénichou et al., 1993; Danan and Bénichou, 1993). These experts in the field evaluated DILI cases for case characteristics, hepatotoxicity criteria, liver injury pattern, and reexposure criteria; they standardized DILI case assessment with specific, quantitative items and validated their method with established positive reexposure DILI case results (Bénichou et al., 1993; Danan and Bénichou, 1993). CIOMS was developed for assessment of a single drug containing a synthetic product and may be used for a single herb containing multiple chemical constituents, but does not allow causality attribution to a single constituent.

CIOMS provides a differentiating range of causality grades for the responsible agent(s) and clearly delineates liver specific criteria for challenge, dechallenge, exclusion of unrelated diseases, and comedication (Bénichou et al., 1993; Danan and Bénichou, 1993). It even takes into account atypical chronology with +1 point for challenge periods of $<5$ days or $>90$ days, whereas the period of 5-90 days renders +2 points (Table 10). It is well adapted for cases with missing data. Physicians suspecting herbal hepatotoxicity can easily use CIOMS, results are readily available within a few minutes.

To facilitate valid actual assessment and possible external reevaluation, CIOMS scale data should be provided individually point by point for each patient (Tables 10, 11), along with the list of alternative diagnoses to be excluded (Table 7). In publications of HILI cases and for submission to regulatory agencies as spontaneous reports, the completed CIOMS scale with all items including individual and final scores should be supplied to ensure data transparency, as published before (Teschke et al., 2008a, 2011a,d,e, 2012b,d,h; Teschke and Bahre, 2009; Teschke, 2010a,c) and presented as example, using the CIOMS scale of the hepatocellular type of injury (Table 15).

Thus, we strongly recommend for HILI case assessment a sequential approach, starting with thorough clinical evaluations and concomitant prospective causality evaluation by the updated CIOMS scale (Tables 10, 11), followed by optional expert opinion based on scored CIOMS items, if uncertainty remains, and finally for reasons of transparency, appropriate documentation of case details (Tables 3, 6, 7, 15). 
TABLE 9 | Analysis of reported positive reexposure test results in cases of suspected herbal Traditional Chinese Medicine (TCM) induced liver injury.

Case reexposure tests in cases of suspected herbal TCM induced liver injury

\section{Chinese herbal mixtures}

- 28-year old UK woman (Perharic-Walton and Murray, 1992): Chinese herbal mixture with 8 different herbs for 3-5 months. Jaundice. ALT value not available. Reexposure: episode of hepatitis reported without liver values, acute liver failure, died despite emergency liver transplantation. Both ALTb and ALTr not available $\rightarrow$ uninterpretable reexposure.

- 39-year old UK woman (Kane et al., 1995): Chinese herbal mixture with eight different herbs for 2 months. Short history of anorexia, nausea, fatigue, dark urine, yellow sclerae, jaundice. ALT 2440 U/L (normal 0-30) with R 68.3, ALT returned to normal after cessation. Reexposure after 6 weeks: ALT 1314U/L. ALTb $<5 \mathrm{~N}$ and ALTr $=2$ $\mathrm{ALTb} \rightarrow$ positive reexposure.

- 9-year old UK girl (Allen and Parkinson, 1990): Unclassified Chinese herbal medicine for 6 months. Nausea, anorexia, central abdominal pain, jaundice, pale stool for the past 4-21 days. ALT 1950 U/L (normal < 45) with R 13.1, ALT returned to $50 \mathrm{U} / \mathrm{L}$ after cessation. Intentional reexposure: ALT 315 U/L. ALTb $<5 \mathrm{~N}$ and ALTr $=2 \mathrm{ALTb} \rightarrow$ positive reexposure.

\section{Ho Shou Wu}

- 54-year old Korean woman (Bae et al., 2010): Unknown dose of Ho Shou Wu containing Polygonum multiflorum for one month. Diagnosis of toxic hepatitis. Cessation of Ho Shou Wu improved her condition. Reexposure started immediately after discharge with aggravation of liver values. English abstract and Korean article $\rightarrow$ uninterpretable reexposure.

\section{Huan Qin}

- 78-year old US woman (Yang et al., 2012a): Move Free Advanced ${ }^{\circledR}$ two tablets/day containing Huan Qin (Scutellaria baicalensis, Chinese skullcap), black catechu, glucosamine, and chondroitin for 3 weeks. Jaundice. ALT 1626 U/L (normal < 60) with R 10.2, ALT 678U/L two weeks after cessation. Reexposure: ALT 1206 U/L. ALTb $=5 \mathrm{~N}$ and $\mathrm{ALTr}<2 \mathrm{ALTb} \rightarrow$ negative reexposure.

\section{Hwang Geun Cho}

- 37-year old male patient from Korea (Kang et al., 2009): Hwang Geun Cho containing Corydalis speciosa. Jaundice. ALT 531 U/L with subsequent decline after cessation of the herb down to $146 \mathrm{U} / \mathrm{L}$. Unintentional reexposure two months after discharge: ALT $381 \mathrm{U} / \mathrm{L}$. ALTb $<5 \mathrm{~N}$ and ALTr $=2 \mathrm{ALTb} \rightarrow$ positive reexposure.

\section{Ji Xue Cao}

- 61-year old Argentinian woman (Jorge and Jorge, 2005): Ji Xue Cao (Centella asiatica, syn.Gotu Kola) tablets for 30 days. Jaundice. ALT 1193 U/L and 2 months after cessation $18 \mathrm{U} / \mathrm{L}$. Unintentional reexposure 7 months later: ALT $481 \mathrm{U} / \mathrm{L}$. ALTb $<5 \mathrm{~N}$ and $\mathrm{ALTr}=2 \mathrm{ALTb} \rightarrow$ positive reexposure.

- 52-year old female patient from Argentinia (Jorge and Jorge, 2005): Ji Xue Coa (Centella asiatica) for 6 months. Jaundice. Not further quantified elevated hepatic enzymes at beginning and after cessation. Unintentional reexposure 1 year later: ALT $1694 \mathrm{U} / \mathrm{L}$. ALTb not availabe $\rightarrow$ uninterpretable reexposure.

\section{Jin Bu Huan}

- 66-year old US woman (Woolf et al., 1994): Jin Bu Huan 2 tablets at night two to three times a week for twelve weeks. Fever, nausea, fatigue for the past 5 weeks. ALT $782 \mathrm{U} / \mathrm{L}$ (normal < 35) with R 8.7, ALT declined to $47 \mathrm{U} / \mathrm{L}$ following cessation. Reexposure: ALT $941 \mathrm{U} / \mathrm{L}$. ALTb $<5 \mathrm{~N}$ and ALTr $=2 \mathrm{ALTb} \rightarrow$ positive reexposure.

- 46-year old US man (Woolf et al., 1994): Jin Bu Huan three tablets three times a week intermittently for 6 months. Fever, headaches, fatigue, tender hepatomegaly. ALT $394 \mathrm{U} / \mathrm{L}$ (normal < 35) 2 weeks after cessation with R 24.2, ALT subsequently $48 \mathrm{U} / \mathrm{L}$. Reexposure: ALT $100 \mathrm{U} / \mathrm{L}$. ALTb $<5 \mathrm{~N}$ and ALTr $=2 \mathrm{ALTb} \rightarrow$ positive reexposure.

- 50-year old US woman (Horowitz et al., 1996): Jin Bu Huan two to three tablets daily or intermittently for around 24 days. Fever. ALT 830 U/L and 330 U/L after cessation. Reexposure: ALT $540 \mathrm{U} / \mathrm{L}$. ALTb $=5 \mathrm{~N}$ and $\mathrm{ALTr}<2 \mathrm{ALTb} \rightarrow$ negative reexposure.

- 70-year old US woman (Horowitz et al., 1996): Jin Bu Huan three to four tablets at night three to five times a week for 31 days. Chills and fever 12 days after start of use, subsequently low-grade fever, malaise. ALT 408 U/L initially, $263 \mathrm{U} / \mathrm{L}$ after 2- week cessation, $67 \mathrm{U} / \mathrm{L}$ after 6-week cessation. Reexposure after 1 month: ALT $77 \mathrm{U} / \mathrm{L}$. $\mathrm{ALTb}<5 \mathrm{~N}$ but $\mathrm{ALTr}<2 \mathrm{ALTb} \rightarrow$ negative reexposure.

\section{Lu Cha}

- 56-year old French woman (Peyrin-Biroulet et al., 2004): Mincifit ${ }^{\circledR} 14 \mathrm{ml} /$ day containing green tea (Camellia sinensis, TCM Lu Cha) and Cassia sp. extracts for 15 days. Jaundice. ALT 54N with R 54.0, ALT normalization 2 months after cessation. Reexposure 5 years later with Dynasvelte forte ${ }^{\circledR} 8-12 \mathrm{~g} /$ day for 21 days (Green tea, Coffea Arabica, and chromium): ALT 99N. ALTb $<5 \mathrm{~N}$ and ALTr $=2 \mathrm{ALTb} \rightarrow$ positive reexposure.

- 45-year old Spanish man (Jimenez-Saenz and Martinez-Sanchez, 2006): Green tea infusion (6 cups/day) over 4 months. Asthenia and jaundice of ten days duration prior to cessation. ALT 1613U/L (normal < 40) with R 4.3, ALT normalized within 2 months of cessation. Reexposure 6 weeks later: ALT 1460 U/L after 1 month of reuse. $\mathrm{ALTb}<5 \mathrm{~N}$ and $\mathrm{ALTr}=2 \mathrm{ALTb} \rightarrow$ positive reexposure.

- 37-year old Hispanic woman from the US (Bonkovsky, 2006): Green tea-containing product with various other herbal extracts for 4 months. Jaundice. ALT 1788 U/L (normal < 40) with R 21.7, ALT $92 \mathrm{U} / \mathrm{L}$ after withdrawal. Reexposure 1 year later for 1 month: ALT $1131 \mathrm{U} / \mathrm{L}$. ALTb $<5 \mathrm{~N}$ and ALTr $=2 \mathrm{ALTb} \rightarrow$ positive reexposure.

- 23-year old Spanish woman García-Cortés et al., 2008: Green tea (Camellia sinensis) for 21 days. Jaundice after 19 days. ALT 56.9N with R 34.7, ALT 0.35N 3 months after withdrawal. Reexposure: ALT values not available. ALTb $<5 \mathrm{~N}$ but ALTr not available $\rightarrow$ uninterpretable reexposure.

- 26-year old Spanish woman García-Cortés et al., 2008: Green tea for 121 days. Jaundice. ALT 32.1N with R 42.2, ALT dechallenge values not available. Reexposure: ALT values not available. Both ALTb and ALTr not available ? uninterpretable reexposure.

- 38-year old French woman (Sarma et al., 2008): Green tea (six caps Tealine ${ }^{\circledR} /$ day, containing also white and red tea) for 20 days. Symptoms not reported. ALT values not available. Reexposure: ALT value not available. Both ALTb and ALTr not available $\rightarrow$ uninterpretable reexposure. 


\section{TABLE 9 | Continued}

\section{Ma Huang}

- 33-year old US woman (Nadir et al., 1996): Unknown daily dose of Ma Huang for around 4 weeks. Nausea, vomiting, abdominal discomfort after use for several days, jaundice under continuing Ma Huang use for another three weeks. ALT $832 \mathrm{U} / \mathrm{L}$ (normal < 65) with R 9.8. ALT dechallenge values not available. Intentional reexposure with a single dose 1 week after discharge: ALT $1586 \mathrm{U} / \mathrm{L}$. Both ALTb and ALTr not available ? uninterpretable reexposure.

\section{Polygonum multiflorum}

- 61-year old Korean man (Jung et al., 2011): Unknown dose of Polygonum multiflorum Thunb for 1 day. Myalgia. ALT 818 U/L with R 21.6, 180 U/L after 9 days of cessation and ALTb $<5 \mathrm{~N}$ as likely assumed. Reexposure after 11.5 months with a single dose of $P$. multiflorum Thunb: ALT 1520 U/L. ALTb $<5 \mathrm{~N}$ and ALTr $=2 \mathrm{ALTb} \rightarrow$ positive reexposure.

\section{Shou Wu Pian}

- 5-year old Netherland girl (Panis et al., 2005): Shou Wu Pian (three tablets daily) for four months. Jaundice. ALT 1543 U/L (normal < 39 U/L), 5 weeks after cessation $50 \mathrm{U} / \mathrm{L}$. Reexposure with tablets Shou Wu Pian daily for 1 month: ALT $1277 \mathrm{U} / \mathrm{L}$. ALTb $<5 \mathrm{~N}$ and ALTr $=2 \mathrm{ALTb} \rightarrow$ positive reexposure.

\section{Xiao Chai Hu Tang}

- 51-year old Japanese woman (Itoh et al., 1995): $7.5 \mathrm{~g}$ of Xia Chai Hu Tang daily for 7 weeks. Jaundice, with preexisting mild elevations of aminotransferases. ALT $855 \mathrm{U} / \mathrm{L}$ (normal < 35) with R 35.9, ALT decrease to $139 \mathrm{U} / \mathrm{L}$ upon cessation. Reexposure: ALT 186 U/L. ALTb < 5N but ALTr < 2 ALTb $\rightarrow$ uninterpretable reexposure. - 52-year old Japanese woman (Itoh et al., 1995): Xia Chai Hu Tang $7.5 \mathrm{~g}$ daily for 6 weeks. Jaundice, preexistent ALT activity of 180 U/L (normal < 35). ALT 600 U/L, near normal 2.5 months after withdrawal. Reexposure: ALT $162 \mathrm{U} / \mathrm{L}$. ALTb $<5 \mathrm{~N}$ and ALTr $=2 \mathrm{ALTb} \rightarrow$ positive reexposure.

- 58-year old Japanese woman (Itoh et al., 1995): Xia Chai Hu Tang $7.5 \mathrm{~g}$ daily for 3 months. Symptoms not reported. ALT 246 U/L (normal < 35) with R 5.0, ALT fell to near normal after 2 months of withdrawal. Intentional 7-day reexposure: ALT $265 \mathrm{U} / \mathrm{L}$. ALTb $<5 \mathrm{~N}$ and ALTr $=2 \mathrm{ALT} \rightarrow$ positive reexposure.

- 42-year old Japanese woman (Itoh et al., 1995): Xia Chai Hu Tang $7.5 \mathrm{~g}$ daily for an unspecified time period to treat hepatitis A infection. Symptoms not specified, ALT 2 $165 \mathrm{U} / \mathrm{L}$ (normal < 35) initially dropped with treatment to $42 \mathrm{U} / \mathrm{L}$ and increased 3 weeks after initiation of treatment. ALT $1335 \mathrm{U} / \mathrm{L}$ with normalization within 2 months after withdrawal. Intentional 2-day reexposure: ALT 195 U/L ALTb $<5 \mathrm{~N}$ and $\mathrm{ALTr}=2 \mathrm{ALTb} \rightarrow$ positive reexposure.

Compilation of some clinical details and laboratory values for assessment of reported positive reexposure test results in 25 cases with suspected herbal hepatotoxicity by TCM products. Data are derived from previous reports, which may provide additional details (Teschke, 2014; Teschke et al., 2014b). Unless otherwise stated, reexposure was commonly unintentional.

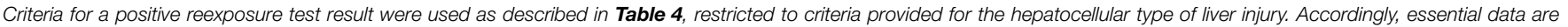

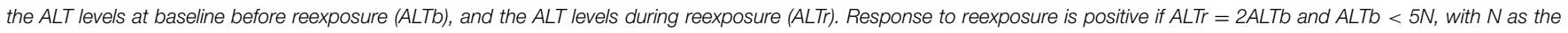

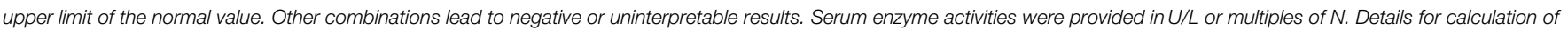

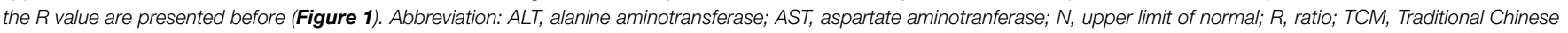
Medicine.

\section{DILIN method}

With use restricted to its own country, the United States DILIN causality method (Chalasani et al., 2008) does not operate within the international HILI and DILI mainstream domains, as opposed to CIOMS (Table 12). The DILIN method may create problems even in its homeland when physicians are waiting for conclusions of expert circles at times HILI is unfolding. Representing a post-clinical, postponed evaluation rather than a rapid assessment of HILI as a critical disease, the DILIN method will not gain the same international popularity as its counterpart CIOMS (Tables 9, 10, 12), also due to other major shortcomings (Table 13).

Although, various CIOMS criteria (Danan and Bénichou, 1993) have been incorporated in the DILIN method (Rochon et al., 2008), the DILIN group missed the chance to establish the fundaments of a newly conceptualized causality method for DILI and HILI, considering the well known pros ad cons of CIOMS (García-Cortés et al., 2011; Teschke et al., 2013a, 2014d), rather than commenting on few shortcomings of CIOMS at the expense on its own DILIN method (Lewis, 2014). As opposed to the transparent CIOMS results shown by tables with individual scored items (Tables 10, 11) and the applied scale with actual 15 assumed HILI cases (Table 15), the DILIN method lacks both transparency and individual item scorings (Teschke et al., 2013a, 2014d). Results presented as percentage ranges only and not given as clearly defined, individually scored items before are irrelevant. Proving a moderate reliability of their DILIN causality approach is far from concordance (Rochon et al., 2008; Teschke et al., 2014d); expert opinion validation therefore seems to be irrelevant. DILIN should close the present evaluating gap by recommending physicians in clinical practice to use CIOMS a priori to improve causality assessment already at origin of clinical data, while DILIN may later use these CIOMS-based itemized data for own assessment.

\section{Naranjo scale}

Causality assessment of hepatotoxicity cases by the Naranjo scale (Naranjo et al., 1981) with its known shortcomings is problematic (Table 13), although favored by the United States Pharmacopeia (USP) (Mahady et al., 2008) but rejected by the United States DILIN group (Lewis, 2014) and other groups (García-Cortés et al., 2011). This scale relates toxic drug reactions to general pharmacological drug actions rather than specifically to idiosyncratic reactions like hepatotoxicity; it contains drug concentrations and monitoring, dose relationship including decreasing dose, placebo response, cross-reactivity, and confirmation of the ADR using unidentified objective evidence, which are irrelevant for HILI (Naranjo et al., 1981; Teschke and Wolff, 2011; Teschke and Schulze, 2012). The hepatotoxicity unspecific feature of the Naranjo scale is unacceptable in suspected HILI cases, its results are heavily disputed (Liss and Lewis, 2009; Mahady et al., 2008; Sarma et al., 2008; Teschke, 2010c; Teschke and Wolff, 2011; 
TABLE 10 | CIOMS scale for the hepatocellular type of injury in HILI cases.

\begin{tabular}{lcc}
\hline Items for hepatocellular injury & Score & Result \\
\hline 1. TIME TO ONSET FROM THE BEGINNING OF THE HERB & +2 \\
- $5-90$ days (rechallenge: $1-15$ days) & +1 \\
$-<5$ or $>90$ days (rechallenge: $>15$ days) & \\
$\begin{array}{l}\text { Alternative: Time to onset from cessation } \\
\text { of the herb }\end{array}$ & +1 \\
- $\leq 15$ days (except for slowly metabolized & +1 \\
chemicals: $>15$ days) &
\end{tabular}

\section{COURSE OF alt AFTER CESSATION OF THE HERB}

Percentage difference between ALT peak

and $\mathbf{N}$

- Decrease $\geq 50 \%$ within 8 days

- Decrease $\geq 50 \%$ within 30 days

- No information or continued drug use

- Decrease $\geq 50 \%$ after the 30th day

- Decrease $<50 \%$ after the 30th day or

recurrent increase

\section{RISK FACTORS}

- Alcohol use (drinks/d: >2 for woman, >3 for men)

- Alcohol use (drinks/d: $\leq 2$ for woman, $\leq 3$ for men)

- Age $\geq 55$ years

- Age $<55$ years

\section{CONCOMITANT HERB(S)/DRUG(S)}

0

- None or no information

- Concomitant herb/drug with incompatible

0

time to onset

- Concomitant herb/drug with compatible or suggestive

- Time to onset $-1$

- Concomitant herb/drug known as hepatotoxin and with compatible or suggestive time to onset

- Concomitant herb/drug with evidence for its role in this case (positive rechallenge or validated test)

\section{SEARCH FOR NON HERB/DRUG CAUSES}

Group I (6 causes)

- Anti-HAV-IgM

- HBsAg, anti-HBc-IgM, HBV-DNA

- Anti-HCV, HCV-RNA

- Hepatobiliary sonography/color Doppler sonography of liver vessels/endosonography/CT/MRC

- Alcoholism (AST/ ALT $\geq 2$ )

- Acute recent hypotension history (particularly if underlying heart disease)

\section{Group II (6 causes)}

- Complications of underlying disease(s) such as sepsis; autoimmune hepatitis, chronic hepatitis B or C, primary biliary cholangitis or sclerosing cholangitis, genetic liver diseases

- Infection suggested by PCR and titer change for

- CMV (anti-CMV-IgM, anti-CMV-lgG)

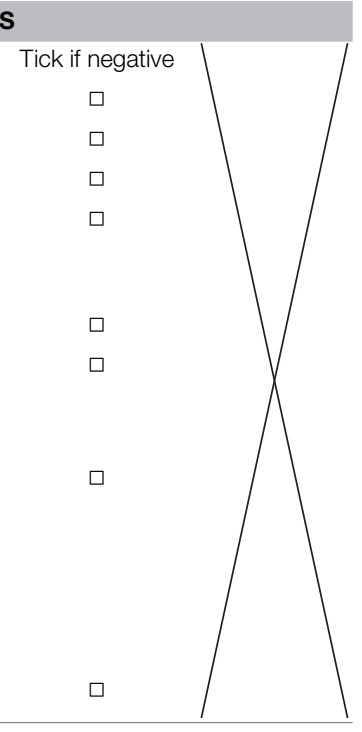

(Continued)
TABLE 10 | Continued

\begin{tabular}{|c|c|c|}
\hline Items for hepatocellular injury & Score & Result \\
\hline - EBV (anti-EBV-IgM, anti-EBV-lgG) & $\square$ & \\
\hline - HEV (anti-HEV-IgM, anti-HEV-lgG) & $\square$ & \\
\hline - HSV (anti-HSV-IgM, anti-HSV-lgG) & $\square$ & \\
\hline - VZV (anti-VZV-lgM, anti-VZV-lgG) & $\square$ & \\
\hline \multicolumn{3}{|l|}{ Evaluation of group I and II } \\
\hline $\begin{array}{l}\text { - All causes-groups I and II -- reasonably ruled } \\
\text { out }\end{array}$ & +2 & \\
\hline - The 6 causes of group I ruled out & +1 & \\
\hline - 5 or 4 causes of group I ruled out & 0 & \\
\hline - Less than 4 causes of group I ruled out & -2 & \\
\hline - Non drug or herb cause highly probable & -3 & \\
\hline \multicolumn{3}{|c|}{ 6. PREVIOUS INFORMATION ON HEPATOTOXICITY OF THE HERB } \\
\hline $\begin{array}{l}\text { - Reaction labeled in the product } \\
\text { characteristics }\end{array}$ & +2 & \\
\hline - Reaction published but unlabeled & +1 & \\
\hline - Reaction unknown & 0 & \\
\hline \multicolumn{3}{|l|}{ 7. RESPONSE TO READMINISTRATION } \\
\hline $\begin{array}{l}\text { - Doubling of ALT with the herb alone, provided } \\
\text { ALT below } 5 \mathrm{~N} \text { before reexposure }\end{array}$ & +3 & \\
\hline $\begin{array}{l}\text { - Doubling of ALT with the herb(s) already given } \\
\text { at the time of first reaction }\end{array}$ & +1 & \\
\hline $\begin{array}{l}\text { - Increase of ALT but less than N in the same } \\
\text { conditions as for the first administration }\end{array}$ & -2 & \\
\hline - Other situations & 0 & \\
\hline
\end{tabular}

The updated CIOMS scale is derived and modified from a previous report (Teschke et al., 2014c). The above items specifically refer to the hepatocellular type of injury rather than to the cholestatic or mixed type (shown in Table 11). Abbreviations: ALT, Alanine aminotransferase; AST, Aspartate aminotransferase; CIOMS, Council for International Organizations of Medical Sciences; CMV, Cytomegalovirus; CT, Computer tomography; DILI, Drug induced liver injury; EBV, Epstein Barr virus; HAV, Hepatitis A virus; $H B c$, Hepatitis B core; $H B s A g$, Hepatitis $B$ antigen; HBV, Hepatitis $B$ virus; $H C V$, Hepatitis $C$ virus; $H E V$, Hepatitis E virus; HILI, Herb induced liver injury; HSV, Herpes simplex virus; MRC, Magnetic resonance cholangiography; $N$, upper limit of the normal range; VZV, Varicella zoster virus. Total score and resulting causality grading: $=0$, excluded; $1-2$, unlikely; $3-5$, possible; 6-8, probable; $\geq 9$, highly probable.

Teschke et al., 2011d,e; Teschke and Schulze, 2012); this also pertains to a shortened version with only 5 of the original 10 items (Teschke and Schulze, 2012). Lack of hepatotoxicity specificity of the Naranjo algorithm was associated with missing definition of liver ADR, unclear time frame and latency period, undefined time frame for dechallenge, lacking risk factor definition, insufficient evaluation of alternative diagnoses, inappropriate assessment of comedication; and missing definition of a positive rechallenge test (Naranjo et al., 1981; Teschke and Schulze, 2012). This scale also was considered insensitive, allowing a possible causality even in the absence of essential data by virtue of the patient simply having taken the suspected agent (Liss and Lewis, 2009; Sarma et al., 2008). The Naranjo scale as modified by USP (Mahady et al., 2008) did not exclude alternative causes such as idiopathic autoimmune hepatitis, alcoholic or cardiac hepatopathy, other preexisting liver diseases, DILI, and drug-induced rhabdomyolysis (Sarma et al., 2008; Teschke, 2014; Teschke et al., 2011d,e). It 
TABLE 11 | CIOMS scale for the cholestatic or mixed type of injury in HIL cases.

\begin{tabular}{|c|c|c|}
\hline Items for cholestatic or mixed injury & Score & Result \\
\hline \multicolumn{3}{|c|}{ 1. TIME TO ONSET FROM THE BEGINNING OF THE HERB } \\
\hline - 5-90 days (rechallenge: 1-90 days) & +2 & \\
\hline - $<5$ or $>90$ days (rechallenge: $>90$ days) & +1 & \\
\hline \multicolumn{3}{|c|}{$\begin{array}{l}\text { Alternative: Time to onset from cessation of the } \\
\text { herb }\end{array}$} \\
\hline $\begin{array}{l}-\leq 30 \text { days (except for slowly metabolized } \\
\text { chemicals: }>30 \text { days) }\end{array}$ & +1 & \\
\hline
\end{tabular}

\section{COURSE OF ALP AFTER CESSATION OF THE HERB}

Percentage difference between ALP peak and $\mathbf{N}$

- Decrease $\geq 50 \%$ within 180 days $\quad+2$

- Decrease $<50 \%$ within 180 days $\quad+1$

- No information, persistence, increase, or continued 0

drug use

\section{RISK FACTORS}

- Alcohol use (drinks/d: >2 for woman, >3 for men) or pregnancy

- Alcohol use (drinks/d: $\leq 2$ for woman, $\leq 3$ for men) 0

- Age $\geq 55$ years

- Age $<55$ years

\section{CONCOMITANT HERB(S)/DRUG(S)}

- None or no information $+1$

0

0

- Concomitant herb/drug with incompatible time to 0 onset

- Concomitant herb/drug with compatible or suggestive time to onset

- Concomitant herb/drug known as hepatotoxin and -2 with compatible or suggestive time to onset

- Concomitant herb/drug with evidence for its role in -3 this case (positive rechallenge or validated test)

\section{SEARCH FOR NON HERB CAUSES}

\section{Group I (6 causes)}

- Anti-HAV-lgM

- HBsAg, anti-HBc-lgM, HBV-DNA

- Anti-HCV, HCV-RNA

- Hepatobiliary sonography / color Doppler sonography of liver vessels / endosonography / $\mathrm{CT} / \mathrm{MRC}$

- Alcoholism (AST/ ALT $\geq 2$ )

- Acute recent hypotension history (particularly if underlying heart disease)

\section{Group II (6 causes)}

- Complications of underlying disease(s) such as sepsis; autoimmune hepatitis, chronic hepatitis B or $\mathrm{C}$, primary biliary cholangitis or sclerosing cholangitis, genetic liver diseases

- Infection suggested by PCR and titer change for CMV (anti-CMV-IgM, anti-CMV-lgG)

- EBV (anti-EBV-lgM, anti-EBV-lgG)

- HEV (anti-HEV-lgM, anti-HEV-lgG)

- HSV (anti-HSV-lgM, anti-HSV-lgG)

- VZV (anti-VZV-IgM, anti-VZV-lgG)

Evaluation of group I and II

- All causes-groups I and II-reasonably ruled out

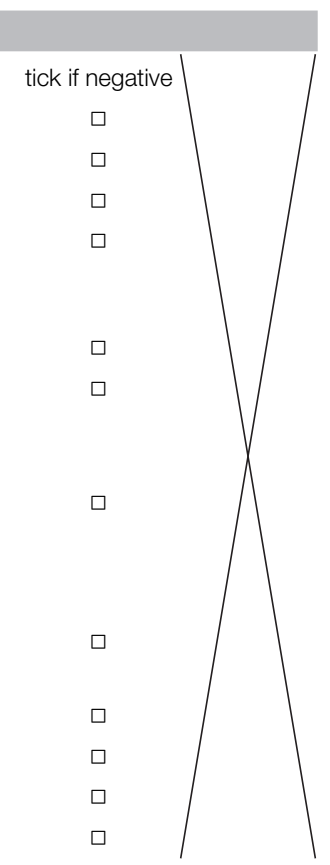

$+2$

(Continued)
TABLE 11 | Continued

\begin{tabular}{|c|c|c|}
\hline Items for cholestatic or mixed injury & Score & Result \\
\hline - The 6 causes of group I ruled out & +1 & \\
\hline - 5 or 4 causes of group I ruled out & 0 & \\
\hline - Less than 4 causes of group I ruled out & -2 & \\
\hline - Non drug cause highly probable & -3 & \\
\hline \multicolumn{3}{|c|}{ 6. PREVIOUS INFORMATION ON HEPATOTOXICITY OF THE HERB } \\
\hline - Reaction labeled in the product characteristics & +2 & \\
\hline - Reaction published but unlabelled & +1 & \\
\hline - Reaction unknown & 0 & \\
\hline \multicolumn{3}{|l|}{ 7. RESPONSE TO READMINISTRATION } \\
\hline $\begin{array}{l}\text { - Doubling of ALP with the herb alone, provided ALP } \\
\text { below } 2 \mathrm{~N} \text { before reexposure }\end{array}$ & +3 & \\
\hline $\begin{array}{l}\text { - Doubling of ALP with the herbs(s) already given at } \\
\text { the time of first reaction }\end{array}$ & +1 & \\
\hline $\begin{array}{l}\text { - Increase of ALP but less than } \mathrm{N} \text { in the same } \\
\text { conditions as for the first administration }\end{array}$ & -2 & \\
\hline - Other situations & 0 & \\
\hline
\end{tabular}

For details see legend to Table 10.

therefore appears that the USP approach (Mahady et al., 2008) is an invalid tool for causality assessment in suspected HILI, leading to the conclusion that quality of causality assessment is more important than quantity of counted cases, not vice versa (Teschke et al., 2012g). Use of this method has raised concern about judgment validity by the USP regarding cases of hepatotoxicty by green tea (Liss and Lewis, 2009; Teschke and Schulze, 2012).

\section{WHO method}

The WHO method in short consists of both the WHO scale and the global introspection by experts (WHO, 2000b) and was applied for assessing causality in cases of kava hepatotoxicity by the WHO (2007a) and of PS hepatotoxicity as erroneously assumed by the German regulatory agency BfArM and the Drug Commission of the German Medical Association (DCGMA, 2011), but the value of this hepatotoxicity unspecific method was heavily debated (Stammschulte and GundertRemy, 2012; Teschke et al., 2012b,c,d) and judged obsolete before (Teschke and Wolff, 2011), considering its known shortcomings (Table 13). In general, global introspection represents a strategy in evaluating the likelihood of drug causality for adverse reactions (Kramer, 1986). Surprisingly, this method also has never been validated for any ADRs (Teschke et al., 2012c); as early as 1986, global introspection by experts has been shown to be neither reproducible nor valid (Kramer, 1986). Both the questions and the answers are ambiguous (Teschke and Wolff, 2011). Specifically, the assessor considers factors that might causally link one or more drugs to an observed ADR, lists all factors, weighs their importance, and decides the probability of drug causation (Kramer, 1986). No specific check list or level of strength is given.

The WHO scale was not validated by a gold standard, is not quantitative, not specific for hepatotoxicity (WHO, 2000b; Teschke and Wolff, 2011; Teschke et al., 2012b,c,d, 2013b,e). 
TABLE 12 | Selective compilation of international registries and regulatory agencies, and associated groups applying the CIOMS scale for causality evaluation in suspected HILI and DILI cases.

\begin{tabular}{|c|c|c|c|c|}
\hline Cases & Products $(n)$ & Country/Region & Group/Agency & References \\
\hline DILI & Synthetic drugs & $\begin{array}{l}\text { Spain } \\
\text { Europe }\end{array}$ & $\begin{array}{l}\text { Spanish Group for the Study of the Drug-Induced Liver Disease, } \\
\text { Malaga }\end{array}$ & Andrade et al., 2004 \\
\hline DILI & Synthetic drugs (461) & $\begin{array}{l}\text { Spain } \\
\text { Europe }\end{array}$ & $\begin{array}{l}\text { Spanish Group for the Study of the Drug-Induced Liver Disease, } \\
\text { Malaga }\end{array}$ & Andrade et al., 2005 \\
\hline DILI & Synthetic drugs (28) & $\begin{array}{l}\text { Spain } \\
\text { Europe }\end{array}$ & $\begin{array}{l}\text { Spain Hepatotoxicity Registry, Grupo de Estudio Para las } \\
\text { Hepatopatías Asociadas a Medicamentos, Malaga }\end{array}$ & Andrade et al., 2004 \\
\hline HILIDILI & $\begin{array}{l}\text { Various herbal TCM (15) } \\
\text { Synthetic drugs (19) }\end{array}$ & $\begin{array}{l}\text { Singapore } \\
\text { Asia }\end{array}$ & National University of Singapore & Wai, 2006 \\
\hline HILI & Black cohosh (31) & $\begin{array}{l}\text { Various countries } \\
\text { Europe }\end{array}$ & European Medicines Agency & EMA, 2007 \\
\hline HILI & Herbs (13) & $\begin{array}{l}\text { Spain } \\
\text { Europe }\end{array}$ & Spanish Liver Toxicity Registry & García-Cortés et al., 2008 \\
\hline HILI & Various herbal TCM (159) & $\begin{array}{l}\text { Korea } \\
\text { Asia }\end{array}$ & Chungnam National University, Daejeon & Kang et al., 2008 \\
\hline DILI & Synthetic drugs (80) & $\begin{array}{l}\text { Serbia } \\
\text { Europe }\end{array}$ & Medicines and Medical Devices Agency of Serbia, Belgrade & Miljkovic et al., 2011 \\
\hline HILI & $\begin{array}{l}\text { Herbal Polygonum } \\
\text { Multiflorum (25) }\end{array}$ & $\begin{array}{l}\text { Korea } \\
\text { Asia }\end{array}$ & $\begin{array}{l}\text { Gyeongsang National University School of Medicine, } \\
\text { Jinju/Sungkyunkwan University School of Medicine, Changwon }\end{array}$ & Jung et al., 2011 \\
\hline HILI & Various herbal TCM (27) & $\begin{array}{l}\text { Hong } \\
\text { Kong }\end{array}$ & $\begin{array}{l}\text { Hong Kong Herb-Induced Liver Injury Network (HK-HILIN), Hong } \\
\text { Kong }\end{array}$ & Chau et al., 2011 \\
\hline DILI & Statins (73) & $\begin{array}{l}\text { Iceland/Sweden } \\
\text { Europe }\end{array}$ & $\begin{array}{l}\text { National University Hospital Reykjvik/ University of Gothenburg/ } \\
\text { Swedish Adverse Drug Reactions Advisory Committee (SADRAC) }\end{array}$ & Björnsson et al., 2012 \\
\hline DILI & Various synthetic Drugs & $\begin{array}{l}\text { Spain } \\
\text { Latin America }\end{array}$ & $\begin{array}{l}\text { Spanish-Latin American Network on drug induced liver Injury, in } \\
\text { progress }\end{array}$ & Bessone, 2012 \\
\hline HILI & $\begin{array}{l}\text { Some Herbalife }{ }^{\circledR} \\
\text { products }\end{array}$ & $\begin{array}{l}\text { Various } \\
\text { countries }\end{array}$ & Various groups & Halegoua-De Marzio et al., 2013 \\
\hline HILI & $\begin{array}{l}\text { Various herbal and dietary } \\
\text { supplements (HDS) }\end{array}$ & $\begin{array}{l}\text { Spain } \\
\text { Europe }\end{array}$ & Spanish group for the Study of the Drug-Induced Liver Injury & Robles-Diaz et al., 2015 \\
\hline
\end{tabular}

Reliability, sensitivity, specificity, positive and negative predictive values are unknown. Its scope is also limited since it cannot discriminate between a positive and a negative correlation, thereby stimulating overdiagnosing and overreporting (Teschke et al., 2013b). The WHO method ignores uncertainties in daily dose, temporal association, start, duration, and end of herbal use, time to onset of ADR, and course of liver values after herb discontinuation. Insufficiently considered or ignored are comedications, pre-existing liver diseases, numerous alternative explanations, and exclusion of virus infections by hepatitis A - C, CMV, EBV, HSV, and VZV (Teschke et al., 2012b,d). Similarly, case duplications and retracted cases remained undetected by the WHO method (Teschke et al., 2012a). Despite these flaws, the WHO method was used for causality assessment in herbal hepatotoxicity cases (Elinav et al., 2007; Schoepfer et al., 2007; DCGMA, 2011; Stammschulte and Gundert-Remy, 2012; Teschke et al., 2012b,d); claimed causality for PS was not confirmed after reevaluation in two studies (Teschke et al., 2012b,d).

\section{Other approaches}

Other attempts to evaluate causality in assumed HILI cases exist (Hung et al., 2011), also the ad-hoc assessment (Kaplowitz, 2001), which was preferentially used for kava cases by the German regulatory agency (BfArM, 2002) and in detail disputed subsequently
(Teschke and Wolff, 2011), and the Karch \& Lasagna method applied in some HILI cases of Herbalife ${ }^{\circledR}$ and considered obsolete recently (Teschke et al., 2013d), due to known shortcomings.

\section{Questionable and Lacking Causality}

Although causality was firmly established for various herbal TCM preparations as well as other herbs and herbal products in reported HILI cases (Tables 1, 2) (Teschke et al., 2011a, 2012a,e, 2014a), causality problems emerged with a few herbs and herbal preparations as evidenced by some full length published reports with detailed analyses. Among these are black cohosh with a possible causality grading in one single HILI case (Teschke, 2010c) and lacking causality in another study (Naser et al., 2011), kava with a highly probable causality level in one HILI case confirmed by a positive reexposure test result (Teschke et al., 2008a), and a confirmed causality grading assessed by a positive reexposure test result for a Herbalife ${ }^{\circledR}$ product in a single HILI case (Teschke et al., 2013d); however, CIOMS/RUCAM based causality for some Herbalife ${ }^{\circledR}$ products was highly probable in one patient and probable in six patients, as preliminarily reported in abstract form without any case details including case data quality (Halegoua-De Marzio et al., 2013), which was described as poor and scattered before (Teschke et al., 2013c). 
TABLE 13 | Core elements of the updated CIOMS scale vs. DILIN method.

\begin{tabular}{lcc}
\hline Items & $\begin{array}{c}\text { CIOMS } \\
\text { scale }\end{array}$ & $\begin{array}{c}\text { DILIN } \\
\text { metho }\end{array}$ \\
\hline Accurate time frame of latency period (score) & + & 0 \\
Detailed time frame of challenge (score) & + & 0 \\
Clear time frame of dechallenge (score) & + & 0 \\
Recurrent ALT or ALP increase (score) & + & 0 \\
Definition of risk factors (score) & + & 0 \\
Details to exclude alternative diagnoses (score) & + & 0 \\
Assessment of HAV, HBV, HCV, HEV (score) & + & 0 \\
Assessment of CMV, EBV, HSV, VZV (score) & + & 0 \\
Liver and biliary tract imaging (score) & + & 0 \\
Color Doppler sonography of liver vessels (score) & + & 0 \\
Assessment of preexisting diseases (score) & + & 0 \\
Evaluation of cardiac hepatopathy (score) & + & 0 \\
Individual score of alternative diagnoses (score) & + & 0 \\
Qualified score of individual comedication (score) & + & 0 \\
Prior known hepatotoxicity of the herb (score) & + & 0 \\
Search for unintended reexposure (score) & + & 0 \\
Definition of unintended reexposure (score) & + & 0 \\
Qualified criteria of unintended reexposure (score) & + & 0 \\
Laboratory criteria for hepatotoxicity & + & + \\
Laboratory hepatotoxicity pattern & + & + \\
Hepatotoxicity specific method & + & + \\
Structured, liver related method & + & 0 \\
Quantitative, liver related method & + & 0 \\
Validated method for hepatotoxicity (gold standard) & + & 0 \\
\hline & + & 0 \\
& + & 0 \\
\hline
\end{tabular}

Adapted and derived from a previous report (Teschke et al., 2013a). Latency period indicates time from herb start to symptoms, alternatively to abnormal liver tests. The symbol + shows that this item is present and the symbol 0 indicates lack of this item. Abbreviations: ALT, Alanine aminotransferase; ALP, Alkaline phosphatase; CIOMS, Council for International Organizations of Medical Sciences; CMV, cytomegalovirus; DILIN, Drug-Induced Liver Injury Network; EBV, Epstein Barr virus; HAV, Hepatitis A virus; HBV, Hepatitis B virus; HCV, Hepatitis C virus; HEV, Hepatitis E virus; HSV, Herpes simplex virus; VZV, Varicella zoster virus.

With Ba Jiao Lian (Dysosma pleianthum), this TCM herb was not further considered as hepatotoxic (Teschke, 2014; Teschke et al., 2014c, 2015b), since not all diagnostic criteria were fulfilled for cases of hepatotoxicity by this herb (NIH, 2014c; Teschke, 2014). In detail, after herbal use at recommended doses, the patients manifested abnormal liver function tests associated with nausea, vomiting, diarrhea, abdominal pain, thrombocytopenia, leucopenia, sensory ataxia, altered consciousness and persistent peripheral tingling or numbness. However, the increase of the aminotransferases was marginal, with preference of AST rather than ALT. The AST increase could reflect isolated damage of the mitochondria around the hepatic central vein or muscular damage, because of the associated increase of creatine phosphokinase, findings not in support for a clinically relevant toxic liver disease (Teschke, 2014). Evidence against a hepatotoxic potential was also provided for Jing Tian San Qi (Sedum aizoon) as another herbal TCM (Teschke, 2014), based on the results of recent studies showing that in patients with HSOS, the hepatotoxic PAs in the herbal TCM Tu San Qi (Gynura segetum) were responsible rather than the misidentified Sedum aizoon lacking these alkaloids (Dai et al., 2006; Gao et al., 2006, 2012; Wu et al., 2008; Lin et al., 2011; Wang and Gao, 2014).

\section{Pathogenetic Aspects of HILI}

Any HILI case report should describe details to ensure a pathogenetic case classification, using appropriate criteria that characterize two major forms of HILI (Figure 1). One of these is named idiosyncratic, the other one intrinsic (Zimmerman, 1999; Teschke et al., 2008a). The idiosyncratic form of injury is unpredictable and independent of the dose; its metabolic and immunologic subtypes require special attention in clinical practice (Figure 1). Conversely, the intrinsic form of liver injury is predictable and dose dependent (Figure 1). Although, valid data are lacking, it appears that most HILI cases are of the idiosyncratic rather than the intrinsic form.

\section{Idiosyncratic Form}

As an example, clinical assessment characterized kava hepatotoxicity as an idiosyncratic liver injury linked to a metabolic aberration in unusually susceptible humans, providing an overall low incidence of kava hepatotoxicity in the normal population (Teschke et al., 2008a). This rarity of kava hepatotoxicity was also considered in the recent kava trial and evaluated as a positive risk/benefit constellation (Court, 2014), opposing previous regulatory assumptions to the contrary (BfArM, 2002). In accordance with other HILI cases of the idiosyncratic form of injury, human kava hepatotoxicity is not reproducible in experimental animals. Therefore, results of preclinical assessments with kava in experimental studies showing lack of liver toxicity are not transferrable to humans with another susceptibility setting and are not suitable to ensure safe use in humans. Since experimental reproducibility is missing, the lack of an experimental model prevents analytical evaluations directed to a proposed molecular mechanism of kava hepatotoxicity. Regarding human kava hepatotoxicity, characteristics of the metabolic subtype of the idiosyncratic form of injury prevail, based on the variable duration of exposure of 1week up to 12 months, associated with a weak dose dependency (Teschke et al., 2008a). Overall, most plants are fairly well tolerated by humans, whether used as normal food, herbal drugs, or HDS.

The pathophysiology of idiosyncratic HILI in humans is difficult to assess due to lack of experimental reproducibility and hence missing existence of an experimental animal model of HILI. There are abundant studies related to effects of herbs on animals or in vitro cell systems, but uncertainty exists whether these experimental results are transferable to human idiosyncratic HILI conditions. However, pathogenetic aspects are well assessable for HILI cases of the intrinsic form, due to available animal models with experimental hepatotoxicity and the possibility of transferring their results to human conditions.

\section{Intrinsic Form}

Germander (Teucrium chamaedrys) hepatotoxicity is a typical liver injury of the intrinsic form, since it is dose dependent and reproducible in mice (Larrey and Faure, 2011). Due to its experimental reproducibility in animals, the molecular pathogenesis of Germander hepatotoxicity can easily be studied in experimental hepatotoxicity and transferred to human 
TABLE 14 | Compilation of causality assessment methods used in suspected HILI cases.

\begin{tabular}{|c|c|c|c|c|c|c|c|}
\hline Herbs Herbal products & Ad hoc (n) & WHO (n) & CIOMS (n) & Naranjo $(n)$ & DILIN (n) & $\mathrm{KL}(n)$ & References \\
\hline Kava & 20 & & & & & & BfArM, 2002 \\
\hline Kava & & 30 & & & & & Denham et al., 2002 \\
\hline Kava & 20 & & & & & & Teschke et al., 2003 \\
\hline Kava & & & 36 & & & & Stickel et al., 2003 \\
\hline Kava & & 80 & & & & & Schmidt et al., 2005 \\
\hline Herbalife products & & 12 & & & & & Elinav et al., 2007 \\
\hline Herbalife products & & 12 & & & & & Schoepfer et al., 2007 \\
\hline Kava & & & 26 & & & & Teschke et al., 2008a \\
\hline Black cohosh & & & & 30 & & & Mahady et al., 2008 \\
\hline Green tea & & & & 34 & & & Sarma et al., 2008[ \\
\hline Hydroxycut & & & & & 17 & & Fong et al., 2010 \\
\hline Black cohosh & & & 22 & & & & Teschke et al., 2011e \\
\hline Greater Celandine & & & 22 & & & & Teschke et al., 2011a \\
\hline Herbalife products & & & & & & 20 & Manso et al., 2011 \\
\hline Various herbs & & & 45 & & & & Chau et al., 2011 \\
\hline Greater Celandine & & & 21 & & & & Teschke et al., $2012 \mathrm{e}$ \\
\hline Pelargonium sidoides & & & 15 & & & & Teschke et al., 2012c \\
\hline Pelargonium sidoides & & & 13 & & & & Teschke et al., 2012d \\
\hline Sum (n) & 63 & 134 & 275 & 64 & 17 & 20 & \\
\hline Sum (percent) & $11.0 \%$ & $23.4 \%$ & $48.0 \%$ & $11.2 \%$ & $3.0 \%$ & $3.4 \%$ & \\
\hline
\end{tabular}

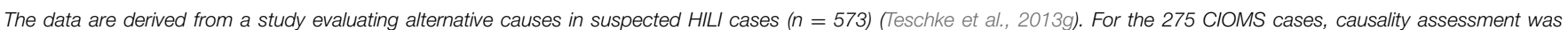

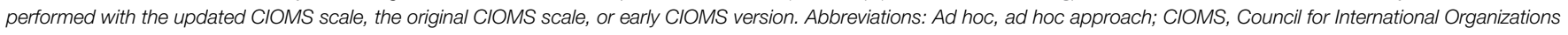
of Medical Sciences scale; DILIN, Drug Induced Liver Injury Network method; KL, Karch \& Lasagna method; Naranjo, Naranjo scale; WHO, World Health Organization method.

Germander hepatotoxicity. Germander components are neoclerodane diterpenoids that are oxidized by the cytochrome $\mathrm{P} 450$ $3 \mathrm{~A}$ isoform into reactive metabolites. These deplete hepatic stores of glutathione and cytoskeleton associated protein thiols, form plasma membrane blebs, and cause apoptosis contributing to liver cell necrosis (Larrey et al., 1992; Larrey and Faure, 2011).

PAs are other good examples for the intrinsic form of liver injury, which again is clearly dose dependent, thereby predictable, and hence preventable. For herbs containing PAs, each consumer of these herbs is at a dose dependent risk developing HSOS as a specific entity of liver disease (Smith and Desmond, 1993; Sperl et al., 1995; Stillman et al., 1977; Fu et al., 2004). PA containing plants are probably the most common poisonous plants affecting not only humans but also livestock and wildlife, with more than 6.000 plants containing PAs and about $3 \%$ of the world's flowering plants containing PAs (Fu et al., 2004). Some of these plants have caused toxic liver disease, recognized as epidemics and sometimes primarily assigned to viral hepatitis and not necessarily to toxic plants (Tandon et al., 1976a,b, 2008). Human embryotoxicity caused by PAs has been described in a newborn whose mother drank one cup of a tea containing PAs per day throughout pregnancy (Roulet et al., 1988; Fu et al., 2004). Some PA containing plants such as Crotalaria species (Bush tea, Rattlebox), Ilex paraguarensis (Mate tea), Symphytum species (Comfrey), Senecio species (Groundsel), Heliotropium species, and Compositae species (Indian herbs) that caused HILI are tabulated (Table 2). These herbs also injure cattle and house animals (Fu et al., 2004) and cause experimental hepatotoxicity in animals (Lin et al., 2011). PAs can be quantified in the serum of patients with HSOS (Lin et al., 2011; Larrey and Faure, 2011). The pathogenesis of PA hepatotoxicity has been elucidated in experimental studies, which showed the involvement of hepatic microsomal cytochrome P450 in the activation of PAs (Larrey and Faure, 2011).

Finally, herbal TCM products containing more than $19 \mathrm{~g}$ dose of Radix bupleuri may increase the hepatotoxicity risk (Lee et al., 2011); this dose dependency was confirmed in experimental animals and provided insights into some pathogenetic processes (Liu et al., 2014).

\section{Juristical Considerations \\ Black Cohosh}

Legal aspects of HILI case assessment rarely provide particular juridical and clinical challenges. Two court decisions merit attention, one relates to BC and the other one to kava. In 2005, a report was published representing a case of a 50 year old woman 
TABLE 15 | Preferred documentation as example: Tabulated causality assessment of 15 patients with primarily suspected HILI by Pelargonium sidoides (PS).

Items

Score

Patients 1-15

\begin{tabular}{|c|c|c|c|c|c|c|c|c|c|c|c|c|}
\hline 2 & 3 & 4 & 5 & 6 & 7 & 8 & 9 & 10 & 11 & 12 & 13 & 14 \\
\hline
\end{tabular}

\section{TIME TO ONSET FROM THE BEGINNING OF THE HERB}

- 5-90 days

- $<5$ or $>90$ days

$+2 ?$

2. TIME TO ONSET FROM CESSATION OF THE HERB

$\bullet \geq 15$ days $+1 ?$

$+2$

$+2+2$

3. COURSE OF alt AFTER CESSATION OF THE HERB

- Decrease $\geq 50 \%$ within 8 days

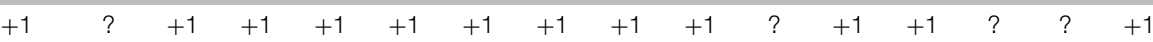

- Decrease $\geq 50 \%$ within 30 days

- No information

- Decrease $\geq 50 \%$ after the 30 th day

- Decrease $<50 \%$ after the 30th day or recurrent

\section{RISK FACTOR ETHANOL}

- Alcohol use (drinks/d: >2 for woman, >3 for men)

- No alcohol use (drinks/d: $\leq 2$ for woman, $\leq 3$ for men)

\section{RISK FACTOR AGE}

- $\geq 55$ years

0

0

$-2$

$0 \quad 0 \quad 0$

$0 \quad 0 \quad 0$

$0 \quad 0$

$0 \quad 0$

- $<55$ years

6. CONCOMITANT HERB(S)/DRUG(S)

- None or no information

- Concomitant herb/drug with incompatible time to onset

- Concomitant herb/drug with compatible or suggestive time to onset

- Concomitant herb/drug known as hepatotoxin and with compatible or suggestive time to onset

- Concomitant herb/drug with evidence for is role in this case (positive rechallenge or validated test)

\section{SEARCH FOR NON HERB/DRUG CAUSES}

Group i (6 causes)

- Anti-HAV-lgM

- Anti-HBc-lgM/HBV-DNA

- Anti-HCV-lgM/HCV-RNA

- Hepato-biliary sonography/color Doppler sonography of liver vessels

- Alcoholism (AST/ ALT $\geq 2$ )

- Acute recent hypotension history (particularly if underlying heart disease)

$\begin{array}{cccccccccccccc}+1 & ? & & & & & & & & & & \\ 0 & 0 & 0 & & 0 & 0 & 0 & 0 & 0 & 0 & 0 & 0 & 0 & ?\end{array}$

\begin{tabular}{|c|c|c|c|c|c|c|c|c|c|c|c|c|c|c|c|}
\hline+1 & +1 & & & & & & +1 & & & & & & & +1 & \\
\hline 0 & & 0 & 0 & 0 & 0 & 0 & & 0 & 0 & 0 & 0 & 0 & 0 & & 0 \\
\hline 0 & 0 & 0 & & & 0 & 0 & 0 & & 0 & & 0 & 0 & 0 & & \\
\hline 0 & & & & & & & & & & 0 & & & & & \\
\hline-1 & & & & -1 & & & & & & & & & & & \\
\hline-2 & & & -2 & & & & & -2 & & & & & & $?$ & -2 \\
\hline-3 & & & & & & & & & & & & & & & \\
\hline
\end{tabular}

\section{Group II}

- Complications of underlying disease(s) such as sepsis; or: autoimmune hepatitis, chronic hepatitis $\mathrm{B}$ and $\mathrm{C}$, primary biliary cholangitis and sclerosing cholangitis, genetic liver diseases

- Infection suggested by PCR and titre change for CMV (Anti-CMV-lgM/lgG) EBV (Anti-EBV-lgM/lgG) HSV (Anti-HSV-lgM/lgG) VZV (Anti-VZV-lgM/lgG) 
TABLE 15 | Continued

\begin{tabular}{|c|c|c|c|c|c|c|c|c|c|c|c|c|c|c|c|c|}
\hline Items & Score & \multicolumn{15}{|c|}{ Patients 1-15 } \\
\hline - All causes - group I and II-reasonably ruled out & +2 & & & & & & & & & & & & & & & \\
\hline - The 6 causes of group I ruled out & +1 & & & & & & & & & & & & & & & \\
\hline - 5 or 4 causes of group I ruled out & 0 & & & & & & & & & & & & & & & \\
\hline \multicolumn{17}{|c|}{ 8. PREVIOUS INFORMATION ON HEPATOTOXICITY OF THE HERB } \\
\hline - Reaction labeled in the product characteristics & +2 & +2 & +2 & +2 & +2 & +2 & +2 & +2 & +2 & +2 & +2 & +2 & +2 & +2 & +2 & +2 \\
\hline - Reaction published but unlabelled & +1 & & & & & & & & & & & & & & & \\
\hline - Reaction unknown & 0 & & & & & & & & & & & & & & & \\
\hline \multicolumn{17}{|l|}{ 9. RESPONSE TO READMINISTRATION } \\
\hline $\begin{array}{l}\text { - Increase of ALT but less than N in the same } \\
\text { conditions as for the first administration }\end{array}$ & -2 & & & & & & & & & & & & & & & \\
\hline - Other situations & 0 & & & & & & & & & & & & & & & \\
\hline - Total points for patient & & 0 & +2 & -1 & +5 & +1 & +2 & +2 & +1 & +4 & 0 & +2 & +5 & -1 & +1 & +1 \\
\hline
\end{tabular}

with fulminant liver failure and liver transplantation in assumed connection with the use of BC (Levitsky et al., 2005). A product liability action was filed by the patient after her recovery (Nebraska, 2006).

The decision of the judge answered the question whether in the specific case under discussion sufficient evidence establishes the herb as a generally or individually specific cause for the observed liver disease; for black cohosh, both aspects of causation were denied. General causation refers to the previously established hepatotoxicity by the same herb, but this was denied because of lack of convincing data. Specific causation refers to the case under discussion; this was also refuted on grounds of conflicting case data, poor case data quality, and numerous confounding variables (Nebraska, 2006). Our clinical diagnosis in this case was herpetic hepatitis and liver disease unrelated to BC or comedicated drugs, and CIOMS based assessment led to an excluded causality for both BC and comedicated drugs (Teschke and Schwarzenboeck, 2009): For this case of BC overdose, conclusions for an update of 22.12.2006 were provided (EMA, 2007): Worst case causality scoring would be possible, if comments of the expert would not be taken into account; because of the clinical experience of the expert and the requested obligatory causality in front of an American court, preference is given keeping the causality at a probable level (EMA, 2007). The conclusions of EMA are cloudy, difficult to reconcile, and ignore presented details, since the judge actually excluded both involved experts from expert testimony as to causation according to Daubert, rule 702 (Nebraska, 2006). As explained in detail, this rule requires that an expert be qualified to render a testimony on the subject, and that his testimony be reliable and relevant. None of the experts obviously met these and other required qualifications. Following the trial, USP reduced the causality for BC in this case from a probable to a possible level (Mahady et al., 2008). An erratum clarified the case conditions (Levitsky et al., 2008). Our clinical diagnosis in this case was herpetic hepatitis and liver disease unrelated to $\mathrm{BC}$ or comedicated drugs; CIOMS based assessment led to an excluded causality for both BC and comedicated drugs (Teschke and Schwarzenboeck, 2009). In retrospect, this court case calls for a thorough transparent documentation of HILI cases, associated with an unbiased expert opinion.

\section{Kava}

Kava was in the focus of another trial in connection with its marketing withdrawal by the German regulatory agency BfArM (Schmidt, 2014). Almost 12 years after the German regulatory agency BfArM issued an intermediate withdrawal of marketing authorization for products containing extracts of kava (Piper methysticum, Piperaceae) root and/or rhizoma (BfArM, 2002), the case has been reviewed by the German administrative court in Cologne (Court, 2014). According to the court's ruling on June 
11,2014 , there was no justification for the ban of kava medicinal products issued by the German BfArM (Schmidt, 2014). The court ruled that based on available evidence, the benefit/risk ratio of kava medicinal products was confirmed as positive and must be considered as positive (Court, 2014), with credit given for previous reports (Schmidt, 2014) assessing causality in cases of assumed kava hepatotoxicity with the CIOMS scale (Teschke et al., 2008a, 2010; Teschke and Wolff, 2009; Teschke, 2010a). Credit was also given (Court, 2014) to the work of others (Sarris et al., 2013). Their double blind, randomized, placebo controlled trial was performed with a well defined noble kava drug that is on the market in Australia, showing both efficacy of kava in patients treated for their generalized anxiety disorders and lack of overt adverse reactions (Sarris et al., 2013), confirming kava efficacy based on a previous Cochrane study (Pittler and Ernst, 2003a). As a consequence of the court's ruling, German kava products have been formally restored to their market status on June 2002. As an update, BfArM appealed the court's ruling on June 30, 2014, but justification for the appeal has not yet been published (Schmidt, 2014). Clearly, the ruling is a major breakthrough, as it strengthens the legal certainty and predictability of regulatory decisions for herbal medicinal product manufacturers in general. It is also a call for the BfArM and other regulatory agencies to present transparent and appropriate clinical documentations of future HILI cases to be evaluated by clinically well trained regulatory assessors and external experts in the field, to be more self-critically, not to dismiss expert views to the contrary a priori, and providing rather than refuting original HILI case data in anonymous form to interested requesting scientists to assist in case evaluations.

\section{Essentials of Herbal Product Quality Herb Authentication and Product Identification}

Good quality of herbal drugs and other herbal products is prerequisite for safe human use (Table 16) (Teschke et al., 2013c). However, shortcomings of herbal products are well documented, both in herbal TCM and herbal modern medicine. Herbal authentication was an issue for BC (Sarma et al., 2008; Health Canada, 2010) and various TCM herbs (Haller et al., 2002; Teschke, 2014; Teschke et al., 2014b). There also was considerable debate whether kava products used by patients with kava hepatotoxicity might have been of poor quality including inappropriate herb authentication. This led to a comprehensive assessment and a proposal for a Kava Quality Standardization Code (Teschke and Lebot, 2011). Actually, several guidelines exist already for Good Agricultural Practices (GAP) and Good Manufacturing Practices (GMP), applicable to medicinal plants and herbal medicines to ensure their product quality (WHO, 2000a, 2003, 2006, 2007b). Despite these official precautionary recommendations for quality improvements, batch and product variability is not unusual (Lebot, 2006; Schmidt, 2007; Teschke and Lebot, 2011; Teschke et al., 2013c). Violation of GAP or GMP rules also will result in herbal products that lack efficacy, safety, or both.

When plants are considered for human use as ingredients of a herbal drug and dietary supplement, a clear definition and identification of plant family, subfamily, species, subspecies, and variety is mandatory, best done by a professional classical botanical description for any herb. Neglect may cause variation in plant
TABLE 16 | Proposal for international harmonization: requirements for regulatory approved herbal drugs.

Specific international qualification required for regulatory approved herbal drugs

Good Agricultural Practices

Good Manufacturing Practices

Definition of plant family, subfamily, species, subspecies, and variety

Definition of plant part

Definition of solvents and solubilizers

Lack of impurities, adulterants, and misidentifications

Minimum of batch and product variability

Lack of variety to variety variability

Brand name with details of ingredients, plant parts, batch number, and expiration date

Manufacturer with address

Regulatory specification of indication of herbal drug use

Daily dose with details of the application form

Maximum duration of herbal drug use

Efficacy of the herbal drug proven by valid RCTs

Description of adverse reactions and their frequency

Information of risk/benefit profile

Internationally approved unified regulatory surveillance

Regulatory harmonization of updated CIOMS scale use to assess causality in suspected HILI

Placebo controlled randomized double blind clinical trials

Risk/benefit profiles

Data are derived and adapted from a previous report (Teschke et al., 2013c).

family and species, contributing to the overall batch and product variability. Appropriate information should be provided by the manufacturers in the consumer's leaflet, thereby being available to the physician who suspects liver injury induced by a herbal product. The leaflet requires the name of the herbal product and the manufacturer's address who will provide additional information upon request. Therefore, all essential data of herb identification and the herbal product should be available before reporting HILI case details as spontaneous reports to the regulatory agencies or as case report publication. However, pitfalls are evident already at this stage of case evaluation.

In kava drug hepatotoxicity as an example, herb identification problems were evident. The manufacturers did not provide details on kava variety identification, so this specific information was missing in all spontaneous reports and case report publications (BfArM, 2002; Schmidt, 2007; WHO, 2007a; Teschke et al., 2008a; Teschke, 2010a,b, 2011). In the South Pacific region of origin, several hundred kava varieties exist-also called kava cultivars-and are grouped into noble, medicinal, and Two-Day varieties (Lebot, 2006; Schmidt, 2007; Teschke and Lebot, 2011; Teschke et al., 2011b). They differ in their kavalactone composition and their pleasant and unwanted, possibly toxic effects. In cases of suspected hepatotoxicity, it remained unclear which kava variety had to be incriminated. Interestingly, regulatory approval of kava drugs neither considered different kava varieties nor required respective labeling (BfArM, 2002). Thus, kava hepatotoxicity remains unexplained. 
Other problems of herb or product identification have been described in detail in various cases of initially suspected herbal hepatotoxicity (EMA, 2007; WHO, 2007b; Mahady et al., 2008; Teschke et al., 2011a,b,d,e). Incomplete herb description complicates accurate association of herbs with liver injury and allows only general assumptions (Teschke, 2010c; Teschke et al., 2013e,f). Besides overall herb descriptions, the brand name of the herbal product has been provided in only a few case reports, and data for manufacturer, plant part, and extraction solvent normally was fragmentary (Teschke et al., 2011e, 2013c). For instance, the rate of undetermined herbal products was 10/16 cases (63\%) among published case reports (Teschke et al., 2011e). This high rate questions the validity of any causality attribution. Additional problems arise from herbal mixtures, in which individual ingredients are not specified (Teschke, 2010c; Teschke et al., 2011d,e). Again, case reports have been published as HILI even if the patients were not sure whether they used a herbal product at all (Teschke et al., 2011e).

For GC, case reports assumed causality for hepatotoxicity in all 21 cases, but details on the GC product were fragmentary (Teschke et al., 2012e). Out of these 21 cases, seven patients used a GC monopreparation and four patients a GC polyherbal product, brand names and manufacturers were known in only nine patients. Fears of liability may contribute to the restriction of detailed product specifications by the authors. On the other hand, the regulatory agency did not hesitate to provide all relevant data of GC products from spontaneous cases of GC hepatotoxicity (Teschke et al., 2011a).

Therefore, unless complete data for herbal identification, ingredients, and name of the herbal product are provided in each HILI case, a valid causality assignment is not realistic. Identification problems are evident also in most HDS providing little specific information (Navarro et al., 2014; Robles-Diaz et al., 2015).

\section{Plant Part Specification}

Reports on HILI rarely provide details of the plant part used, ignoring specific toxic properties attributable to different parts of a plant. The regulatory recommendation for kava drugs was to use its peeled rhizome (Teschke and Lebot, 2011). In various assumed HILI cases by kava it remained unclear, whether also unpeeled rhizomes, peeled and unpeeled roots, and/or stem peelings were used, hampering evaluation of the causative agent of kava hepatotoxicity (WHO, 2007a; Teschke, 2011). For the U.S. FDA, peeled kava rhizomes were recommended for kava supplements (Teschke and Schulze, 2010), and according to the Australian Therapeutic Goods Administration, the commonly used medicinal kava products are derived from peeled rhizomes (Sarris et al., 2009). Plant part specification can be a major regulatory, agricultural, manufactural, pharmaceutical, and clinical issue (Teschke and Lebot, 2011).

\section{Solvents and Solubilizers}

Herbal drugs and supplements are specified as extracts that are either water based or prepared from organic solvents like ethanol or acetone, but regulatory advice is often lacking (Teschke and Lebot, 2011). Thus, herbal extracts will substantially differ in their composition depending on the solvent. In addition, numerous solubilizers like macrogol, craspovidon, mentha oil, methyl acrylic acid polymer and polysorbate polyols may be included in herbal products to facilitate gastrointestinal uptake (Teschke, 2010b). Therefore, solvents and solubilizers may influence the composition of chemicals in the herbal product and selectively affect the bioavailability for the liver as the target organ. These variations hamper causality attribution in suspected HILI cases, leading to the recommendation that kava drugs and supplements should be water based extracts lacking any solvents or solubilizers (WHO, 2007a; Teschke and Schulze, 2010; Teschke et al., 2011b).

\section{Misidentifications, Impurities, and Adulterants}

For herbal product quality, not only plant misidentification but also contaminants, impurities and adulterants still remain key problems (Kang-Yum and Oransky, 1992; Espinoza et al., 1995; Gertner et al., 1995; Huang et al., 1997; Ko, 1998; Ernst, 2002; Estes et al., 2003; Lebot, 2006; Schmidt, 2007; Seeff, 2007; WHO, 2007b; Mahady et al., 2008; Navarro, 2009; Teschke et al., 2009, 2011c,e; Health Canada, 2010; Larrey and Faure, 2011; Teschke and Lebot, 2011). Adulterants are not uncommon in herbal TCM mixtures; they usually consist of synthetic drugs to provide or fortify product efficacy. Although rarely addressed by analytical approaches in patients with actually reported HILI, Health Canada was the only regulatory agency with recently reported interest in the analytical assessment of herbal products to evaluate quality, providing evidence for misidentification of herbs in some products and presenting results that the accused herb was not present in the herbal products used by the affected patients (Health Canada, 2010).

It remains to be established to what extent misidentifications, impurities, and adulterants are responsible for individual HILI cases. For instance, possible causality for hepatotoxicity cases of the herbal TCM mixtures Chaso and Onshido was ascribed to $\mathrm{N}$-nitroso-fenfluramine, found as adulterant in these slimming aid products that had been produced in China and sold in Japan (Adachi et al., 2003). However, there is only little clinical or experimental evidence for a potential hepatotoxicity by this adulterant (Kanda et al., 2003a,b; Lau et al., 2004). It rather appears that green tea as ingredient was the causative agent if supplied as extract (Teschke, 2014).

Misidentification may create major clinical challenges and harm dramatically the health of consumers, shown for the following cases (Teschke, 2014). Until 2008, overall 41 cases from China with HSOS, the former HVOD, were reported and causally attributed to the herbal TCM Jing Tian San Qi (Sedum aizoon, syn. Stonecrop) (Wu et al., 2008), but causal attribution to Sedum aizoon was obviously incorrect. Sedum aizoon lacks PAs, and when applied to experimental animals, HSOS did not eme.g., Lin et al., 2011, suggesting that a herb containing PAs likely is reponsible for the reported cases (Wu et al., 2008). In line with this is another hepatotoxicity case from Hong Kong with HSOS that initially also was ascribed to Sedum aizoon, but it turned out to have been caused by the herbal TCM Tu San Qi (Gynura segetum) (Lin et al., 2011). The name and appearance of Sedum aizoon is similar to the one of Gynura segetum, but botanical differentiation was considered possible for the eye of experts (Lin et al., 2011). 
Comparative studies with both herbs provided clear supportive evidence for Gynura segetum as culprit for additional cases of HSOS as compared to Sedum aizoon. Respective studies in mice showed that Gynura segetum as the PA containing herb but not Sedum aizoon lacking PAs causes experimental HSOS as assessed by liver histology results (Lin et al., 2011). In an earlier experimental study, a model of the hepatic veno-occlusive disease was established by PAs derived from a herb described erronously as Sedum aizoon (Gao et al., 2006), which again does not contain PAs (Lin et al., 2011; Gao et al., 2012; Wang and Gao, 2014). This suggests that the described experimental model (Gao et al., 2006) was due to the action of a herb containing PAs, most likely Gynura segetum (Lin et al., 2011; Gao et al., 2012; Wang and Gao, 2014), rather than to Sedum aizoon lacking PAs (Gao et al., 2012). Based on these well founded considerations, evidence for a hepatotoxic potential of Jing Tian San Qi is lacking. The herbal TCM Sedum aizoon should therefore not be tabulated any more as hepatotoxic herb, as done until recently (Teschke et al., 2012h).

Gynura segetum was involved in other cases of herbal misidentification. In two Chinese women, HSOS emerged, which was induced by PAs of the herbal TCM Gynura segetum (syn. Ju Shan Qi, Ju Ye San Qi, Shan Chi, San Qi Cao, Shan Chi, Shan Chi) (Dai et al., 2006). Additional six cases were earlier suspected (Kumana et al., 1983, 1985); in at least four cases, the culprit was the PA containing herb Heliotropium lasiocarpum rather than Gynura segetum (Culvenor et al., 1986).

\section{New Encouraging Steps}

Modern medicine is well established on our globe but provides health facilities only to parts of the population with focus on patients who can afford the expenditures. Challenges of modern medicine include management of chronic disorders and orphan diseases, all at reasonable costs. To achieve this goal, support may come from herbal medicine, but this will require major efforts at various levels. Since abundant plants grow in all countries around the world and are ready to be used for treating human diseases, herbal medicine may have encouraging perspectives to become a global player, provided efficacy is proven and associated risks such as liver toxicity are limited and easily recognizable.

\section{Progress in Developing Valid Diagnostic Biomarkers}

Numerous valid clinical biomarkers exist and enable a firm diagnosis of most liver diseases unrelated to HILI and DILI, for instance by assessing specific antibodies of viral hepatitis (Table 7). New encouraging steps with the development of specific biomarkers for HILI are discussed (Larrey and Faure, 2011) in reference to a sensitive and specific assay enabling fthe detection of a reactive pyrrole-protein adduct in the serum of patients with HSOS. This disease was attributed to the Tusanqi preparation made erroneously with Gynura segetum containing PAs instead with Segetum aizoon lacking PAs (Lin et al., 2011). The results of this assay show that the patient actually consumed a herb containing PAs, which are metabolized in the liver to a reactive PA metabolite, reacting with a protein and forming an adduct (Larrey and Faure, 2011). However, this assay does not prove that PAs have caused the hepatotoxicity in this particular patient, needing supportive evidence in the clinical context. Measuring herbal toxins or their metabolites in the serum is useful in HILI cases in a setting of some intoxication, if high levels of the herbal toxin are expected in the serum due to large amounts of the consumed herb, high cumulative doses, or a prolonged degradation of the toxic herbal chemical. These conditions apply to HILI cases of the intrinsic form but not to those of the idiosyncratic form, which accounts for most HILI cases. For idiosyncratic HILI, similar restrictions apply regarding circulating micro-RNA (mRNA), presently investigated in intrinsic DILI and detectable in fluids including the serum (Zhou et al., 2013). Omics technologies, including genomics, proteomics, and metabolomics might well change but not revolutionize our understanding in the diagnosis of intrinsic hepatotoxicity (Yang et al., 2012b).

Interest in biomarkers to identify idiosyncratic hepatotoxicity risks in individuals who use drugs is continuing. For idiosyncratic DILI, numerous genetic and nongenetic risk factors have been described as possible biomarkers to predict DILI in some individuals (Chalasani and Björnsson, 2010), but whether these are useful to diagnose idiosyncratic HILI is unknown.

\section{Conformed Diagnostic HILI Case Management}

At an international level and to provide transparency and comparability, an overall accepted pragmatic stratification of HILI case assessment and data presentation should be adopted and more enforced. Sequential case management and presentation should focus on narrative case details for an overview of clinical features. This kind of information is best provided as table, easily also published even for a high number of cases, as illustrated for 16 HILI cases in a single report (Table 3); this facilitates HILI characterization caused by a single herb such as GC (Table 4). Detailed presentation of established criteria of hepatotoxicity definition, differentiation of hepatocellular, cholestatic, and mixed form of liver injury, and pathogenetic classification should be mandatory (Figure 1). Information of provided or missed case details and diagnostic parameters are valuable tools that signify case data quality and ensure transparency (Table 6). The concept of a sequential diagnostic approach in suspected HILI cases best starts with thorough clinical case assessments, subsequently combined with the use of the updated CIOMS scale (Tables 10, 11) as the mainstream tool (Tables 12,13), and followed by expert opinion, if uncertainty remains. This worldwide applicable strategy allows transparency and provides a quick basis for final causality assignments of individual HILI cases by calculating individual and final scores of individual CIOMS items (Tables 10, 11, 15). This strategy of diagnostic harmonzation is pragmatic, time and cost saving, and facilitates potential reassessment by other clinicians, scientists, manufacturers, or regulatory agencies.

\section{International Harmonization of Regulatory Efforts and Surveillance}

Encouraging efforts are reported from the Chinese State Food and Drug Administration (SFDA), progress is underway to improve regulatory surveillance of TCM herbal products (Zhang et al., 2012). In 2012, the SFDA model of safety monitoring and risk management of TCM drugs was still under exploration, 
with numerous regulatory and clinical issues. These include information on adulteration and counterfeit TCM drugs and clarification that except for SFDA approved Chinese and Western compound products, the addition of Western drugs into a TCM drug formula is illegal. SFDA has established examination methods and shelf sampling inspection of products in order to protect the safety of patients. It is not described whether SFDA proves causality in suspected HILI by TCM and CIOMS is used in analogy to other international registries and regulatory agencies (Tables 12, 14).

The regulatory situation of herbal medicines has thoroughly been evaluated worldwide for most countries of all continents (WHO, 2005). For herbal supplements, regulatory control varies among countries and commonly is less stringent or missing, whereas regulatory approved herbal drugs in Europe are under strict regulatory surveillance, as are approved synthetic drugs (EMA, 2014; MHRA, 2014). Regulatory efforts regarding herbal medicine products should be advanced, aiming at an identical quality level in all countries. This harmonization is best achieved by regulatory lifting all HDS to the level of herbal drugs, provided new regulations are formulated and strictly followed, and preclinical and clinical safety as well as efficacy is proven. Consumers will benefit from worldwide pharmacovigilance harmonization and quality control standards of herbal drugs (Table 16), deviced as previously outlined for kava quality standards (Teschke and Lebot, 2011).

\section{Sophisticated Evidence Based Trials}

China is the country with an extremely high number of published randomized controlled clinical trials (RCTs) (Wang et al., 2007), evaluating herbal TCM, but their efficacy has rarely been established due to poor study quality (Manheimer et al., 2009; Teschke et al., 2015a,b). There is increasing awareness that valid evidence based clinical trials for any herbal treatment should be mandatory as shown for kava through a Cochrane analysis (Pittler and Ernst, 2003a), associated with a robust risk management and balanced risk/benefit profiles (Tang et al., 1999; Wang et al., 2007; Manheimer et al., 2009; NIH, 2014a,b; Teschke et al., 2015a,b). For Europe, these trials are commonly required by EMA and national regulatory agencies for herbal drug approvement; this established system should be adopted by the WHO for global harmonization.

\section{Promising New Drug Research and Development}

Plants are natural producers of chemical substances, enforcing great expectations that in the future more synthetic drugs are developed based on herbal ingredients being effective in human diseases. In fact, for most of history, herbal medicine was the only available medicine. It has also been estimated that one third to one half of currently used drugs were originally derived from plants (Bent, 2008). Encouraging developments are underway (Pelkonen et al., 2014), with focus on herbal TCM (Li et al., 2012; Zhao et al., 2012).

\section{Globalization}

With pragmatic modern drug medicine in competition, herbal medicine should contribute some of its items to a modern type of drug medicine as part of globalized health care systems at reasonable costs. On a long run, this approach appears feasible, provided traditional and modern herbal medicine conform to the expectations and needs of patients and consumers (Leonti and Casu, 2013), requiring new steps and improvements based on debated issues outlined above. Globalization of herbal medicine needs unrestricted exchange of herbal drugs among all countries. To ensure worldwide high quality, each herbal medicine should undergo strict regulatory surveillance and be classified as herbal drug according to internationally agreed criteria. Among these are strict adherence to GAP and GMP items, clear definitions of plants, plant parts, and solvents to be used, well defined indications and treatment modalities, proof of evidence based efficacy for the proposed indications, evaluation of adverse reactions, and positive risk/benefit profiles (Table 16). Presently, HDS fulfill these criteria only marginally and need a move to the herbal drug category; otherwise withdrawal from the market will be the alternative. Concern exists that presently limited scientific evidence exists to establish the safety and efficacy of most herbal products (Bent, 2008). Of the top 10 herbs in the United States, five herbs (ginkgo, garlic, St. John's wort, soy, and kava) have scientific evidence suggesting efficacy, but concerns over safety may temper the decision to use these products. Consequently, herbal products are not likely to become an important alternative to standard medical therapies or a global player, unless there are changes to the regulation and standardization of these products (Bent, 2008).

\section{Concluding Remarks}

Herbal use is common in traditional and modern medicine and requires more international harmonization to promote herbal medicine to a global player. In analogy to European regulatory settings, herbal medicinal products should be manufactured, marketed, and supervised as regulatory approved drugs similar to synthetic drugs. Certainly, this requires global consent and major efforts but it could open a global market for these drugs. International agreement should be reached on various issues, including best quality of herbal drugs, definition of indications, and proof of therapeutic efficacy by clinical trials, determination of therapy modalities such as posology, and assessment of adverse reactions in line with risk/benefit profiles. Present issues focus on poor herbal product quality, lack of proven efficacy, and rare adverse reactions including hepatotoxicity. These should be better recognized in the future by thorough clinical evaluation associated with the CIOMS scale as the best recognized causality assessing tool worldwide, possibly followed by expert opinion if uncertainty remains. 


\section{References}

Abdualmjid, R. J., and Sergi, C. (2013). Hepatotoxic botanicals - an evidenced-based systematic review. J. Pharm. Pharmaceut. Sci. 16, 376-404.

Abu el Wafa, Y., Benaventa Fernandez, A., Talavera Fabuel, A., Perez Ramos, M. A., and Ramos-Clemente, J. I. (2005). Acute hepatitis induced by Camellia sinensis (green tea). An. Med. Interna. 22, 298.

Adachi, M., Saito, H., Kobayashi, H., Horie, Y., Kato, S., Yoshioka, M., et al. (2003). Hepatic injury in 12 patients taking the herbal loss aids Chaso and Onshido. Ann. Intern. Med. 139, 488-492. doi: 10.7326/0003-4819-139-6-20030916000012

Aiba, T., Takahashi, T., Suzuki, K., Okoshi, S., Nomoto, M., Uno, K., et al. (2007). Liver injury induced by a Japanese herbal medicine, sairei-to (TJ-114, Bupleurum and Hoelen combination, Chai-Ling-Tang). J. Gastroenterol. Hepatol. 22, 762-763. doi: 10.1111/j.1440-1746.2006.03373.x

Aithal, G. P., Watkins, P. B., Andrade, R. J., Larrey, D., Molokhia, M., Takikawa, H., et al. (2011). Case definition and phenotype standardization in druginduced liver injury. Clin. Pharmacol. Ther. 89, 806-815. doi: 10.1038/clpt. 2011.58

Alderman, S., Goldfarb, S., and Malone, D. G. (1994). Cholestatic hepatitis after ingestion of chaparral leaf: confirmation by endoscopic retrograde cholangiopancreatography and liver biopsy. J. Clin. Gastroenterol. 19, 242-247.

Allen, B. R., and Parkinson, R. (1990). Chinese herbs for eczema (letters). Lancet 336:177.

Altan, E., Bitik, B., Kalpkci, Y., and Dogan E Altundag, K. (2009). Probable hepatotoxicity related to Nerium oleander extract in a patient with metastatic synovial sarcoma of the knee. J. Altern. Complement. Med. 15, 113. doi: 10.1089/acm.2008.0459

Anderson, I. B., Mullen, W. H., Meeker, J. E., Khojasteh-Bakht, S. C., Oishi, S., Nelson, S. D., et al. (1996). Pennyroyal toxicity: Measurement of toxic metabolite levels in two cases and review of the literature. Ann. Intern. Med. 124, 726-734.

Andrade, R. J., Camargo, R., Lucena, M. I., and González-Grande, R. (2004). Causality assessment in drug-induced hepatotoxicity. Expert Opin. Drug Saf. 3: 329-344. doi: 10.1517/14740338.3.4.329

Andrade, R. J., Lucena, M. I., Fernández, M. C., Pelaez, G., Pachkoria, K., GarcíaRuiz, E., et al. (2005). Drug-induced liver injury: an analysis of 461 incidences submitted to the Spanish registry over a 10-year period. Gastroenterology 129, 512-521. doi: 10.1016/j.gastro.2005.05.006

Appelhans, K., Frankos, V., and Shao, A. (2012). Misconceptions regarding association between Herbalife products and liver related case reports in Spain. Pharmacoepidemiol. Drug Saf. 21, 333-334. doi: 10.1002/pds.3203

Appelhans, K., Smith, C., Bejar, E., and Henig, Y. S. (2011). Revisiting acute liver injury associated with Herbalife products. World J. Hepatol. 3, 275-277. doi: 10.4254/wjh.v3.i10.275

Bach, N., Thung, S. N., and Schaffner, F. (1989). Comfrey herb tea-induced hepatic veno-occlusive disease. Am. J. Med. 87, 97-99. doi: 10.1016/S00029343(89)80492-9

Bae, S. H., Kim, D. H., Bae, Y. S., Lee, K. J., Kim, D. W., Yoon, J. B., et al. (2010). Toxic hepatitis associated with Polygoni multiflori. Korean J. Hepatol. 16, 182-186. doi: 10.3350/kjhep.2010.16.2.182

Bakerink, J. A., Gospe, S. M., Dimand, R. J., and Eldridge, M. W. (1996). Multiple organ failure after ingestion of pennyroyal oil from herbal tea in two infants. Pediatrics 98, 944-947.

Banarova, A., Koller, T., and Payer, J. (2012). Toxic hepatitis induced by Polygonum multiflorum. Vnitr. Lek. 58, 958-962.

Batchelor, W. B., Heathcote, J., and Wanless, I. R. (1995). Chaparral-induced hepatic injury. Am. J. Gastroenterol. 90, 831-833.

Battinelli, L., Daniele, C., Mazzanti, G., Mastroianni, C. M., Lichtner, M., Coletta, S., et al. (2004). New case of acute hepatitis following the consumption of Shou Wu Pian, a Chinese herbal product derived from Polygonum multiflorum. Ann. Intern. Med. 140, 587-588.

Bénichou, C. (1990). Criteria of drug-induced liver disorders. Report of an international consensus meeting. J. Hepatol. 11, 272-276.

Bénichou, C., Danan, G., and Flahault, A. (1993). Causality assessment of adverse reactions to drugs - II. An original model for validation of drug causality assessment methods: case reports with positive rechallenge. J. Clin. Epidemiol. 46, 1331-1336.
Benninger, J., Schneider, H. T., Schuppan, D., Kirchner, T., and Hahn, E. G. (1999). Acute hepatitis induced by Greater Celandine (Chelidonium majus). Gastroenterology 117, 1234-1237.

Bent, S. (2008). Herbal medicine in the United States: review of efficacy, safety, and regulation. J. Gen. Intern. Med. 23, 854-859. doi: 10.1007/s11606-008-0632-y

Bessone, F., Hernandez, N., Dávalos, M., Paraná, R., Schinoni, M. I., Lizarzabal M., et al. (2012). Building a Spanish-Latin American network on Drug Induced Liver Injury; much to get from a joint collaborative initiative. Ann. Hepatol 11, 544-549.

Beuers, U., Spengler, U., and Pape, G. R. (1991). Hepatitis after chronic abuse of senna. Lancet 337, 372-373.

BfArM. (2002). Bundesinstitut für Arzneimittel und Medizinprodukte, Bonn. Federal Institute for Drugs and Medicinal Products in Germany. Rejection of Drug Risks, Step II. As related to: Kava-Kava (Piper methysticum)-Containing, and Kavain-Containing Drugs, Including Homeopathic Preparations with a Final Concentration up to, and Including D4. June 14, 2002. Available online at: http://www.spc.int/cis/documents/02_0714_BfArM_Kava_Removal.pdf (Accessed December 30, 2014).

BfArM. (2005). Bundesinstitut für Arzneimittel und Medizinprodukte (German regulatory agency). Bekanntmachung. Abwehr von Gefahren durch Arzneimittel, Stufe II, Anhörung: Schöllkraut-haltige Arzneimittel zur innerlichen Anwendung. May 6, 2005. Available online at:http://www.bfarm.de/cae/servlet/contentblob/1014620/publicationFile/6619 8/schoellkraut-anhoerung_050505.pdf (Accessed December 30, 2014).

Björnsson, E. S., Bergmann, O. M., Björnsson, H. K., Kvaran, R. B., and Olafsson, S. (2013). Incidence, presentation and outcomes in patients with druginduced liver injury in the general population of Iceland. Gastroenterology 144, 1419-1425. doi: 10.1053/j.gastro.2013.02.006

Björnsson, E., and Olsson, R. (2007). Serious adverse liver reactions associated with herbal weight loss supplements. J. Hepatol. 47, 295-297.

Björnsson, E., Jacobsen, E. I., and Kalaitzakis, E. (2012). Hepatotoxicity associated with statins: Reports of idiosyncratic liver injury post-marketing. J. Hepatol. 56, 374-380. doi: 10.1016/j.jhep.2011.07.023

Bonkovsky, H. L. (2006). Hepatotoxicity associated with supplements containing Chinese green tea (Camellia sinensis). Ann. Intern. Med. 144, 68-71. Erratum in: Ann Intern Med 144, 380. doi: 10.7326/0003-4819-144-1-200601030-00020

Borum, M. L. (2001). Fulminant exacerbation of autoimmune hepatitis after the use of Ma Huang. Am. J. Gastroenterol. 96, 1654-1655. doi: 10.1111/j.15720241.2001.03827.x

Bottenberg, M. M., Wall, G. C., Harvey, R. L., and Habib, S. (2007). Oral Aloe verainduced hepatitis. Ann. Pharmacother. 41, 1740-1743. doi: 10.1345/aph.1K132

Bujanda, L., Palacios, A., Silvariño, R., Sánchez, A., and Muñoz, C. (2002). Hepatitis aguda icterica secundaria a kava. Gastroenterol. Hepatol. 25, 434-435. doi: 10.1016/S0210-5705(02)70281-1

Bunchorntavakul, C., and Reddy, K. R. (2013). Review article: herbal and dietary supplement hepatotoxicity. Aliment Pharmacol. Ther. 37, 3-17. doi: 10.1111/apt.12109

But, P. P. H., Tomlinson, B., and Lee, K. L. (1996). Hepatitis related to the Chinese medicine Shou-wu-pian manufactured from Polygonum multiflorum. Vet. Hum. Toxicol. 38, 280-282.

Caldwell, S. H., Feeley, J. W., Wieboldt, T. F., Featherston, P. L., and Dickson, R. C. (1994). Acute hepatitis with use of over-the-counter herbal remedies. Va. Med. Q. 121, 31-33.

Cárdenas, A., Restrepo, J. C., Sierra, F., and Correa, G. (2006). Acute hepatitis due to shen-min: a herbal product derived from Polygonum multiflorum. J. Clin. Gastroenterol. 40, 629-632. doi: 10.1097/00004836-200608000-00014

Centers of Disease Control and Prevention. (1992). Chaparral-induced toxic hepatitis California and Texas. J. Am. Med. Assoc. 268, 3295-3298.

Chalasani, N., and Björnsson, E. (2010). Risk factors for idiosyncratic drug-induced liver injury. Gastroenterology 138, 2246-2259. doi: 10.1053/j.gastro.2010.04.001

Chalasani, N., Fontana, R. J., Bonkovsky, H. L., Watkins, P. B., Davern, T., Serrano, J., et al., (2008). Causes, clinical features, and outcomes from a prospective study of drug-induced liver injury in the United States. Gastroenterology 135, 1924-1934. doi: 10.1053/j.gastro.2008.09.011

Chao, S., Anders, M., Turbay, M., Olaiz, E., Mc Cormack, L., and Mastai, R. (2008). Toxic hepatitis by consumption of Herbalife products: a case report. Acta Gastroenterol. Latinoam. 38, 274-277. 
Chau, T. N. (2008). Drug-induced liver injury: an update. Hong Kong Med. Diary $13,23-26$.

Chau, T. N., Cheung, W. I., Ngan, T., Lin, J., Lee, K. W. S., Poon, W. T., et al. (2011). Causality assessment of herb-induced liver injury using multidisciplinary approach and the Roussel Uclaf Causality assessment Method (RUCAM). Clin. Toxicol. 49, 34-39. doi: 10.3109/15563650.2010. 537662

Chen, G. C., Ramanathan, V. S., Law, D., Funchain, P., Chen, G. C., French, S., et al. (2010). Acute liver injury induced by weight-loss herbal supplements. World J. Hepatol. 2, 410-415. doi: 10.4254/wjh.v2.i11.410

Chen, M. Y., Cai, J. T., and Du, Q. (2007). Hepatic veno-occlusive disease associated with the use of Gynura segetum. Eur. J. Intern. Med. 18, 609. doi: 10.1016/j.ejim.2007.03.006

Cheung, W. I., Tse, M. L., Ngan, T., Lin, J., Lee, W. K., Poon, W. T., et al. (2009). Liver injury associated with the use of Fructus Psoraleae (Bol-gol-zhee or Bugu-zhi) and its related propriety medicine. Clin. Toxicol. 47, 683-685. doi: 10.1080/15563650903059136

Christl, S. U., Seifert, A., and Seeler, D. (2009). Toxic hepatitis after consumption of traditional kava preparation. Int. Soc. Trav. Med. 16, 55-56. doi: 10.1111/j.1708-8305.2008.00259.x

Cohen, S. M., Heywood, E., Pillai, A., and Ahn, J. (2012). Hepatotoxicity associated with the use of White Flood, a nutritional supplement. Pract. Gastroenterol. 10, 45-48.

Colin-Jones, D. G., and Harvey, J. (1982). Mistletoe hepatitis. Br. Med. J. 284, 744-745. doi: 10.1136/bmj.284.6317.744-b

Conti, E., De Checchi, G., Mencarelli, R., Pinato, S., and Rovere, P. (2008). Lycopodium similiaplex-induced acute hepatitis: a case report. Eur. J. Gastroenterol. Hepatol. 20, 469-471. doi: 10.1097/MEG.0b013e3282f1623d

Cortez, E., Boulger, C., and Bernard, A. (2012). Ban Tu Wan hepatotoxicity. BMJ Case Reports doi: 10.1136/bcr-2012-006438

Court. (2014). Administrative Coiurt, Cologne, Germany. Court ruling $7 \quad K \quad 2197 / 12$ of May 2010, 2014. Available online at: http://www.justiz.nrw.de/nrwe/ovgs/vg_koeln/j2014/7_K_2197_12_Urteil_201 40520.html (Accessed December 30, 2014).

Crijns, A. P., de Smet, P. A., van den Heuvel, M., Schot, B. W., and Haagsma, E. B. (2002). Acute hepatitis after use of herbal preparation with greater celandine (Chelidonium majus). Ned. Tijdschr. Geneeskd. 146, 124-128.

Culvenor, C. C. J., Edgar, J. A., Smith, L. W., Kumana, C. R., and Lin, H. J. (1986). Heliotropium lasiocarpum Fisch and Mey identified as cause of veno-occlusive disease due to herbal tea. Lancet 1, 978.

Dai, H. F., Gao, Y., Yang, M., Yu, C. H., Gu, Z. Y., and Chen, W. X. (2006). Hepatic veno-occlusive disease induced by Gymura segetum: report of two cases. Hepatobiliary Pancreat Dis. Int. 5, 406-408.

Danan, G. (1988). Consensus meetings on: causality assessment of drug-induced liver injury. J. Hepatol. 7, 132-136.

Danan, G., and Bénichou, C. (1993). Causality assessment of adverse reactions to drugs - I. A novel method based on the conclusions of international consensus meetings: application to drug-induced liver injuries. J. Clin. Epidemiol. 46, 1323-1330.

Dao, T., Peytier, A., Galateau, F., and Valla, A. (1993). Chronic hepatitis due to germander. Gastroenterol. Clin. Biol. 17, 614-615.

Dara, L., Hewett, J., and Lim, J. K. (2008). Hydroxycut hepatotoxicity: a case series and review of liver toxicity from herbal weight loss supplements. World J. Gastroenterol. 14, 6999-7004. doi: 10.3748/wjg.14.6999

Datta, D. V., Khuroo, M. S., Mattocks, A. R., Aikat, B. K., and Chhuttani, P. N. (1978). Herbal medicines and veno-occlusive disease in India. Postgrad. Med. J. 54, 511-515.

Davies, E. G., Pollock, I., Steel, H. M. (1990). Chinese herbs for eczema. Lancet 336:117.

DCGMA, Drug Commission of the German Medical Association (Arzneimittelkommission der Deutschen Ärzteschaft). (2011). Hepatitis in connection with Umckaloabo ${ }^{\circledR}$. Dtsch Ärztebl. 108, C1399-C1400.

De Smet, P. A. G. M., Van Den Eertwegh, A. J. M., Lesterhuis, W., and Stricker, B. H. C. (1996). Hepatotoxicity associated with herbal tablets. BMJ 313, 92.

Denham, A., McIntyre, M., and Whitehouse, J. (2002). Kava - the unfolding story: report on a work-in-progress. J. Altern. Complement. Med. 8, 237-263. doi: $10.1089 / 10755530260127943$
Dhanasekaran, R., Owens, V., and Sanchez, W. (2013). Chinese skullcap in move free arthritis supplement causes drug induced liver injury and pulmonary infiltrates. Case Reports Hepatol. 965092. doi: 10.1155/2013/965092

Divinsky, M. (2002). Case report: Jin Bu Huan - not so benign herbal medicine. Can. Fam. Physician 48, 1640-1642.

Duenas Sadornil, C., Fabregas Piugtio, S., and Durandez, R. (2004). Hepatotoxicity due to Camelia sinensis. Med. Clin. (Barc) 122, 677-678. doi: 10.1157/13061393

Dunbar, K., and Solga, S. F. (2007). Black cohosh, safety, and public awareness. Liver Int. 27, 1017-1018.

Duque, J. M., Ferreiro, J., Salgueiro, E., and Manso, G. (2007). Hepatotoxicity associated with the consumption of herbal slimming products. Med. Clin. 128, 238-239.

Eisenberg, D. M., Davis, R. B., Ettner, S. L., Appel, S., Wilkey, S., Van Rompay, M., et al. (1998). Trends in alternative use in the United States, 1990-1997: results of a follow-up national study. JAMA 280, 1569-1575.

Ekor, M. (2014). The growing use of herbal medicines: issues relating to adverse reactions and challenges in monitoring safety. Front. Pharmacol. 4:177. doi: 10.3389/fpharm.2013.00177

Elinav, E., Pinsker, G., Safadi, R., Pappo, O., Bromberg, M., Anis, E., et al. (2007) Association between consumption of Herbalife nutritional supplements and acute hepatotoxicity. J. Hepatol. 47, 514-520. doi: 10.1016/j.jhep.2007.06.016

EMA. (2007). Assessment of Case Reports Connected to Herbal Medicinal Products Containing Cimicifugae Racemosae Rhizoma (Black Cohosh, Root). Issued May 8, 2007. Available online at: http://www.ema.europa.eu/docs/en_GB/document_library/Herbal_-_HMPC_ assessment_report/2010/02/WC500074167.pdf (Accessed December 30, 2014).

EMA. (2010). European Medicines Agency. Assessment Report on Chelidonium majus L., herba. Draft. November 25, 2010. Available online at: http://www.ema.europa.eu/docs/en_GB/document_library/Public_statement/ 2011/01/WC500100940.pdf. (Accessed December 30, 2014).

EMA. (2014). Herbal Medicinal Products. Available online at: http://ec.europa. eu/health/human-use/herbal-medicines/index_en.htm (Accessed November 30, 2014).

Engels, M., Wang, C., Matoso, A., Maidan, E., and Wands, J. (2013). Tea not tincture; hepatotoxicity associated with Rooibos herbal tea. ACG Case Rep. J. 1, 58-60. doi: 10.14309/crj.2013.20

Ernst, E. (2002). Adulteration of Chinese herbal medicines with synthetic drugs: a systematic review. J. Intern. Med. 252, 107-113. doi: 10.1046/j.13652796.2002.00999.x

Escher, M., Desmeules, J., Giostra, E., and Mentha, G. (2001). Hepatitis associated with kava, a herbal remedy for anxiety. Br. Med. J. 322, 139. doi: 10.1136/bmj.322.7279.139

Espinoza, E. O., Mann, M. J., and Bleasdell, B. (1995). Arsenic and mercury in traditional Chinese herbal balls. N Engl. J. Med. 333, 803-804.

Estes, J. D., Stolpman, D., Olyaei, A., Corless, C. L., Ham, J. M., Schwartz, J. M., et al. (2003). High prevalence of potentially hepatotoxic herbal supplement use in patients with fulminant hepatic failure. Arch. Surg. 138, 852-858. doi: 10.1001/archsurg.138.8.852

Farnsworth, N. R., and Loub, W. D. (1982). Mistletoe hepatitis. Br. Med. J. 283, 1058.

Federico, A., Tiso, A., and Loguercio, C. (2007). A case of hepatotoxicity caused by green tea. Free Radic. Biol. Med. 43, 474. doi: 10.1016/j.freeradbiomed.2007.05.010

Fenkel, J. M., and Navarro, V. J. (2011). Review: herbal and dietary supplementinduced liver injury. Gastroenterol. Hepatol. 7, 695-696.

Fong, T. L., Klontz, K. C., Canas-Coto, A., Casper, S. J., Durazo, F. A., Davern, T. J., et al. (2010). Hepatotoxicity due to Hydroxycut: a case series. Am. J. Gastroenterol. 105, 1561-1566. doi: 10.1038/ajg.2010.5

Fox, D. W., Hart, M. C., Bergeson, P. S., Jarrett, P. B., Stillman, A. E., and Huxtable, R. J. (1978). Pyrrolizidine (Senecio) intoxication mimicking Reye syndrome. J. Pediatr. 93, 980-982.

Fraquelli, M., Colli, A., Cocciolo, M., and Conte, D. (2000). Adult syncytial giant cell chronic hepatitis due to herbal remedy. J. Hepatol. 33, 505-508. doi: 10.1016/S0168-8278(00)80289-5

Fu, P. P., Xia, Q., Lin, G., and Chou, M. W. (2004). Pyrrolizidine alkaloids - genotoxicity, metabolism enzymes, metabolic activation, and mechanisms. Drug Metab. Rev. 36, 1-55. doi: 10.1081/DMR-120028426 
Furukawa, M., Kasajima, S., Nakamura, Y., Shouzushima, M., Nagatani, N., Takinishi, A., et al. (2010). Toxic hepatitis induced by Show-Wu-Pian, a Chinese herbal preparation. Intern. Med. 49, 1537-1540. doi: 10.2169/internalmedicine.49.3509

Gao, H., Li, N., Wang, J. Y., Zhang, S. C., and Lin, G. (2012). Definitive diagnosis of hepatic sinusoidal obstruction syndrome induced by pyrrolizidine alkaloids. J. Dig. Dis. 13, 33-39. doi: 10.1111/j.1751-2980.2011.00552.x

Gao, X. S., Xiao, S. S., and He, J. F. (2006). Analysis of alkaloids in Sedum aizoon and establishment of hepatic veno-occlusive model in mice. Chin. J. Integr. Trad. Western Med. Digest. 14, 311-313.

García-Cortés, M., Borraz, Y., Lucena, M. I., Peláez, G., Salmerón, J., Diago, M., et al. (2008). Liver injury induced by "natural remedies": an analysis of cases submitted to the Spanish Liver Toxicity Registry. Rev. Esp. Enferm. Dig. 100, 688-695.

García-Cortés, M., Stephens, C., Lucena, M. I., Fernández-Castañer, A., Andrade, R. J., on behalf of the Spanish Group for the Study of DrugInduced Liver Disease. (2011). Causality assessment methods in drug induced liver injury: strengths and weaknesses. J. Hepatol. 55, 683-691. doi: 10.1016/j.jhep.2011.02.007

Garcia-Moran, S., Saez-Royuela, F., Gento, E., Lopez Morante, A., and Arias, L. (2004). Acute hepatitis associated with Camellia tea and Orthosiphon stamineus ingestion. Gastroenterol. Hepatol. 27, 559-560. doi: 10.1157/13068145

Georgia, M. (1988). Hepatotoxicity due to Atractylis gummifera. Clin. Toxicol. 26, 487-493. doi: 10.3109/15563658809038564

Gertner, E., Marshall, P. S., Filandrinos, D., Potek, A. S., and Smith, T. M. (1995). Complications resulting from the use of Chinese herbal medications containing undeclared prescription drugs. Arthritis Rheum. 38, 614-617. doi: 10.1002/art.1780380506

Gloro, R., Hourmand-Ollivier, I., Mosquet, B., Mosquet, L., Rousselot, P., Salamé E., et al. (2005). Fulminant hepatitis during self-medication with hydroalcoholic extract of green tea. Eur J Gastroenterol Hepatol 17: 1135-1137. doi: 10.1097/00042737-200510000-00021

Gono, Y., Odaguchi, H., Hayasaki, T., Suzuki, K., Oikawa, T., Muranushi, A., et al. (2010). Clinical analysis of cases with drug-induced liver injury for Kampo medicine. Kampo Med. 61, 828-833. doi: 10.3937/kampomed.61.828

Gordon, D. W., Rosenthal, G., Hart, J., Sirota, S., and Baker, A. L. (1995). Chaparral ingestion: the broadening spectrum of liver injury caused by herbal medications. JAMA 273, 489-490.

Gow, P. J., Connelly, N. J., Hill, R. L., Crowley, P., and Angus, P. W. (2003). Fatal fulminant hepatic failure induced by a natural therapy containing kava. Med. J. Aust. 178, 442-443.

Greving, I., Meister, V., Monnerjahn, C., Müller, K. M., and May, B. (1998). Chelidonium majus: a rare reason for severe hepatotoxic reaction. Pharmacoepidemiol. Drug Saf. 7, S66-S69. doi: 10.1002/(SICI)10991557(199808)7:1+<S66::AID-PDS349>3.3.CO;2-7

Gunawan, B. and Kaplowitz, N. (2004). Clinical perspectives on xenobioticinduced hepatotoxicity. Drug Metab. Rev. 36, 301-312. doi: 10.1081/DMR120034148

Halegoua-De Marzio, D., Vega, M., Schifter Weber, J., Aithal, G. P., Andrade, R. J., Bessone, F., et al. (2013). An international effort to assess hepatotoxicity associated with some Herbalife ${ }^{\circledR}$ products. Hepatology 58, 383A-384A.

Haller, C. A., Dyer, J. E., Ko, R., and Olson, K. R. (2002). Making a diagnosis of herbal-related toxic hepatitis. West J. Med. 176, 39-44. doi: 10.1136/ewjm.176.1.39

Hardeman, E., van Overbeke, L., Ilegems, S., and Ferrante, M. (2003). Acute hepatitis induced by greater celandine (Chelidonium majus). Acta Gastroenterol. Belg. 71, 281-282.

Harvey, J., and Colin-Jones, D. G. (1981). Mistletoe hepatitis. Br. Med. J. (Clin. Res. Ed) 282, 186-187.

Health Canada. (2010). Black cohosh products and liver toxicity: update. Can. Adverse React. Newsl. 20, 1-3.

Hoffmann, M., Marbet, U. A., Hurni, A., Bianchi, L., and Göldi, H. (2005). Rezidiv einer medikamentös-toxischen Hepatitis. Schweiz Med. Forum 5, 147-148.

Horowitz, R. S., Feldhaus, K., Dart, R. C., Stermitz, F. R., and Beck, J. J. (1996). The clinical spectrum of Jin Bu Huan toxicity. Arch. Intern.Med. 156, 899-903.

Hsu, L. M., Huang, Y. S., Tsay, S. H., Chang, F. Y., and Lee, S. D. (2006). Acute hepatitis induced by Chinese hepatoprotective herb xiao-chai-hu-tang. J. Chin. Med. Assoc. 69, 86-82. doi: 10.1016/S1726-4901(09)70119-4
Huang, W. F., Wen, K. C., and Hsiao, M. L. (1997). Adulteration by synthetic therapeutic substances of traditional Chinese medicines in Taiwan. J. Clin. Pharmacol. 37, 344-350. doi: 10.1002/j.1552-4604.1997.tb04312.x

Hullar, T. E., Sapers, B. L., Ridker, P. M., Judkins, R. L., Huth, T. S., and Farraye, F. A. (1999). Herbal toxicity and fatal hepatic failure (letter). Am. J. Med. 106, 267-268.

Humberston, C. L., Akhtar, J., and Krenzelok, E. P. (2003). Acute hepatitis induced by kava kava. J. Toxicol. Clin. Toxicol. 41, 109-113. doi: 10.1081/CLT120019123

Hung, S. K., Hillier, S., and Ernst, E. (2011). Case reports of adverse effects of herbal medicinal products (HMPs): a quality assessment. Phytomedicine 18, 335-343. doi: 10.1016/j.phymed.2010.07.007

Hwang, S. H., Park, J. A., Jang, Y. S., Lee, K. M., Lee, D. S., Ahn, B. M., et al. (2001). Case of acute cholestatic hepatitis caused by the seeds of Psoralea-corylifolia. Korean J. Hepatol. 7, 341-344.

Hyde, F. F. (1981). Mistletoe hepatitis. Br. Med. J. 282, 739.

IARC Monographs. (2002). Vol. 82. Introduction 1. History of Use Of Traditional Herbal Medicines. Available online at: http://monographs.iarc.fr/ENG/ Monographs/vol82/mono82-6A.pdf (Accessed December 30, 2014).

Inoue, H., Yamazaki, S., Shimizu, M., Uozki, H., Goto, T., Ohnishi, S., et al. (2011). Liver injury induced by the Japanese herbal drug kamishoyosan. Gastroenterol. Hepatol. 7, 692-695.

Itoh, S., Marutani, K., Nishijima, T., Matsuo, S., and Itabashi, M. (1995). Liver injuries induced by herbal medicine, Syo-saiko-to (xiao-chai-hu-tang). Dig. Dis. Sci. 40, 1845-1848.

Jang, J. S., Seo, E. G., Han, C., Chae, H. B., Kim, S. J., Lee, J. D., et al. (2008). Four cases of toxic liver injury associated with Dictamnus dasycarpus. Korean J. Hepatol. 14, 206-212. doi: 10.3350/kjhep.2008.14.2.206

Javaid, A., and Bonkovsky, H. L. (2006). Hepatotoxicity due to extracts of Chinese green tea (Camellia sinensis): a growing concern. J. Hepatol. 45, 334-335. doi: 10.1016/j.jhep.2006.05.005

Jimenez-Saenz, M., and Martinez-Sanchez M del, C. (2006). Acute hepatitis associated with the use of green tea infusions. J. Hepatol. 44, 616-617. doi: 10.1016/j.jhep.2005.11.041

Jóhannsson, M., Ormarsdóttir, S., and Olafsson, S. (2010). Hepatotoxicity associated with the use of Herbalife. Laeknabladid 96, 167-172.

Jones, F. J., and Andrews, A. H. (2007). Acute liver injury associated with the herbal supplement hydroxycut in a soldier deployed to Iraq. Am. J. Gastroenterol. 102, 2357-2358. doi: 10.1111/j.1572-0241.2007.01353_10.x

Jorge, O. A., and Jorge, A. D. (2005). Hepatotoxicity associated with the ingestion of Centella asiatica. Rev. Esp.Enferm. Dig. 97, 115-124. doi: 10.4321/S113001082005000200006

Joshi, D., Cross, T. J. S., and Wong, V. S. (2007). Acute drug induced hepatitis secondary to a weight loss product purchased over the internet. Nutr. J. 6 :13. doi: 10.1186/1475-2891-6-13

Jung, K. A., Min, H. J., Yoo, S. S., Kim, H. J., Choi, S. N., Ha, C. Y., et al. (2011). Drug-induced liver injury: twenty five cases of acute hepatitis following ingestion of Polygonum multiflorum Thun. Gut Liver 5, 493-499. doi: 10.5009/gnl.2011.5.4.493

Kakar, F., Akbarian, Z., Leslie, T., Mustafa, M. L., Watson, J., van Egmond, H. P., et al. (2010). An outbreak of hepatic veno-occlusive disease in western Afghanistan associated with exposure to wheat flour contaminated with pyrrolizidine alkaloids. J. Toxicol. 2010:313280. doi: 10.1155/2010/313280

Kamiyama, T., Nouchi, T., Kojima, S., Murata, N., Ikeda, T., and Sato, C. (1997). Autoimmune hepatitis triggered by administration of an herbal medicine. Am. J. Gastroenterol. 92, 703-704.

Kanat, O., Ozet, A., and Ataegin, S. (2006). Aloe vera-induced acute toxic hepatitis in a healthy young man. Eur. J. Intern. Med. 17, 589. doi: 10.1016/j.ejim.2006.04.017

Kanda, T., Yokosuka, O., Okada, O., Suzuki, Y., and Saisho, H. (2003a). Severe hepatotoxicity associated with Chinese diet product "Ohnshidou-Genbi-Kounou." J. Gastroeneterol. Hepatol. 18, 354-355. doi: 10.1046/j.1440-1746.2003.02952.x

Kanda, T., Yokosuka, O., Tada, M., Kurihara, T., Yoshida, S., Suzuki, Y., et al. (2003b). N-nitroso-fenfluramine hepatotoxicity resembling chronic hepatitis. J. Gastroenterol. Hepatol. 18, 999-1000. doi: 10.1046/j.1440-1746.2003. 03074.x

Kane, J. A., Kane, S. P., and Jain, S. (1995). Hepatitis induced by traditional Chinese herbs: possible toxic components. Gut 36, 146-147. 
Kang, H. S., Choi, H. S., Yun, T. J., Lee, K. G., Seo, Y. S., Yeon, J. E., et al. (2009). A case of acute cholestatic hepatitis induced by Corydalis speciosa Max. Korean J. Hepatol. 15, 517-523. doi: 10.3350/kjhep.2009.15.4.517

Kang, S. H., Kim, J. I., Jeong, K. H., Ko, K. H., Ko, P. G., Hwang, S. W., et al. (2008). Clinical characteristics of 159 cases of acute toxic hepatitis. Korean J. Hepatol. 14, 483-484. doi: 10.3350/kjhep.2008.14.4.483

Kang-Yum, E., and Oransky, S. H. (1992). Chinese patent medicine as a potential source of mercyry poisoning. Vet. Hum. Toxicol. 34, 235-238.

Kao, W. F., Hung, D. Z., Tsai, W. J., Lin, K. P., and Deng, J. F. (1992). Podophyllotoxin intoxication: toxic effect of Bajiaolian in herbal therapeutics. Hum. Exp. Toxicol. 11, 480-487.

Kaplowitz, N. (2001). Causality assessment versus guilt-by-association in drug hepatotoxicity. Hepatology 33, 308-310.

Katz, M., and Saibil, F. (1990). Herbal hepatitis: subacute hepatic necrosis secondary to chaparral leaf. J. Clin. Gastroenterol. 12, 203-206.

Kim, S. Y., Yim, H. J., Ahn, J. H., Kim, J. H., Kim, J. N., Yoon, I., et al. (2009). Two cases of toxic hepatitis caused by arrowroot juice. Korean J. Hepatol. 15, 504-509. doi: 10.3350/kjhep.2009.15.4.504

Kim, Y. J., Ryu, S. L., Shim, J. W., Kim, D. S., Shim, J. Y., Park, M. S., et al. (2012). A pediatric case of toxic hepatitis induced by Hovenia dulcis. Pediatr. Gastroenterol. Hepatol. Nutr. 15, 111-116. doi: 10.5223/pghn.2012.15.2.111

Ko, R. J. (1998). Adulterants in Asian patent medicines. N. Engl. J. Med. 339, 847.

Kramer, M. S. (1986). Assessing causality of adverse drug reactions: global introspection and its limitations. Dug Inf. J. 20, 433-437.

Kumana, C. R., Ng, M., Lin, H. J., Ko, W., Wu, P. C., and Todd, D. (1983). Hepatic veno-occlusive disease due to toxic alkaloid in herbal tea. Lancet 2, 1360-1361.

Kumana, C. R., Ng, M., Lin, H. J., Ko, W., Wu, P. C., and Todd, D. (1985). Herbal tea induced hepatic veno-occlusive disease: quantification of toxic alkaloid exposure in adults. Gut 26, 101-104.

Laird, A. R., Ramchandani, N., deGoma, E. M., Avula, B., Khan, I. A., and Gesundheit, N. (2008). Acute hepatitis associated with the use of an herbal supplement (Polygonum multiflorum) mimicking iron-overload syndrome. Clin. Gastroenterol. 42, 861-862. doi: 10.1097/MCG.0b013e3181492515

Laliberté L., and Villeneuve, J. P. (1996). Hepatitis after the use of germander, a herbal remedy. Can. Med. Ass. J. 154, 1689-1692.

Lapi, F., Gallo, E., Giocaliere, E., Vietri, M., Baronti, R., Pieraccini, G., et al. (2010). Acute liver damage due to Serenoa repens: a case report. Br. J. Clin. Pharmacol. 69, 558-560. doi: 10.1111/j.1365-2125.2010.03618.x

Larrey, D. (1997). Hepatotoxicity of herbal remedies. J. Hepatol. 26(Suppl. 1), 47-51.

Larrey, D., and Faure, S. (2011). Herbal medicine hepatotoxicity: a new step with development of specific biomarkers. J. Hepatol. 54, 599-601. doi: 10.1016/j.jhep.2010.12.003

Larrey, D., Vial, T., Pauwels, A., Castot, A., Biour, M., David, M., et al. (1992). Hepatitis after germander (Teucrium chamaedrys) administration: another instance of herbal medicine hepatotoxicity. Ann. Intern. Med. 117, 129-132.

Lau, G., Lo, D. S., Yao, Y. J., Leong, H. T., Chan, C. L., and Chu, S. S. (2004). A fatal case of hepatic failure possibly induced by nitrosofenfluramine: a case report. Med. Sci. Law 44, 252-263. doi: 10.1258/rsmmsl.44.3.252

Lebot, V. (2006). The quality of kava consumed in the South Pacific. HerbalGram $71,34-37$.

Lee, C. H., Wang, J. D., and Chen, P. C. (2011). Risk of liver injury associated with Chinese herbal products containing Radix bupleuri in 639,779 patients with hepatitis B virus infection. PLoS ONE 6:e16064. doi: 10.1371/journal.pone.0016064

Leonti, M., and Casu, L. (2013). Traditional medicine and globalization: current and future perspectives in ethnopharmacology. Front. Pharmacol. 4:92. doi: 10.3389/fphar.2013.00092

Levitsky, J., Alli, T. A., Wisecarver, J., and Sorrell, M. F. (2005). Fulminant liver failure associated with the use of black cohosh. Dig. Dis. Sci. 50, 538-539. doi: 10.1007/s10620-005-2470-7

Levitsky, J., Alli, T. A., Wisecarver, J., and Sorrell, M. F. (2008). Fulminant liver failure associated with the use of black cohosh. Dig. Dis. Sci. 53, 869. doi: 10.1007/s10620-007-9907-0

Lewis, J. H. (2014). Causality assessment: which is best - expert opinion or RUCAM? Clin. Liver Dis. 4, 4-8. doi: 10.1002/cld.365

Li, C., Liang, X. S., and Li, C. Z. (2010). Sinusoidal obstruction syndrome associated with the ingestion of gynura root. Clin. Toxicol. 48, 962-964. doi: $10.3109 / 15563650.2010 .527851$
Li, J., Lu, C., Jiang, M., Niu, X., Guo, H., Li, L., et al. (2012). Traditional Chinese medicine-based network pharmacology could lead to new multicompound drug discovery. Evid. Based Complement Alternat. Med. 2012:149762. doi: 10.1155/2012/149762

Lin, G., Wang, J. Y., Li, N., Li, M., Gao, H., Ji, Y., et al. (2011). Hepatic sinusoidal obstruction syndrome associated with consumption of Gynura segetum. J. Hepatol. 54, 666-673. doi: 10.1016/j.jhep.2010.07.031

Lin, T. J., Su, C. C., Lan, C. K., Jiang, D. D., Tsai, J. L., and Tsai, M. S. (2003). Acute poisonings with Breynia officinalis - an outbreak of hepatotoxicity. J. Toxicol. Clin. Toxicol. 41, 591-594. doi: 10.1081/CLT-120023760

Lin, T. J., Tsai, M. S., Chiou, N. M., Deng, J. F., and Chiu, N. Y. (2002). Hepatotoxicity caused by Breynia officinalis. Vet. Hum. Toxicol. 44, 87-88.

Lindstrom, A., Ooyen, C., Lynch, M. E., Blumenthal, M., and Kawa, K. (2014). Sales of herbal dietary supplements increase by $7.9 \%$ in 2013, marking a decade of rising sales. HerbalGram 103, 52-56.

Linnebur, S. A., Rapacchietta, O. C., and Vejar, M. (2010). Hepatotoxicity associated with chinese skullcap contained in Move Free Advanced dietary supplement: two case reports and review of the literature. Pharmacotherapy 750, 258e-262e. doi: 10.1592/phco.30.7.750

Liss, G., and Lewis, J. H. (2009). Drug-induced liver injury: what was new in 2008? Expert Opin. Drug. Metab. Toxicol. 5, 843-860. doi: $10.1517 / 17425250903018904$

Liu, Y., Li, Z., Liu, X., and Pan, R. (2014). Review on the toxic effects of radix Bupleuri. Curr. Opin. Complement Altern. Med. 1, 3-7.

López-Cepero Andrada, J. M., Lerma Castilla, S., Fernandèz Olvera, M. D., and Amaya Vidal, A. (2007). Hepatotoxicity caused by a Noni (Morinda citrifolia) preparation. Esp. Patol. Dig. 99, 179-181.

Ma, X., Peng, J. H., and Hu, Y. Y. (2014). Chinese herbal medicine-induced liver injury. J. Clin. Transl. Hepatol. 2, 170-175. doi: 10.14218/JCTH.2014. 00009

MacGregor, F. B., Abernethy, V. E., Dahabra, S., Cobden, I., and Hayes, P. C. (1989). Hepatotoxicity of herbal remedies. Br. Med. J. 299, 1156-1157. doi: 10.1136/bmj.299.6708.1156

Mahady, G. B., Low Dog, T., Barrett, M. L., Chavez, M. L., Gardiner, P., Ko, R., et al. (2008). United States Pharmacopeia review of the black cohosh case reports of hepatotoxicity. Menopause 15, 628-638. doi: 10.1097/gme.0b013e3181 $6054 \mathrm{bf}$

Major, R. H. (1954). History of Medicine Vol. 1. Springfield: Charles C. Thomas Publisher.

Manheimer, E., Wieland, S., Kimbrough, E., Cheng, K., and Berman, B. M. (2009). Evidence from the Cochrane Collaboration for traditional Chinese Medicine therapies. J. Altern. Complement. Med. 15, 1001-1004. doi: 10.1089/acm.2008.0414

Manso, G. (2012). Author's reply. Pharmacoepidemiol. Drug Saf. 21, 335. doi: $10.1002 /$ pds.3201

Manso, G., López-Rivas, L., Salgueiro, M. E., Duque, J. M., Jimeno, F. J., Andrade, R. J., et al. (2011). Continuous reporting of new cases in Spain supports the relationship between Herbalife products and liver injury. Pharmacoepidemiol. Drug Saf. 20, 1080-1087. doi: 10.1002/pds.2180

Manso, G., López-Rivaz, L., Duque, J. M., and Salgueiro, E. (2008). Spanish reports of hepatotoxicity associated with Herbalife. J. Hepatol. 49, 289-290. Author reply 290-292.

Martinez-Sierra, C., Rendon Unceta, P., and Martin Herrera, L. (2006). Acute hepatitis after green tea ingestion. Med. Clin. (Barc) 127, 119

Mathieu, N., Bouallegue, L., Mognol, P., Vallot, T., and Soule, J. C. (2005). Hepatic toxicity probably due to X-elles in phytotherapy. Gastroenterol. Clin. Biol. 29, 1188-1189. doi: 10.1016/S0399-8320(05)82193-1

Mattéi, A., Rucay, P., Samuel, D., Feray, C., Michel, R., and Bismuth, H. (1995). Liver transplantation for acute liver failure after herbal medicine ( $\mathrm{Teu}$ crium polium) administration (letter). J. Hepatol. 22, 597. doi: 10.1016/01688278(95)80458-7

Mazzanti, G., Menniti-Ippolito, F., Moro, P. A., Cassetti, F., Raschetti, R., Santuccio, C., et al. (2009). Hepatotoxicity from green tea: a review of the literature and two unpublished cases. Eur. J. Clin. Pharmacol. 65, 331-341. doi: 10.1007/s00228-008-0610-7

McDonnell, W. M., Bhattacharya, R., and Halldorson, J. B. (2009). Fulminant hepatic falure after use of the herbal weight-loss supplement Exilis. Ann. Intern. Med. 151, 673-674. doi: 10.7326/0003-4819-151-9-20091103000021 
McGee, J., Patrick, R. S., Wood, C. B., and Blumgart, L. H. (1976). A case of venoocclusive disease of the liver in Britain associated with herbal tea consumption. J. Clin. Pathol. 29, 788-794. doi: 10.1136/jcp.29.9.788

Mennecier, D., Saloum, T., Dourthe, P. M., Bronstein, J. A., Thiolet, C., and Farret, O. (1999). Acute hepatitis after phytotherapy. Présse Med. 28, 966.

MHRA. (2014). Herbal Medicines Regulation: Registered Traditional Herbal Medicines. Available online at: http://www.mhra.gov.uk/Howweregulate/ Medicines/Herbalmedicinesregulation/RegisteredTraditionalHerbalMedicines (Accessed December 30, 2014).

Millonig, G., Stadlmann, S., and Vogel, W. (2005). Herbal hepatotoxicity: acute hepatitis caused by a Noni preparation (Morinda citrifolia). Eur. J. Gastroenterol. Hepatol. 17, 445-447. doi: 10.1097/00042737-200504000-00009

Miljkovic, M. M., Dobric, S., Dragojevic-Simic, V. (2011). Consistency between causality assessments obtained with two scales and their agreement with clinical judgments in hepatotoxicity. Pharmacoepidemiol. Drug Saf. 20, 272-285.

Miskelly, F. G., and Goodyer, L. I. (1992). Hepatic and pulmonary complications of herbal medicine (letter). Postgrad. Med. J. 68, 935. doi: 10.1136/pgmj.68.805.935

Mohabbat, O., Younos, M. S., Merzad, A. A., Srivastava, R. N., Sediq, G. G., and Aram, G. N. (1976). An outbreak of hepatic veno-occlusive disease in north-western Afghanistan. Lancet 308, 269-271. doi: 10.1016/S0140-6736(76) 90726-1

Mokhobo, K. P. (1976). Herb use and necrodegenerative hepatitis. S. Afr. Med. J. 50, 1096-1099.

Molinari, M., Watt, K. D., Kruszyna, T., Nelson, R., Walsh, M., Huang, W. Y., et al. (2006). Acute liver failure induced by green tea extracts: case reports and review of the literature. Liver Transpl. 12, 1892-1895. doi: 10.1002/lt.21021

Moro, P. A., Cassetti, F., Giugliano, G., Falce, M. T., Mazzanti, G., MennitiIppolito, F., et al. (2009). Hepatitis from Greater celandine (Chelidonium majus L.): review of literature and report of a new case. J. Ethnopharmacol. 124, 328-332. doi: 10.1016/j.jep.2009.04.036

Mostefa-Kara, N., Pauwels, A., Pines, E., Biour, M., and Levy, V. G. (1992). Fatal hepatitis after herbal tea (letter). Lancet 340, 674. doi: 10.1016/01406736(92)92209-X

Motoyama, H., Enomoto, M., Yasuda, T., Fujii, H., Kobayashi, S., Iwai, S., et al. (2008). Drug-induced liver injury caused by a herbal medicine, bofu-tsu-shosan. Nihon Shokakibyo Gakkai Zasshi 105, 1234-1239.

Mrzljak, A., Kosuta, I., Skrtic, A., Kanizaj, T. F., and Vrhovac, R. (2013). Druginduced liver injury associated with Noni (Morinda citrifolia) juice and phenobarbital. Case Rep. Gastroenterol. 7. 19-24. doi: 10.1159/000343651

Nadir, A., Agrawal, S., King, P. D., and Marshall, J. B. (1996). Acute hepatitis associated with the use of a Chinese herbal product, ma-huang. Am. J. Gastroenterol. 91, 1436-1438.

Nadir, A., Reddy, D., and Van Thiel, D. H. (2000). Cascara sagrada-induced intrahepatic cholestasis causing portal hypertension: case report and review of herbal hepatotoxicity. Am. J. Gastroenterol. 95, 3634-3637. doi: 10.1111/j.15720241.2000.03386.x

Nahin, R. L., Barnes, P. M., Stussman, B. J., and Bloom, B. (2009). Costs of Complementary and Alternative Medicine (CAM) and Frequency of Visits to CAM Practitioners: United States, 2007. National Health Statistics Reports; no. 18. Hyattsville, MD: National Center for Health Statistics. Available online at: http://www.cdc.gov/nchs/data/nhsr/nhsr018.pdf (Accessed December 30, 2014).

Nam, S. W., Baek, J. T., Lee, D. S., Kang, S. B., Ahn, B. M., and Chung, K. W. (2005). A case of acute cholestatic hepatitis associated with the seeds of Psoralea corylifolia (Boh-Gol-Zhee). Clin. Toxicol. 43, 589-5891. doi: 10.1081/CLT-200068863

Naranjo, C. A., Busto, U., Sellers, E. M., Sandor, P., Ruiz, I., Roberts, E. A., et al. (1981). A method for estimating the probability of adverse drug reactions. Clin. Pharmacol. Ther. 30, 239-245. doi: 10.1038/clpt.1981.154

Naser, B., Schnitker, J., Minkin, M. J., de Arriba, S. G., Nolte, K. U., and Osmers, R. (2011). Hepatotoxicity suspected by black cohosh: No evidence by metaanalysis of randomized controlled clinical trials for isopropanolic black cohosh extract. Menopause 18, 366-375. doi: 10.1097/gme.0b013e3181fcb2a6

Navarro, V. J. (2009). Herbal and dietary supplement hepatotoxicity. Semin. Liver Dis. 29, 373-382. doi: 10.1055/s-0029-1240006

Navarro, V. J., Barnhart, H., Bonkovsky, H. L., Davern, T., Fontana, R. J., Grant, L., et al. (2014). Liver injury from herbals and dietary supplements in the U.S. Drug-Induced Liver Injury Network. Hepatology 60, 1399-1408. doi: 10.1002/hep. 27317
Navarro, V. J., Bonkovsky, H. L., Hwang, S. I., Vega, M., Barnhart, H., and Serrano, J. (2013). Catechins in dietary supplements and hepatotoxicity. Dig. Dis. Sci. 58, 2682-2690. doi: 10.1007/s10620-013-2687-9

Nebraska. (2006). Nebraska Judgement of 8. September 2006. Available onlie at: http://ahpa.org/portals/0/pdfs/06_0908_Blackcohosh_NebraskaDistrictCt.pdf (Accessed 30 December 3 2014).

NIH. (2013). National Institutes of Health, National Center for Complementary and Alternative medicine (NCCAM). Traditional Chinese medicine: An introduction. Last Updated October 2013. Available online at: http://nccam.nih.gov/health/ whatiscam/chinesemed.htm (Accessed December 30, 2014).

NIH. (2014a). National Institutes of Health, National Center for Complementary and Alternative medicine (NCCAM). LiverTox. Drug record. Overview: Herbals and dietary supplements. introduction. Last Updated 04 November 2014. Available online at: http://livertox.nih.gov/Herbals_and_Dietary_Supplements.htm (Accessed December 30, 2014).

NIH. (2014b). National Institutes of Health, National Institute of Diabetes and Digestive and Kidney Diseases (NIDDK). LiverTox. Agents included in LiverTox by drug class. Last Updated 4 November 2014. Available online at: http://livertox. nih.gov/drugliverinjury.html (Accessed December 30, 2014).

NIH. (2014c). National Institutes of Health (NIH) and LiverTox: Drug Record. Ba Jiao Lian (Dysosma pleianthum). Last Updated19 May 2014. Available online at: http://livertox.nih.gov/BaJiaoLian.htm (Accessed December 30, 2014).

Nishimura, K., Plotnikoff, G. A., and Watanabe, K. (2009). Kampo medicine as an integrative medicine in Japan. JMAJ 52, 147-149.

Panis, B., Wong, D. R., Hooymans, P. M., De Smet, P. A. G. M., and Rosias, P. R. (2005). Recurrent toxic hepatitis in a Caucasian girl related to the use of Shou-Wu-Pian, a Chinese herbal preparation. J. Pediat. Gastroenterol. Nutr. 41, 256-258. doi: 10.1097/01.MPG.0000164699.41282.67

Park, G. J. H., Mann, S. P., and Ngu, M. C. (2001). Acute hepatitis induced by Shou-Wu-Pian, a herbal product derived from Polygonum multiflorum. J. Gastroenterol. Hepatol. 16, 115-117. doi: 10.1046/j.1440-1746.2001. 02309.x

Park, H. L., Lee, H. S., Shin, B. C., Liuk, J. P., Shang, Q., Yamashita, H., et al. (2012). Traditional medicine in China, Korea, and Japan: a brief introduction and comparison. Evid. Based Complement Alternat. Med. 2012:429103 doi: $10.1155 / 2012 / 429103$

Patwardhan, B., Warude, D., Pushpangadan, P., and Bhatt, N. (2005). Ayurveda and traditional Chinese medicine: a comparative overview. Evid. Based Complement Alternat. Med. 2, 465-473. doi: 10.1093/ecam/neh140

Pelkonen, O., Xu, O., and Fan, T. P. (2014). Why is research on herbal medicinal products important and how can we improve quality? J Tradit. Complement Med. 4, 1-7. doi: 10.4103/2225-4110.124323

Perharic-Walton, L., and Murray, V. (1992). Toxicity of traditional Chinese herbal remedies. Lancet 340, 674.

Peyrin-Biroulet, L., Petitpain, N., Kalt, P., Ancel, D., Petit-Laurent, F., Trechot, P., et al. (2004). Probable hepatotoxicity from epigallocatecol gallate used for phytotherapy. Gastroenterol. Clin. Biol. 28, 404-406. doi: 10.1016/S03998320(04)94944-5

Picciotti, A., Campo, N., Brizzolara, R., Giusto, R., Guido, G., Sinelli, N., et al. (1998). Chronic hepatitis induced by Jin Bu Huan. J. Hepatol. 28, 165-167. doi: 10.1016/S0168-8278(98)80217-1

Pittler, M. H., and Ernst, E. (2003a). Kava Extract for Treating Anxiety (Cochrane Review). Cochrane Database Syst Rev 2003a; Issue 1: CD003383. Wiley Interscience. Available online at: Cochrane Database Syst Rev. (2):CD003383. (Accessed December 30, 2014. doi: 10.1002/14651858

Pittler, M. H., and Ernst, E. (2003b). Systematic review: hepatotoxic events associated with herbal medicinal products. Aliment Pharmacol. Ther. 18, 451-471. doi: 10.1046/j.1365-2036.2003.01689.x

Podsadzki, P., Watson, L. K., and Ernst, E. (2013). Adverse effects of herbal medicines: an overview of systematic reviews. Clin. Med. 13, 7-12. doi: 10.7861/clinmedicine.13-1-7

Popat, A., Shear, N. H., Malkiewicz, I., Stewart, M. J., Steenkamp, V., Thomson, S., et al. (2001). The toxicity of Callilepis laureola, a South African traditional herbal medicine. Clin. Biochem. 34, 229-236. doi: 10.1016/S00099120(01)00219-3

Rabe, C., Musch, A., Schirrmacher, P., Kruis, W., and Hoffmann, R. (2005). Acute hepatitis induced by an aloe vera preparation: a case report. World J. Gastroenterol. 11, 303-304. doi: 10.3748/wjg.v11.i2.303 
Raghavendra, H. L., Yogesh, H. S., Gopalakrishna, B., Chardrashkhar, V. M., Sathish Kumar, B. P., and Kumar, V. (2009). An overview of herbal medicine. Int. J. Pharmaceut. Sci. 1, 1-20.

Ramachandran, R., and Kakar, S. (2009). Histological patterns in drug-induced liver disease. J. Clin. Pathol. 62, 481-492. doi: 10.1136/jcp.2008.058248

Reuben, A., Koch, D. G., Lee, W. M., and the Acute Liver Failure Study Group. (2010). Drug-induced acute liver failure: results of a U.S. multicenter, prospective study. Hepatology 52, 2065-2076. doi: 10.1002/hep.23937

Ridker, P. M., and McDermott, W. V. (1989). Comfrey herbs tea and hepatic venoocclusive disease. Lancet 333, 657-658. doi: 10.1016/S0140-6736(89)92154-5

Ridker, P. M., Ohkuma, S., McDermott, W. V., Trey, C., and Huxtable, R. J. (1985). Hepatic venoocclusive disease associated with the consumption of pyrrolizidine-containing dietary supplements. Gastroenterology 88, 1050-1054

Rifai, K., Flemming, P., Manns, M. P., and Trautwein, C. (2006). Severe drug hepatitis caused by Chelidonium majus. Internist 47, 749-751. doi: 10.1007/s00108006-1617-8

Robles-Diaz, M., Gonzalez-Jimenez, A., Medina-Caliz, I., Stephens, C., GarcíaCortes, M., García-Muñoz, B., et al. (2015). Distinct phenotype of hepatotoxicity associated with illicit use of anabolic androgenic steroids. Aliment Pharmacol. Ther. 41, 116-125.

Rochon, J., Protiva, P., Seeff, L. B., Fontana, R. J., Liangpunsakul, S., Watkins, P. B., et al. (2008). Reliability of the Roussel Uclaf Causality Assessment Method for assessing causality in drug-induced liver injury. Hepatology 48, 1175-1183. doi: 10.1002/hep.22442

Rohde, J., Jacobsen, C., and Kromann-Andersen, H. (2011). Toxic hepatitis triggered by green tea. Ugeskr Laeger 173, 205-220.

Roselle, H., Ekatan, A., Tzeng, J., Sapienza, M., and Kocher, J. (2008). Symptomatic hepatitis associated with the use of herbal Red Yeast Rice. Ann. Intern. Med. 149, 516-517. doi: 10.7326/0003-4819-149-7-200810070-00021

Roulet, M., Laurini, R., Rivier, L., and Calame, A. (1988). Hepatic veno-occlusive disease in newborn Infant of a woman drinking herbal tea. J. Pediatr. 112, 433-436. doi: 10.1016/S0022-3476(88)80330-5

Russmann, S., Barguil, Y., Cabalion, P., Kritsanida, M., Duhet, D., and Lauterburg, B. H. (2003). Hepatic injury due to traditional aqueous extracts of kava root in New Caledonia. Eur. J. Gastroenterol. Hepatol. 15, 1033-1036. doi: 10.1097/00042737-200309000-00015

Sangsuwan, C., Udompanthurak, S., Vannasaeng, S., and Thamlikitkul, V. (2004). Randomized controlled trial of Tinospora crispa for additional therapy in patients with type 2 diabetes mellitus. J. Med. Assoc. Thai 87, 543-546.

Sarma, D. N., Barrett, M. L., Chavez, M. L., Gardiner, P., Ko, R., Mahady, G. B., et al. (2008). Safety of green tea extract: a systematic review by the US Pharmacopeia. Drug Saf. 31, 469-484. doi: 10.2165/00002018-200831060-00003

Sarris, J., Kavanagh, D. J., Byrne, G., Bone, K. M., Adams, J., and Deed, G. (2009). The Kava Anxiety Depression Spectrum Study (KADSS): a randomized, placebo-controlled crossover trial using an aqueous extract of Piper methysticum. Psychopharmacology 205, 399-407. doi: 10.1007/s00213-009-1549-9

Sarris, J., Stough, C., Bousman, C. A., Wahid, T., Murray, G., Teschke, R., et al. (2013). Kava in the treatment of generalized anxiety disorder: a double-blind, randomized, placebo-controlled study. J. Clin. Psychopharmacol. 33, 643-648. doi: 10.1097/JCP.0b013e318291be67

Schmidt, M. (2007). Quality criteria for kava. HerbalGram 73, 45-49.

Schmidt, M. (2014). German court ruling reverses kava ban; German regulatory authority appeals decision. HerbalGram 103, 38-42.

Schmidt, M., Morgan, M., Bone, K., and McMillan, J. (2005). "Kava: a risk-benefit assessment," in The Essential Guide to Herbal Safety, eds M. Mills and K. Bone K (St. Louis: Elsevier Churchill Livingstone), 155-221.

Schoepfer, A. M., Engel, A., Fattinger, K., Marbet, U. A., Criblez, D., Reichen, J., et al. (2007). Herbal does not mean innocuous: ten cases of severe hepatotoxicity associated with dietary supplements from Herbalife products. J. Hepatol. 47, 521-526. doi: 10.1016/j.jhep.2007.06.014

Schulze, J., Raasch, W., and Siegers, C. P. (2003). Toxicity of kava pyrones, drug safety and precautions - a case study. Phytomedicine 10(Suppl. IV), 68-73. doi: 10.1078/1433-187X-00300

Seeff, L. B. (2007). Are herbals as safe as their advocates believe? J. Hepatol. 50, $13-16$.

Seybold, U., Landauer, L., Hillebrand, S., and Goebel, F. D. (2004). Sennainduced hepatitis in a poor metabolizer. Ann. Intern. Med. 141, 650-651. doi: 10.7326/0003-4819-141-8-200410190-00024
Sgro, C., Clinard, F., Ouazir, K., Chanay, H., Allard, C., Guilleminet, C., et al. (2002). Incidence of drug-induced hepatic injuries: a French population-based study. Hepatology 36, 451-455. doi: 10.1053/jhep.2002.34857

Sheikh, N. M., Philen, R. M., and Love, L. A. (1997). Chaparralassociated hepatotoxicity. Arch. Intern. Med. 157, 913-919. doi: 10.1001/archinte.1997.00440290099011

Shim, M., and Saab, S. (2009). Severe hepatotoxicity due to Hydroxycut: a case report. Dig. Dis. Sci. 54, 406-408. doi: 10.1007/s10620-008-0353-4

Skoulidis, F., Alexander, G. J., and Davies, S. E. (2005). Ma huang associated acute liver failure requiring liver transplantation. Eur. J. Gastroenterol. Hepatol. 17, 581-584. doi: 10.1097/00042737-200505000-00017

Smith, B. C., and Desmond, P. V. (1993). Acute hepatitis induced by the ingestion of the herbal medication chaparral. Aust. N. Z. J. Med. 23, 526. doi: 10.1111/j.1445-5994.1993.tb01846.x

Smith, L. W., and Culvenor, C. C. J. (1981). Plant sources of hepatotoxic pyrrolizidine alkaloids. J. Nat. Prod. 44, 129-152. doi: 10.1021/np50014a001

Sohn, C. H., Cha, M. I., Oh, B. J., Yeo, W. H., Lee, J. H., Kim, W., et al. (2008). Liver transplantation for acute toxic hepatitis due to herbal medicines and preparations. J. Korean Soc. Clin. Toxicol. 6, 110-116.

Sperl, W., Stuppner, H., Gassner, I., Judmaier, W., Dietze, O., and Vogel, W. (1995). Reversible hepatic veno-occlusive disease in an infant after consumption of pyrrolizidine-containing herbal tea. Eur. J. Pediatr. 154, 112-116. doi: 10.1007/BF01991912

Stadlbauer, V., Fickert, P., Lackner, C., Schmerlaib, J., Krisper, P., Trauner, M., et al. (2005). Hepatotoxicity of NONI juice: report of two cases. World J. Gastroenterol. 11, 4758-4760.

Stadlbauer, V., Weiss, S., Payer, F., and Stauber, R. E. (2008). Herbal does not at all mean innocuous: the sixth case of hepatotoxicity associated with Morinda citrifolia (Noni). Am. J. Gastroenterol. 103, 2406-2407. doi: 10.1111/j.15720241.2008.02010_8.x

Stammschulte, T., and Gundert-Remy, U. (2012). Letter to the Editor. Regul. Toxicol. Pharmacol. 64:342.

Starakis, I., Siagris, D., Leonidou, L., Mazakopakis, E., Tsamandas, A., and Karatza, C. (2006). Hepatitis caused by the herbal remedyTeucrium polium L. Eur. J. Gastroenterol. Hepatol. 18, 681-683. doi: 10.1097/00042737-200606000-00016

Stevens, T., Qadri, A., and Zein, N. N. (2005). Two patients with acute liver injury associated with use of the herbal weight-loss supplement hydroxycut. Ann Intern. Med. 14, 477-478. doi: 10.7326/0003-4819-142-6-200503150-00026

Stickel, F., Droz, S., Patsenker, E., Bögli-Stuber, K., Aebi, B., and Leib, S. L. (2009). Severe hepatotoxicity following ingestion of Herbalife nutritionally supplements contaminated with Bacillus subtilis. J. Hepatol. 50, 111-117. doi: 10.1016/j.jhep.2008.08.017

Stickel, F., Pöschl, G., Seitz, K. H., Waldherr, R., Hahn, E. G., and Schuppan, D. (2003). Acute hepatitis induced by Greater Celandine (Chelidonium majus). Scand. J. Gastroenterol. 38, 565-568. doi: 10.1080/00365520310000942

Stillman, A. S., Huxtable, R., Consroe, P., Kohnen, P., and Smith, S. (1977). Hepatic veno-occlusive disease due to pyrrolizidine (Senecio) poisoning in Arizona. Gastroenterology 73, 349-352.

Stirpe, F. (1983). Mistletoe hepatitis. Br. Med. J. 1, 29.

Strahl, S., Ehret, V., Dahm, H. H., and Maier, K. P. (1998). Necrotising hepatitis after taking herbal remedies. Dtsch. Med. Wschr. 123, 1410-1414. doi: $10.1055 / \mathrm{s}-2007-1024196$

Sullivan, J. B., Rumack, B. H., Thomas, H., Peterson, R. G., and Bryson, P. (1979). Pennyroyal oil poisoning and hepatotoxicity. JAM A 242, 2873-2974. doi: 10.1001/jama.1979.03300260043027

Tajiri, K., and Shimizu, Y. (2008). Practical guidelines and early management of drug-induced liver injury. W. J. Gastroenterol. 14, 6774-6785. doi: 10.3748/wig. 14.67774

Takegoshi, K., Tohyama, T., Okuda, K., Suzuki, K., and Ohta, G. (1986). A case of Venoplant-induced hepatic injury. Gastroenterol. Jpn. 21, 62-65.

Talari, P., Talari, G., Gundareddy, V., Vemula, P., and Barmecha, J. (2010). Acute Hepatitis Associated with the Chinese Herbal Product Bai Shi Wan. Available online at: http://www.toothpicks.info/rc2/ posters/2010/Internal_Medicine/Talari_P_Acute_hepatitis_asscciated.pdf (Accessed December 30, 2014).

Tandon, B. N., Tandon, H. D., Tandon, R. K., Narndranathan, M., and Joshi, Y. K. (1976a). An epidemic of veno-occlusive disease of the liver in central India. Lancet 308, 272. doi: 10.1016/S0140-6736(76)90727-3 
Tandon, H. D., Tandon, B. N., and Mattocks, A. R. (2008). An epidemic of veno-occlusive disease of the liver in Afghanistan. Am. J. Gastroenterol. 70, 607-613.

Tandon, R. K., Tandon, B. N., and Tandon, H. D. (1976b). Study of an epidemic of venoocclusive disease in India. Gut 17, 849-855. doi: 10.1136/gut.17.11.849

Tang, J. L., Zhan, S. Y., and Ernst, E. (1999). Review of randomised controlled clinical trials of traditional Chinese medicine. BMJ 319, 160-161. doi: 10.1136/bmj.319.7203.160

Tarantino, G., Di Minno, M. N. D., Pezullo, M. G., Pezzullo, L. S., Milone, F., Milone, M., et al. (2009). Drug-induced liver injury due to "natural products" used for weight loss: a case report. World J. Gastroenterol. 15, 2414-2417. doi: 10.3748/wjg.15.2414

Teschke, R. (2010a). Kava hepatotoxicity: a clinical review. Ann. Hepatol. 9, 251-265.

Teschke, R. (2010b). Kava hepatotoxicity: pathogenetic aspects and prospective considerations. Liver Int. 30, 1270-1279. doi: 10.1111/j.1478-3231.2010.02308.x

Teschke, R. (2010c). Black cohosh and suspected hepatotoxicity - inconsistencies, confounding variables, and prospective use of a diagnostic causality algorithm: a critical review. Menopause 17, 426-440. doi: 10.1097/gme.0b013e3181c5159c

Teschke, R. (2011). Special report. Kava and the risk of liver toxicity: past, current, and future. Am. Herbal Prod. Assoc. 26, 1-17.

Teschke, R. (2014). Traditional Chinese Medicine induced liver injury. J. Clin. Translat. Hepatol. 2, 80-94. doi: 10.14218/JCTH. (2009).2014.00003

Teschke, R., and Bahre, R. (2009). Severe hepatotoxicity by Indian Ayurvedic herbal products: a structured causality assessment. Ann. Hepatol. 8, 258-266.

Teschke, R., and Frenzel, C. (2014). Drug induced liver injury: do we still need a routine liver biopsy for diagnosis today? Ann. Hepatol. 13, 121-126.

Teschke, R., and Lebot, V. (2011). Proposal for a Kava Quality Standardization Code. Food Chem. Toxicol. 49, 2503-2516. doi: 10.1016/j.fct.2011.06.075

Teschke, R., and Schulze, J. (2010). Risk of kava hepatotoxicity and the FDA consumer advisory. JAMA 304, 2174-2175. doi: 10.1001/jama.2010.1689

Teschke, R., and Schulze, J. (2012). Suspected herbal hepatotoxicity: requirements for appropriate causality assessment by the US Pharmacopeia. Drug Saf. 12, 1091-1097. doi: 10.1007/BF03261996

Teschke, R., and Schwarzenboeck, A. (2009). Suspected hepatotoxicity by cimicifugae racemosae rhizoma (black cohosh, root): critical analysis and structured causality assessment. Phytomedicine 16, 72-84. doi: 10.1016/j.phymed.2008.09.009

Teschke, R., and Wolff, A. (2009). Kava hepatotoxicity: regulatory data selection and causality assessment. Dig. Liv. Dis. 41, 891-901. doi: 10.1016/j.dld.2009.04.003

Teschke, R., and Wolff, A. (2011). Regulatory causality evaluation methods applied in kava hepatotoxicity: are they appropriate? Regul. Toxicol. Pharmacol. 59, 1-7. doi: 10.1016/j.yrtph.2010.09.006

Teschke, R., Bahre, R., Genthner, A., Fuchs, J., Schmidt-Taenzer, W., and Wolff, A. (2009). Suspected black cohosh hepatotoxicity-challenges and pitfalls of causality assessment. Maturitas 63, 302-314. doi: 10.1016/j.maturitas.2009.05.006

Teschke, R., Eickhoff, A., and Schulze, J. (2013a). Drug and herb induced liver injury in clinical and translational hepatology: causality assessment methods, quo vadis? J. Clin. Translat. Hepatol. 1, 59-74. doi: 10.14218/JCTH.2013. D002X

Teschke, R., Eickhoff, A., Wolff, A., Frenzel, C., and Schulze, J. (2013b). Herbal hepatotoxicity and WHO global introspection method. Ann. Hepatol. 12, $11-21$.

Teschke, R., Frenzel, C., Glass, X., Schulze, J., and Eickhoff, A. (2012a). Greater Celandine hepatotoxicity: a clinical review. Ann. Hepatol. 11, 838-848.

Teschke, R., Frenzel, C., Glass, X., Schulze, J., and Eickhoff, A. (2013c). Herbal hepatotoxicity: a critical review. Br. J. Clin. Pharmacol. 75, 630-636. doi: 10.1111/j.1365-2125.2012.04395.x

Teschke, R., Frenzel, C., Schulze, J., and Eickhoff, A. (2012b). Spontaneous reports of primarily suspected herbal hepatotoxicity by Pelargonium sidoides: was causality adequately ascertained? Regul. Toxicol. Pharmacol. 63, 1-9. doi: 10.1016/j.yrtph.2012.02.009

Teschke, R., Frenzel, C., Schulze, J., and Eickhoff, A. (2012c). Suspected herbal hepatotoxicity: the pharmacovigilance dilemma with disputed and obsolete evaluation methods. Regul. Toxicol. Pharmacol. 64, 343-344. doi: 10.1016/j.yrtph.2012.06.010
Teschke, R., Frenzel, C., Schulze, J., and Eickhoff, A. (2013e). Herbal hepatotoxicity: challenges and pitfalls of causality assessment methods. World J. Gastroenterol. 19, 2864-2882. doi: 10.3748/wjg.v19.i19.2864

Teschke, R., Frenzel, C., Schulze, J., Schwarzenboeck, A., and Eickhoff, A. (2013d). Herbalife hepatotoxicity: evaluation of cases with positive reexposure tests. World J. Hepatol. 5, 353-363. doi: 10.4254/wjh.v5.i7.353

Teschke, R., Frenzel, C., Wolff, A., Eickhoff, A., and Schulze, J. (2014a). Drug induced liver injury: accuracy of diagnosis in published reports. Ann. Hepatol. $13,248-255$

Teschke, R., Frenzel, C., Wolff, A., Herzog, J., Glass, X., Schulze, J., et al. (2012d). Initially purported hepatotoxicity by Pelargonium sidoides: the dilemma of pharmacovigilance and proposals for improvements. Ann. Hepatol. 11, 500-512.

Teschke, R., Fuchs, J., Bahre, R., Genthner, A., and Wolff, A. (2010). Kava hepatotoxicity: comparative study of two structured quantitative methods for causality assessment. J. Clin. Pharm. Ther. 10, 545-563. doi: 10.1111/j.13652710.2009.01131.x

Teschke, R., Gaus, W., and Loew, D. (2003). Kava extracts: safety and risks including rare hepatotoxicity. Phytomedicine 10, 440-446. doi: 10.1078/0944-711300314

Teschke, R., Genthner, A., Wolff, A., Frenzel, C., Schulze, J., and Eickhoff, A. (2014b). Herbal hepatotoxicity: analysis of cases with initially reported positive reexposure tests. Dig. Liv. Dis. 46, 264-269. doi: 10.1016/j.dld.2013.10.020

Teschke, R., Glass, X., and Schulze, J. (2011a). Herbal hepatotoxicity by Greater Celandine (Chelidonium majus): causality assessment of 22 spontaneous reports. Regul. Toxicol. Pharmacol. 61, 282-291. doi: 10.1016/j.yrtph.2011.08.008

Teschke, R., Glass, X., Schulze, J., and Eickhoff, A. (2012e). Suspected Greater Celandine hepatotoxicity: liver specific causality evaluation of published case reports from Europe. Eur. J. Gastroenterol. Hepatol. 24, 270-280. doi: 10.1097/MEG.0b013e32834f993f

Teschke, R., Qiu, S. X., Xuan, T. D., and Lebot, V. (2011b). Kava and kava hepatotoxicity: requirements for novel experimental, ethnobotanical, and clinical studies based on a review of the evidence. Phytother. Res. 25, 1262-1274. doi: 10.1002/ptr.3464

Teschke, R., Sarris, J., and Lebot, V. (2011c). Contaminant hepatotoxins as culprits for hepatotoxicity - fact or fiction? Phytother. Res. 27, 472-474. doi: $10.1002 /$ ptr.4729

Teschke, R., Sarris, J., and Schweitzer, I. (2012f). Kava hepatotoxicity in traditional and modern use: the presumed Pacific kava paradox hypothesis revisited. Br. J. Clin. Pharmacol. 73, 170-174. doi: 10.1111/j.1365-2125.2011.04070.x

Teschke, R., Schmidt-Taenzer, W., and Wolff, A. (2011d). Spontaneous reports of assumed herbal hepatotoxicity by black cohosh: is the liver unspecific Naranjo scale precise enough to ascertain causality? Pharmacoepidemiol. Drug Saf. 20, 567-582. doi: $10.1002 /$ pds. 2127

Teschke, R., Schmidt-Taenzer, W., and Wolff, A. (2012g). USP suspected herbal hepatotoxicity: quality of causality assessment is more important than quantity of counted cases, not vice versa. Pharmacoepidemiol. Drug Saf. 21, 336-338. doi: $10.1002 /$ pds.3209

Teschke, R., Schulze, J., Schwarzenboeck, A., Eickhoff, A., and Frenzel, C. (2013g). Herbal hepatotoxicity: suspected cases assessed for alternative causes. Eur. J. Gastroenterol. Hepatol. 25, 1093-1098. doi: 10.1097/MEG.0b013e3283603e89

Teschke, R., Schwarzenboeck, A., and Akinci, A. (2008b). Kava hepatotoxicity: a European view. N.Z. Med. J. 121:1283.

Teschke, R., Schwarzenboeck, A., and Hennermann, K. H. (2008a). Kava hepatotoxicity: a clinical survey and critical analysis of 26 suspected cases. Eur. J. Gastroenterol. Hepatol. 20, 1182-1193. doi: 10.1097/MEG.0b013e3283036768

Teschke, R., Schwarzenboeck, A., and Hennermann, K. H. (2008c). Causality assessment in hepatotoxicity by drugs and dietary supplements. Br. J. Clin. Pharmacol. 66, 758-766. doi: 10.1111/j.1365-2125.2008.03264.x

Teschke, R., Schwarzenboeck, A., Eickhoff, A., Frenzel, C., Wolff, A., and Schulze, J. (2013f). Clinical and causality assessment in herbal hepatotoxicity. Expert Opin. Drug Saf. 12, 339-366. doi: 10.1517/14740338.2013.774371

Teschke, R., Schwarzenboeck, A., Schmidt-Taenzer, W., Wolff, A., and Hennermann, K. H. (2011e). Herb induced liver injury presumably caused by black cohosh: a survey of initially purported cases and herbal quality specifications. Ann. Hepatol. 11, 249-259. 
Teschke, R., Wolff, A., Frenzel, C., and Schulze, J. (2014c). Review article: herbal hepatotoxicity - an update on traditional Chinese medicine preparations. Aliment. Pharmacol. Ther. 40, 32-50. doi: 10.1111/apt.12798

Teschke, R., Wolff, A., Frenzel, C., Eickhoff, A., and Schulze, J. (2015a). Herbal traditional Chinese medicine and evidence base for gastrointestinal disorders. World J. Gastroenterol.

Teschke, R., Wolff, A., Frenzel, C., Schulze, J., and Eickhoff, A. (2012h). Herbal hepatotoxicity: a tabular compilation of reported cases. Liver Int. 32, 1543-1556. doi: 10.1111/j.1478-3231.2012.02864x

Teschke, R., Wolff, A., Frenzel, C., Schwarzenboeck, A., Schulze, J., and Eickhoff, A. (2014d). Drug and herb induced liver injury: Council for International Organizations of Medical Sciences scale for causality assessment. World J. Hepatol. 6, 17-32. doi: 10.4254/wjh.v6.i1.17

Teschke, R., Zhang, L., Long, H., Schwarzenboeck, A., Schmidt-Taenzer, W., Genthner, A., et al. (2015b). Traditional Chinese medicine and herbal hepatotoxicity: a tabular compilation of reported cases. Ann. Hepatol. 14, 7-19.

Teschke, R., Zhang, L., Melzer, L., Schulze, J., and Eickhoff, A. (2014e). Green tea extract and the risk of drug-induced liver injury. Expert Opin. Drug Metab. Toxicol. 10, 1663-1676. doi: 10.1517/17425255.2014.971011

Tsuda, T., Yashiro, S., Gamo, Y., Watanabe, K., Hoshino, T., Oikawa, T., et al. (2010). Discrepancy between clinical course and drug-induced lymphocyte stimulation tests in a case of saireito-induced liver injury accompanied by Sjögren syndrome. J. Altern. Complement. Med. 16, 501-505. doi: $10.1089 / \mathrm{acm} .2009 .0183$

UN. (2000). United Nations Conference on Trade and Development. Systems and National Experiences for Protecting Traditional Knowledge, Innovations and Practices. Background Note by the UNCTAD Secretariat. Geneva. United Nations Conference on Trade and Development, 2000 (Document Reference TD/B/COM.1/EM.13/2). p.18. Available online at: http://unctad.org/en/Docs/ clem13d2.en.pdf (Accessed December 30, 2014).

Valente, G., Sanges, M., Campione, S., Bellevicine, C., De Franchis, G., Sollazzo, R., et al. (2010). Herbal hepatotoxicity: a case of difficult interpretation. Eur. Rev. Med. Pharmacol. Sci. 14, 865-870. doi: 10.1016/S1590-8658(10)60350-7

Vallance, W. B. (1955). Pennyroyal poisoning: a fatal case. Lancet October 22, 850.

Vanderperren, B., Rizzo, M., Angenot, L., Haufroid, V., Jadoul, M., and Hantson, P. (2005). Acute liver failure with renal impairment related to the abuse of Senna anthraquinone glycosides. Ann. Pharmacother. 39, 1353-1357. doi: 10.1345/aph.1E670

Vautier, G., and Spiller, R. C. (1995). Safety of complementary medicines should be monitored. BMJ 311, 633. doi: 10.1136/bmj.311.7005.633b

Verheist, X., Burvenich, P., Van Sassenbroeck, D., Gabiel, C., Lootens, M., and Baert, D. (2009). Acute hepatitis after treatment for hair loss with oral green tea extracts (Camellia sinensis). Acta Gastroenterol. Belg. 72, 262-264.

Verucchi, G., Calza, L., Attard, L., and Chiodo, F. (2002). Acute hepatitis induced by traditional Chinese herbs used in the treatment of psoriasis. J. Gastroenterol. Hepatol. 17, 1342-1343. doi: 10.1046/j.1440-1746.2002.02887.x

Wai, C. T. (2006). Presentation of drug-induced liver injury in Singapore. Singapore Med. J. 47, 116-120.

Wainwright, J., and Schonland, M. M. (1977). Toxic hepatitis in black patients in Natal. S. Afr. Med. J. 51, 571.

Wainwright, J., Schonland, M. M., and Candy, H. A. (1977). Toxicity of Callilepis laureola. S. Afr. Med. J. 52, 313-315.

Wang, G., Mao, B., Xiong, Z. Y., Fan, T., Chen, X. D., Wang, L., et al. (2007). The quality of reporting of randomized controlled trials of traditional Chinese Medicine: a survey of 13 randomly selected journals from mainland China. Clin. Ther. 29, 1456-1467. doi: 10.1016/j.clinthera.2007.07.023

Wang, J. Y., and Gao, H. (2014). Tusanqi and hepatic sinusoidal obstruction syndrome. J. Dig. Dis. 15, 105-107. doi: 10.1111/1751-2980.12112

Weinstein, D. H., Twaddell, W. S., Raufman, J. P., Philosophe, B., and Mindikoglu, A. L. (2012). SlimQuick ${ }^{\circledR}$-associated hepatotoxicity in a woman with alpha-1 antitrypsin heterozygosity. World J. Hepatol. 4, 154-157.

Weise, B., Wiese, M., Plötner, A., and Ruf, B. R. (2002). Toxic hepatitis after intake of kava-kava. Verdauungskrankheiten 4, 166-169

Weston, C. F. M., Cooper, B. T., Davies, J. D., and Levine, D. F. (1987). Venoocclusive disease of the liver secondary to ingestion of comfrey. Br. Med. J. (Clin. Res. Ed) 295, 183. doi: 10.1136/bmj.295.6591.183

WHO. (2000a). General Guidelines for Methodologies on Research and Evaluation of Traditional Medicine. Available online at http://whqlibdoc.who.int/ hq/2000/ (Accessed December 30, 2014). WHO_EDM_TRM_2000.1.pdf?ua=1 Last accessed 30 November 2014

WHO. (2000b). World Health Organization. The use of the WHO-UMC system for standardised case causality assessment. WHO Collaboratoring Centre for International Drug Monitoring (Uppsala Monitoring Centre, UMC), Database 2000. Available online at: http://who-umc.org/Graphics/24734.pdf (Accessed December 30, 2014).

WHO. (2002). World Health Organization. WHO Traditional Medicines Strategy 2002-2005. Geneva: WHO. Available online at: http://www.wpro.who.int/ health_technology/book_who_traditional_medicine_strategy_2002_2005.pdf (Accessed December 30, 2014).

WHO. (2003). Guideline on good agricultural and collection practices (GACP) for medicinal plants. Geneva, WHO. Available online at: http://whqlibdoc.who.int/ publications/2003/9241546271.pdf (Accessed December 30, 2014).

WHO. (2005). Regulatory Situation of Herbal Medicines. A Worldwide Review. Edited by X. Zhang. Available online at:http://apps.who.int/medicinedocs/pdf/ whozip57e/whozip57e.pdf. (Accessed December 30, 2014).

WHO. (2006). Technical Report Series, No. 937, 2006. Annex 3. Supplementary Guidelines on Good Manufacturing Practices for the Manufacture of Herbal Medicines. Available online at:http://infocollections.org/medregpack/ documents/d0099/d0099.pdf (Accessed December 30, 2014).

WHO. (2007a). World Health Organization. Assessments of the Risk of Hepatotoxicity with Kava Products. Geneva: WHO Document Production Services.

WHO. (2007b). Guidelines for Assessing Quality of Herbal Medicines with Reference to Contaminants and Residues. Available online at: http://apps.who.int/ medicinedocs/documents/s14878e/s14878e.pdf (Accessed December 30, 2014).

WHO. (2013). World Health Organization. WHO Traditional Medicines Strategy 2014-2023. Geneva: WHO. Available online at: http://www.who.int/medicines/publications/traditional/trm_strategy14_23/en/ (Accessed December 30, 2014).

Woolf, G. M., Petrovic, L. M., Rojter, S. E., Wainwright, S., Villamil, F. G., Katkov, W. N., et al. (1994). Acute hepatitis associated with the Chinese herbal product Jin Bu Huan. Ann. Intern. Med. 121, 729-735. doi: 10.7326/0003-4819-121-10199411150-00001

Wu, G. L., Yu, G. Y., and Chen, J. (2008). Clinical analysis of hepatic veno-occlusive disease induced by Sedum aizoon. Zhongguo Zhong Yao Za Zhi 33, 2402-2404.

Yang, H. N., Kim, D. J., Kim, Y. M., Kim, B. H., Sohn, K. M., Choi, M. J., et al. (2010). Aloe-induced toxic hepatitis. J. Korean Med. Sci. 25, 492-495. doi: 10.3346/jkms.2010.25.3.492

Yang, L., Aronsohn, A., Hart, J., and Jensen, D. (2012a). Herbal hepatotoxicity from Chinese skullcap: a case report. World J. Hepatol. 4, 231-233. doi: 10.4254/wjh.v4.i7.231

Yang, X., Salminen, W. F., and Schnackenberg, L. K. (2012b). Current and emerging biomarkers of hepatotoxicity. Curr. Biomarker Find 2, 43-55.

Yoshida, E. M., McLean, C. A., Cheng, E. S., Blanc, P. D., Somberg, K. A., Ferrell, L. D., et al. (1996). Chinese herbal medicine, fulminant hepatitis, and liver transplantation. Am. J. Gastroenterol. 91, 2647-2648.

Yu, E. L., Sivagnanam, M., Ellis, L., and Huang, J. S. (2011). Acute hepatotoxicity after ingestion of Morinda citrifolia (Noni Berry) juice in a 14-year-old boy. J. Pediatr. Gastroenterol. Nutr. 52, 222-224. doi: 10.1097/MPG.0b013e3181eb69f0

Yüce, B., Gülberg, V., Diebold, J., and Gerbes, A. L. (2006). Hepatitis induced by Noni juice from Morinda citrifolia: a rare cause of hepatotoxicity or the tip of a iceberg? Digestion 73, 167-170. doi: 10.1159/000094524

Yuen, M. F., Tam, S., Fung, J., Wong, D. K. H., Wong, B. C. Y., and Lai, C. L. (2006). Traditional Chinese Medicine causing hepatotoxicity in patients with chronic hepatitis B infection: a 1-year prospective study. Aliment Pharmacol. Ther. 24, 1179-1186. doi: 10.1111/j.1365-2036.2006.03111.x

Zhang, L., Yan, J., Liu, X., Ye, Z., Yang, X., Meyboom, R., et al. (2012). Pharmacovigilance practice and risk control of Traditional Chinese Medicine drugs in China: current status and future perspective. J. Ethnopharmacol. 140, 519-525. doi: 10.1016/j.jep.2012.01.058

Zhao, L., Nicholson, J. K., Lu, A., Wang, Z., Tang, H., Holmes, E., et al. (2012). Targeting the human genome-microbiome axis for drug discovery: inspirations from global systems biology and traditional Chinese medicine. J. Proteome Res. 11, 3509-3519. doi: 10.1021/pr3001628

Zhou, Y., Qin, S., and Wang, K. (2013). Biomarkers of drug-induced liver injury. Curr. Biomarker Find 3, 1-9. 
Zimmerman, H. J. (1999). Hepatotoxicity. Philadelphia: Lippincott Williams and Wilkins.

Conflict of Interest Statement: The authors declare that the research was conducted in the absence of any commercial or financial relationships that could be construed as a potential conflict of interest.
Copyright (c) 2015 Teschke and Eickhoff. This is an open-access article distributed under the terms of the Creative Commons Attribution License (CC BY). The use, distribution or reproduction in other forums is permitted, provided the original author(s) or licensor are credited and that the original publication in this journal is cited, in accordance with accepted academic practice. No use, distribution or reproduction is permitted which does not comply with these terms. 